US - Vietnam Relations 1975 - 2006: A Theoretical Approach

\author{
Viet Tuan Nguyen \\ Hanoi, Vietnam
}

M.A., University of Virginia, 2008

M.A., Assumption University of Thailand, 2004

B.A., Diplomatic Academy of Vietnam, 1996

A Dissertation presented to the Graduate Faculty of the University of Virginia in Candidacy for the Degree of

Doctor of Philosophy

Department of Politics

University of Virginia

August, 2014 


\begin{abstract}
This dissertation seeks to explore the rationale behind the three-decade long and bumpy process of normalization of US-Vietnam relations since the end of the Vietnam War in 1975 until the two countries reached full normalcy in 2006. The dissertation goes beyond conventional theories of international relations to explore the role of ideas (i.e. national beliefs about effective means for achieving interests, and the war mentality that vividly exists in both countries) and asymmetry of power in shaping the pace and scope of the normalization process. Through the employment of congruence and process tracing methods, the dissertation finds that the interaction of different ideas in the context of disparity of capabilities between the two countries, given the special history of the relationship, generated unique outcomes that cannot be reduced to strategic circumstances: the extreme sluggishness and politics of inattention on the US side, and the over-skepticism and frustration on the Vietnamese side throughout the process, all contributed to the prolonged and rough path to normalization. Such findings are confirmed by empirical evidence obtained in different periods of the normalization process. The dissertation concludes with an overall evaluation of competing theories in explaining the normalization process, followed by some implications and recommendations for future US-Vietnam relations.
\end{abstract}




\section{TABLE OF CONTENTS}

ABSTRACT

2

ABBREVIATIONS

5

ACKNOWLEDGEMENTS

INTRODUCTION

PART I

(US-Vietnam Relations 1975-1986)

Chapter 1

Realist explanation for the frozen relationship

Chapter 2

Ideas and Asymmetry: Legacies of the War

PART II

(US-Vietnam relations 1986 - 1995)

Chapter 3

Realist approach: an incremental path to normalization

Chapter 4

Ideas and Asymmetry: Moving the goalposts and politics of inattention

PART III

(US-Vietnam Relations 1995 - 2006)

Chapter 5

Realist Approach: Geopolitical circumstances and the wavy path to normalcy

\section{Chapter 6}

Ideas and Asymmetry: "Peaceful Evolution" and the war mentality: a 
final push to normalcy

CONCLUSION

APPENDIXES

271

BIBLIOGRAPHY

279 
ABBREVIATIONS

ASEAN

AFTA

APEC

ARF

BTA

COC

COMECON

CGDK

CPV

DK

IFIs

IMF

MOD

MOFA

PRK

PNTR

POW/MIA
Association of Southeast Asian Nations

ASEAN Free Trade Area

Asia-Pacific Economic Cooperation

ASEAN Regional Forum

Bilateral Trade Agreement

Code of Conduct (in the South China Sea)

Council of Mutual Economic Assistance

Coalition Government of Democratic Kampuchea

Communist Party of Vietnam

Democratic Kampuchea

International Financial Institutions

International Monetary Fund

Ministry of Defense (of Vietnam)

Ministry of Foreign Affairs (of Vietnam)

People's Republic of Kampuchea

Permanent Normal Trade Relations

Prisoners of War/ Missing in Action 
TPP

UN

US

U.S.S.R.

WB

WTO
Trans-Pacific Partnership

United Nations

United States

Union of Soviet Socialist Republics

World Bank

World Trade Organization 


\section{ACKNOWLEDGEMENT}

I would like to extend my special gratitude to Professor Brantly Womack, my primary dissertation advisor, who has inspired me on the topic for the dissertation and continuously guided me through this project with invaluable assistance and endless support. His seminal work on power asymmetry and insightful expertise on Vietnamese politics have been of vital help to my research.

I would also like to express my sincere thanks to other members of my dissertation committee. Professor Herman Schwartz not only provided me with useful feedback and superb instruction on research method that set the foundation for my research, but also financially enabled me to pursue the PhD program at UVa with a Politics Department's teaching assistant fellowship for my first two years in the program. Professor Jeffrey Legro's prominent theory of ideas and his systemic thinking offered me the essential guideline to approach the topic and sharpen my arguments for the dissertation, and his useful feedback proves to be of significant importance to my research. Professor Robert Sutter's insightful knowledge of American politics and his wide connection with US government policy making elite not only provided me with useful suggestions for improvement of the dissertation but also with important contact information for data collection. Professor Brad Brown has been very helpful and encouraging with his useful comments and recommendations for my dissertation.

I am also deeply indebted to the Diplomatic Academy of Vietnam for granting me sabbatical to write the dissertation, and to the Department of Politics of UVa, the Ford Foundation, the Malone \& Gallatin Fellowships, the Buckner W. Clay Endowment for 
Humanities, the Society of Fellows and the AHSS Summer Research Fund of UVa for financially sponsoring my research.

I am sincerely thankful to Dr. Lewis Stern of the Department of Defense, Dr. Bill Nell of the Aspen Institute Congressional Program, and Dr. Gerald Warburg of the Frank Batten School for Leadership and Public Policy for their assistance with achieved documents and my interviews with high ranking American officials for data collection.

I owe thanks to Professor Jeffery Jenkins, Cassandra Thomas, Bonnie Bragg, Sue Sherrill, Sharon Marsh, Anita Dodds, Daniel McDowell, Jon Shoup, Jonathan Forney, Ana Alves, Marina Omar for their kind assistance and support at the Department of Politics.

I would also like to express my wholehearted gratitude to Professor Harry Harding and Professor Shirley Lin for being my second family here in the United States with their ever warm care, encouragement and companionship throughout my dissertation writing process. They have opened their house - Pavilion III of the Academical Village - to me and offered me the best of their support.

Finally, I would like to thank my family in Vietnam for their ever warm support and encouragement, and their patience to wait for my completion of the dissertation and my return. 


\section{INTRODUCTION AND LITERATURE REVIEW}

"We shared the view that the Viet Nam-US relations have recorded enormous gains and are entering into a new stage of development. Today, Americans view Vietnam "as a country, not a war". This perception probably explains why our bilateral relations have recently seen encouraging developments. The progress serves as a good start and a basis for the two countries to build a framework of relations commensurate with the vast potentials of both nations."

President Nguyen Minh Triet

"The overall US-Vietnam relationship-economic, political, and culturalis improving. US-Vietnam ties represent more than the Bilateral Trade Agreement and the sum of our direct and indirect official development assistance. We are well on the way toward putting together a network of linkages - humanitarian programs, academic and cultural exchanges, military and law enforcement cooperation, and dialogue on strategic issues - that represent truly normalized relations. ${ }^{1,}$

President George W. Bush

The above diplomatic statements are of a sort commonly seen in international relations among countries that share normal relations, but in the case of US-Vietnam relations such statements carry special significance. It took a hard period of thirty years for the leaders of United States and Vietnam to be able to address such statements to each other. Such statements served as the bench mark for full normalcy after the United States and

\footnotetext{
${ }^{1}$ Memos of conversation between the two leaders June 22, 2007.
} 
Vietnam have travelled through a very long and bumpy road since the Vietnam War, from being the "most dangerous enemy" of each other to "comprehensive partnership." Not until twenty years after the Vietnam War ended in 1975 did the two countries initially establish diplomatic relations in 1995, and it took another long decade of ups and downs for them to reach to normalcy. The United States eventually granted Permanent Normal Trade Relations (PNTR) status for Vietnam in 2006 which was considered to be the benchmark for normalcy.

Why did it take so long for the United States and Vietnam to normalize relations with each other? What explains this rough and lengthy normalization process? The dissertation aims to seek answers to these research questions.

Looking back to history, the withdrawal of the last American combat units in March 1973 marked the end of the US military involvement in Vietnam. However, in many respects the conflict continued for another two decades. Immediately following the victory of North Vietnam in 1975 and the re-unification of the country, the United States extended the long-standing embargo against communist North Vietnam, which had been ratified under the Trading with the Enemy Act passed during the early years of the conflict, to encompass the entirety of the newly reunited Vietnam and at the same time halted credits and loans from monetary institutions such as the World Bank, International Monetary Fund and Asian Development Bank, and repeatedly vetoed Hanoi's application for membership in the United Nations in 1975 and 1976.

Confrontation continued to persist even when an opportunity for normalization arose as both countries found strategic interests and sound rationale in normalizing relations with 
each other in the 1977-1978 period. The Carter Administration had incentives to promote relations with Vietnam in order to solve the Prisoners of War and Missing In Action (POW/MIA) issues, and at the same time preventing Vietnam from leaning toward the Soviet Union and resuming US role as the key balancing force in the region. Vietnamese leadership viewed normalization as a means of ending isolation, eliminating the embargo and acquiring US war reconstruction aid that President Nixon had promised. However, normalization never happened as both countries stubbornly and unreasonably persisted on their own terms for normalization. The unique opportunity therefore was regretfully missed.

US rapprochement to China amidst China-Vietnam intense confrontation further distanced Vietnam away from the United States into the embrace of the Soviet Union, and at the same time the Vietnam's military intervention and occupation of Cambodia, as well as the boat people issue, added another nail on the coffin of US-Vietnam relations in the late 1970s and the whole of 1980s, resulting in the roughest period in US-Vietnam post-war relations.

The United States continued to be considered "the most dangerous and permanent" enemy of Vietnam until the reform (Doi Moi) was initiated in Vietnam in 1986. Doi Moi resulted in significant re-orientation of Vietnam foreign policy toward the international community in general, and to the United States in particular. This sharp shift in foreign policy ideas resulted in positive moves by Vietnam in promoting relations with the United States, including significant efforts in searching for American POW/MIAs and a gradual withdrawal of Vietnamese troops from Cambodia. However, the withdrawal of 
Vietnamese troops from Cambodia in 1989 and increasing cooperation on POW/MIA did not immediately bring about any significant thaw in US-Vietnam relations. Official contacts were limited to American efforts to discover the fate of servicemen still listed as missing in action and the United States kept moving the goalposts in the "roadmap" which was presented to Vietnam as a set of conditions and procedures for normalization.

Vietnamese enthusiasm continued to contrast with US sluggishness and incremental approach in the normalization process. Vietnam completed its withdrawals of troops from Cambodia in 1991 and fully cooperated in solving POW/MIAs issues but not until 1994 did the United States remove the embargo, and in 1995 under the pressure that Vietnam had already normalized relations with major countries including China, the European Union and ASEAN, the United States eventually decided to establish diplomatic relations with Vietnam, being at the end of the diplomatic receiving line.

However, normalization did not automatically bring about normalcy in the case of USVietnam relations. There have always been caution and skepticism as the two countries move forward in their relationship. Vietnam remained skeptical of US intention for peaceful evolution since US former President Clinton, in his speech on the day of diplomatic relations on July $11^{\text {th }}$ in 1995 , made it explicit that there was an ulterior motive of the United States in normalizing relations with Vietnam as "normalization and increased contact between Americans and Vietnamese will advance the cause of freedom in Vietnam, just as it did in the Eastern Europe and the former Soviet Union",2.

\footnotetext{
${ }^{2}$ Bill Clinton. Normalization with Vietnam. Washington DC: White House, Office of the Press Secretary, 1995.
} 
Moreover, obstacles remained vivid in US-Vietnam relations after 1995 on various issue areas. In the realm of economic ties, even with diplomatic normalization Vietnam was still not accorded "most favored nation" (MFN) status, and the Jackson Vanik Amendment that links MFN status for communist and former communist countries to freedom of emigration continued to block trade relations between the two countries. Furthermore, the negotiation for the signing of the Bilateral Trade Agreement was the longest and most complicated process in the histories of both the United States and Vietnam. In addition, the legal procedure for the approval of the PNTR status for Vietnam, which is essential for normal trade relations between the two countries, encountered significant opposition in US congress, and Hanoi's bilateral WTO accession agreement with Washington was the last - and according to most observers, the most difficult - of the twenty eight bilateral agreements Vietnam completed, although Vietnam's entry into the WTO did not establish any new obligations on the part of the United States. It was not until December 2006 that PNTR was granted to Vietnam.

While economic ties gradually obtained some progress, security and defense relations between the two countries remained modest and symbolic. There has been significant reluctance to move forward due to skepticism from both sides even after diplomatic relations were established. This is considered such a sensitive issue that the term "military to military cooperation" has been used instead of defense relations to avoid misinterpretation. Together with different perceptions about human rights and the remaining legacy of the war (the MIA and Agent Orange issues), all contributed to the abnormal and prolonged normalization process, and continued to be obstacles in USVietnam relations into the future. 
Such prolonged and tough process of normalization of US-Vietnam relations despite the given strategic interests and circumstances presented to the two countries seem puzzling to conventional international relations theories, notably Realism. In the realist lens, USVietnam normalization should have moved much faster since both countries had strategic and economic interests in further promoting the relationship. In other words, the pace and scope of normalization do not persistently follow realist logics, and normalization progressed slower than Realism would expect.

Given the special history between the two countries when the war legacy and mentality still vividly exists, together with the persisting ideological differences, and particularly the huge gap in capability and the power asymmetry between the United States and Vietnam that put them in an unique situation in which the stronger side was ironically not the winner in the war, I argue that it is necessary to move beyond realist logics to explain US-Vietnam relations. While the power and interests under realist lens may provide certain insights for exploring the normalization process, it is important that the impact of ideas (continuity and change ${ }^{3}$ ) and power asymmetry be taken into consideration in order to have a comprehensive understanding of US-Vietnam relations.

In my argument, ideas refer to national attitudes toward international society which affect the orientation of foreign policy. In addition to preferences and strategies, each country must also have ideas or beliefs about which strategy (of those available) is best suited to achieving the preferred outcome. Ideas matter in US-Vietnam relations because ideas, in their own transformation, had distinct influence that cannot be reduced to strategic

\footnotetext{
${ }^{3}$ Change in this study refers to a significant shift in the way a state conceives of its relations with the world, whereas continuity refers to a basic uniformity of such concept over time.
} 
circumstances. The fact that significant changes in US-Vietnam relations happened only after major shifts in ideas occurred within each country, e.g. the Doi Moi cause in Vietnam brought about a sharp shift in its policy toward the United States, or the shift in US foreign policy ideas after 9/11 resulted in a different approach to Southeast Asian countries including Vietnam, and that the war mentality continues to haunt the relationship, all call for a close look at the role of the continuity and change of ideas play in the normalization process.

While ideas, together with power and strategic interests, are useful in explaining how the preferences for normalization of each country are shaped, asymmetry of power give ways to explain further how these preferences interact with each other to produce the observed outcomes in US-Vietnam relations, because asymmetry generates a structure and gives way of interaction for the dyadic relationship. Asymmetry of power matter in USVietnam relations because moving the goalposts in the normalization process by the United States proved to be the major issue, and Vietnam's caution vis-à-vis the United States was a reaction to American sluggishness and "politics of inattention". In other words, there are preferences (which are taken for granted by Realism), but there are also interaction. US-Vietnam relations therefore serve as an extreme case of process affected by ideas and asymmetry, an archetypal case that brings their effects together in a particularly clear way.

The theoretical foundation of ideas and asymmetry arguments, and the logics for how the two theories work together, will be further discussed in the literature review and research method sections of this chapter. 
It is also noted that in attempting to answer the research question "why did the normalization process take so long?", the dissertation does not attempt to explore why the US and Vietnam normalized relations with each other in a specific time, but instead focuses more on exploring the process of normalization. The key Dependent Variable therefore is process (or speed) of the normalization. There are many factors that contribute to normalization, but it is the process and actual interaction of the relationship that is of central analysis of this study.

\section{The significance and contribution of dissertation:}

It is believed that the dissertation will make important contribution to the understanding of US-Vietnam relations in particular, and to the development of IR theories in general.

First, while the current literature on US-Vietnam relations remains relatively modest, most studies have been conducted to explore some certain periods of the relationship, especially on the pre-normalization period. The dissertation will be the first research that explores comprehensively the whole normalization process. Since most previous studies on Vietnam-US relations are atheoretical and policy or empirically oriented, the dissertation hopes to provide a new theoretical approach to the topic that has been attracting more and more scholarly attention recently.

Second, the dissertation hopes to make important contribution to the development of theories on ideas and asymmetry theory. While the role of ideas has long been of strong interests by scholars of international relations and making significant contribution to the realm of IR theories, the existing literature limits its scope in exploring either how 
psychology of individuals affect policy decision, or how collective ideas under certain mechanisms affect foreign policy making, and how ideas of great powers are formed and the transformation of these ideas themselves have significant influence on international politics. However, there is still room to explore how different ideas of countries (including small countries) help form their preferences and how these ideas and preferences themselves interact with each other in relationships to produce outcomes in international politics. It is the interaction of ideas that the dissertation hope to bring scholarly attention to.

In addition, the dissertation is also believed to make contribution to the understanding and development of asymmetry theory. Asymmetry theory analyzes dyadic asymmetric relationships by identifying the linkage between relative capacities and characteristic perspectives that have not been explored by conventional IR theories. While theories on ideational dynamics provide powerful explanation for how preferences are formed, asymmetry theory gives way for clear interaction of these preferences. Therefore, the combination of these two schools of thoughts (ideas and asymmetry) should shed more light to the understanding of international politics, and that is the contribution that the dissertation hopes to make.

Finally, the dissertation will also make important contribution to the empirical record of US-Vietnam relations. Perhaps the most important contribution that my research will bring about is the collection of interviews for the project in both countries, since most of the major figures involved in the war and in the normalization are still alive, and many of them have been willing to talk about their role in the process. While it would be possible 
for scholars in either country to do a one-sided narration, I have the privilege to be in a unique position of having access to both sides.

\section{Literature Review}

In contrast to enormous scholarly interests in the US-Vietnam relations during the Vietnam War, US-Vietnam post-war relationship has not attracted comparable attention. The existing literature on US-Vietnam relations in general, and on the normalization process in particular, can be characterized as: 1) focusing on limited periods rather than covering the whole normalization process, and 2) mostly atheoretical and policy oriented with focus on particular issue areas.

First, the currently existing literature on US-Vietnam relations, conducted either by Vietnamese or American and foreign scholars, tend to focus on single and small period of the normalization process. There has been a tendency to treat US-Vietnam post-war relations as three separate periods. The first period (which is commonly referred to in the literature as the pre-normalization period) examines the timeframe from 1975 when the Vietnam War ended until 1986 when Doi Moi was launched in Vietnam. While there was a large literature written by American scholars on the impact of the Vietnam War and the Vietnam syndrome on US foreign policy (Young 1991; Isaacs 1997; Slabey 1996; Miller 1991 \& 2002; Hearden 2005; Arnold 2006; Roper 2007 etc..), there was relatively limited literature that focused directly on US-Vietnam relations. Such studies conducted on this period tends to put US-Vietnam relations in a much broader context of the Cold War and 
examines the relationship as part of US relations with the Soviet Union, China and regional countries (ASEAN) (Chanda 1986; Brown 1989; Stern 1995). This reflects the fact that Vietnam was no longer of strategic interests to the United States after the Vietnam War.

While the period after Doi Moi of Vietnam from 1986 until 1995 when diplomatic relations were established receive relatively modest attention (Brown 2000; Thompson 2004), the normalization period from 1995 until 2006 when the United States granted PNRT for Vietnam have attracted more scholarly interest from both Vietnam and the United States (Bui Thanh Son 1996; Dang Dinh Quy 2012; Le Dinh Tinh 2013; Thayer 1999, 2004 \& 2008; Brown 2000; Stern 2001). However, there has not been a comprehensive research effort that covers the whole period of US-Vietnam relations from the end of the war until normalcy was achieved.

Second, there exists a striking feature of recent writings on US-Vietnam relations in the sense that they are largely atheoretical, with only a few exceptions. Empiricism long dominated academic treatments of US-Vietnam relations in post-war periods. This does not imply that the contribution of these empirical works is not valuable; in fact they do serve as crucial foundations for later theorization. However, the traditional way in which US-Vietnam relation studies were conducted (i.e., theoretically uninformed) has rendered the research findings less systematic and generalizable. Instead of applying or testing IR theories in explaining US-Vietnam relations, most of the studies focus on issue areas and serve as foundation for policy recommendations (Manyin serial annual reports to the Congress 1998-2006; Hoang Anh Tuan 2010). There have been studies focusing on the 
economic aspect of the relationship (Aheam 1999; Riedel \& Parker 2003; Nguyen Hong Duong 2003), while others pay attention to POW/MIA issues (Stern 1995; Reports of Select Committee on POW/MIA affairs by US Senate 1993) or defense relations (Stern 2001, 2012 \& 2014).

While most explanations of US-Vietnam relations appear to refrain from applying and testing theories, some of them are implicitly theoretical in identifying the rationales behind the normalization process, and in observing the process with certain theoretical lenses: these studies apply realist logics in explaining the normalization process (Le Dinh Tinh 2013; Brandon 2004; Ruff 2009; Almonte 2004, Bunyavejchewin 2010)

The following section will review in depth the theoretical background that has been used to explore US-Vietnam relations in the literature, including Realism, and Ideas and Asymmetry theories.

\section{Realist Approach}

As stated earlier, empiricism and policy-orientated trends long dominated academic treatments of US-Vietnam post-war relations. However, there have been a modest number of exceptions in which theories are used as tools to analyze the relationship, among which the most dominant is Realism.

The realist tradition envisions states as unitary actors, primarily concerned with physical survival in an anarchic world arena (Morgenthau 1948; Waltz 1978). Accordingly, states 
pay primary attention to the military and economic resources that might make them vulnerable, or that could provide future protection. Realist studies give pride of place to the strategic (especially power) circumstances that states face and emphasize the important role of systemic imperatives in shaping nation-states by depicting states as rational actors reacting instrumentally to international conditions to maximize security (Gilpin 1981; Mearsheimer 2001). Since states' preferences are given and these selfinterested states are subject to constraints of the strategic environment surrounding them, the variation in the constraints that these actors face will determine/shape their behaviors (Krasner 1978).

Under a realist lens, US-Vietnam relations are of no exception to these logics. Realist scholars look at the variations of strategic environments and power factor throughout different periods in US-Vietnam relations to explain the normalization process. USVietnam early post-war relations were heavily driven by the Cold War context in which US power competition with the Soviet Union and the complicated relations of these two superpowers with China and regional countries shaped the directions (Horn 1978; Weinstein 1983). US-China rapprochement in the 1970s amidst Soviet-Chinese confrontation, as well as Vietnam's alliance with the Soviets and confrontation with China, together with Vietnam's occupation of Cambodia in the 1980s, were therefore the key determinants of the frozen relationship.

In the post-Cold War context, realists see the rise of China as the key variable in shaping US-Vietnam relations. Realists looking at Asia after the Cold War contended that major change in the power structure was likely to lead to conflict within the international 
system (Gilpin 1981). They tended to offer pessimistic predictions of a potential US drawdown in the region accompanied by the rise of China and Japan's remilitarization all leading to a more diffused and dangerous security landscape as the other countries, individually or collectively, engaged in arms buildups (Friedberg 1993-1994; Buzan \& Segal 1994).

In a wide range of literature on this topic, realists believe that the rise of China will evoke counterbalancing efforts from other states which are concerned about Chinese power (as a challenger to current world order), especially the United States (the hegemon) whose influence and power is being challenged (Mearsheimer 2005; Ott 2001; Goldstein 2005; Khalilzard 2001). Along this line, the existing literature on the Southeast Asia - US China security dynamic tends to assume that China's rise is leading to a systemic power transition scenario in which the region will have to choose between the rising challenger and the incumbent power. The de facto expectation is that Southeast Asian countries, including Vietnam, will want to balance against China because a rising China is inherently threatening. Thus, they will flock toward the United States as the leading balancer, seeing the United States as the critical balancing force, both in the military and political-economic spheres (Tyner 2007; Bellacqua 2012).

Other realist scholars offer a more optimistic view about the rise of China and its implication (Sutter 2003, 2005, 2008; Goh 2005). According to Sutter, China's rises over the years has created a new "inside-out" model of Asian regional politics in which an indigenous state rather than an outsider - has become the primary focus (Sutter 2008: 91 - 103). Therefore regional countries will not choose to "hard-balance" against China. 
However, the United States still remains as the "least distrusted power" in Southeast Asia with no territorial or other ambitions directly at odds with regional countries' interests and therefore still pay an important role in regional countries' efforts in soft-balancing against the rise of China. Along this line, other realists observe a "hedging strategy" by regional countries in their relations with the two powers (Goh 2005; Goh \& Simon 2008).

Whether it is "hard" or "soft" balancing rationale, realists of all stripes agree that China factor is the key determinant of and driving force behind US-Vietnam normalization process.

While realist literature offers important explanation for US-Vietnam relations, the literature encounters shortcomings when it comes to explaining the actual process of interaction between the two countries. There are anomalies that remain inadequately explained by a realist approach, and realist prediction and actual state thinking and behavior seemed to occasionally diverge in the case of US-Vietnam relations. Realists would be puzzled in observing that Vietnam stubbornly stuck to its resolute demand for war reconstruction aids as the precondition for normalization of relations with the United States during the 1977-1978 despite much more important strategic interests Vietnam would gain if normalization had happened, and the US equally rigid manner in negotiating for normalization, leading to the missed opportunity for normalization that both countries desired; or the fact that the pace and scope of normalization was observed to be slower and more limited than realist logic would expect.

It can be argued that states do not always read the markers of systemic incentives in a way that could be predicted from those conditions alone because the search for security, 
based simply on circumstances, is a complex, difficult, and uncertain task (Legro 2005: 18). Furthermore, even if systemic conditions are clear they may not suggest a single optimal response, as in the case of the above-mentioned missed opportunity in USVietnam relations. The practical implication is that we cannot understand and predict what states will do without knowing how they think about appropriate action (ideas). As a result, it is important to explore how state's preferences are formed and how these preferences interact to produce the observed outcomes, for which the role of ideas and asymmetry of power deserve a thorough examination.

\section{Ideas and Asymmetry of Power:}

\section{Theories of ideas:}

Among IR theories that have been used to explain the process of normalization of relations between Vietnam and the United States, theories of ideational factors seems to be the most modest literature. In contrast with Realist literature where a number of scholars directly address US-Vietnam relations, ideational literature does not offer a direct account for US-Vietnam relations, but mostly focuses on explaining how ideas cast certain impact on each individual country's foreign policy in general.

The literature tends to pay attention to three main areas: psychology, ideology and collective (national) ideas. The psychology approach accounts for the impact of the psychological wounds of the Vietnam War and the Vietnam syndrome on the making of US foreign policy in particular, and to American society in general. Many years have passed since the Vietnam War ended, but "the ghost of the Vietnam War" has still been 
haunting US policy making, especially with regards to potential wars that the United State might engage in (Khong 1993; Hadar 2009; Sasikuma 2005). There is also a large literature on the impact of Vietnam War on American society (Young 1991; Isaacs 1997; Slabey 1996; Miller 1991 \& 2002; Hearden 2005; Arnold 2006; Roper 2007). Similarly, Vietnamese literature on the impact American War on society is also very popular. However, both Vietnamese and US literatures tend to focus on the impact of war mentality on each country, rather than having explored such impact on the bilateral relationship particularly. There has not been a systemic study that specifically addresses how the war mentality influences US-Vietnam relations.

There has also been a number of studies conducted to explore how ideologies and their differences have impact on each country's foreign policy in general, and on US-Vietnam relations in particular (Nguyen Mai 2007; MOFA 2013; Palmujoki 1999; Thayer \& Amer 1999; Thayer 1999), but the literature remains relatively modest in its scope, and similarly to the previous branch of literature, there is a lack of theorization on the linkage between ideological differences and the observed outcomes of US-Vietnam relations.

The rest of the existing literature explores the impact of national (collective) foreign policy ideas about how to relate to international society, both directly and indirectly, on US-Vietnam relationship. There have been a number of studies on the impact of the Doi Moi (the Reform) in Vietnam and how it changes Vietnamese foreign policy orientation toward the international community in general, and to the United States in particular (Thayer 1999, 2004, 2008; Thayer \& Amer 1999; Bui Thanh Son 1999; Nguyen Son 2004; Nguyen Mai 2007). On American side, there has been a number of studies 
exploring how American re-orientation of foreign policy ideas after 9/11 affect its relations to the world in general (Legro 2005), and to Southeast Asia in particular (Tyner 2007, Kelly 2003, Brandon 2004). While this literature offers useful insights about how ideas affect both domestic and international politics, it tends to focus on one country's ideas rather than on the bilateral relationship.

While the role of ideas on US-Vietnam relations have not been fully explored as discussed above, the role of ideas in international relations in general has been thoroughly studied and resulted in an increasingly enriched literature. The term "ideas" are very broad and therefore can invoke a wide range of images, and consequently a large literature. For the sake of this research on a specific topic on US-Vietnam relations, there are two types of ideas that will be studied: (1) national (collective) foreign policy ideas about how to relate to international society (e.g. the Doi Moi (Reform) brought about the "integrationist" idea that resulted in a big shift in Vietnamese policy to the United States). These ideas can be differentiated from other types of ideas in three basic ways that relate to their level, type and content: they are collective ideas (instead of individual ideas), they involve beliefs about effective means, and they refer specifically to national conceptions about international society; and (2) the war mentality as one type of collective memories/ideas that exists in both American and Vietnamese societies, whose continuity (or change) has significant influence on the relationship.

The question of interest for proponents for the role of ideas has been: How do ideas matter, and through which mechanism do they matter? 
Scholars of ideas share some agreement with the realist account in that international relations is seen as a product of strategic national behavior determined by interests and relative power. However, they argue that the realist premise is incomplete because it ignores a necessary component - how nations believe they can achieve their desired outcomes (Legro 2005, Goldstein \& Keohane 1993). In addition to preferences and strategies, actors must also have ideas or beliefs - some notion about which strategy of those available - is best suited to achieving the preferred outcome.

We may know what societies desires, we may know they balance of power among them, and we may know the prevailing domestic and international rules. Yet, unless we also understand how states conceive of appropriate action - and when such conceptions are likely to change - we cannot understand how interests will be achieved, how power will constrain or enable such efforts, and which rules are likely to be heeded or violated (Legro 2005: 11)

Under this light, ideational scholars suggest that policy outcomes can be explained only when interests and power are combined with a rich understanding of human beliefs. In other words, international relations are shaped not just by the power states have but the ideas that states hold about how that power should be used: "Power, of course, is a tool, and ideas about the uses of tools vary considerably. Power does not determine ideas nor do power transitions among states inevitably lead to conflict” (Legro 2005 :3).

There are three main pathways that ideas as collective beliefs can influence policy: when the principled or causal beliefs they embody provide road maps that increase actor's clarity about goals or ends-means relationships; when they affect outcomes of strategic 
situations in which there is no unique equilibrium; and when they become embedded in political institutions (Goldstein \& Keohane 1993: 10). In addition, such collective ideas (beliefs about most effective means), in their own transformation, have distinct influence that cannot be reduced to strategic circumstances (Legro 2005: 14).

Theories of ideas therefore pay close attention to how states' preferences are formed and how ideas cast their influence during this process, instead of stipulating states' preferences for some outcome and take them for granted as Realism does. States' preferences for particular policy outcomes are not given but acquired because world views and principled beliefs structure people's views about the fundamental nature of human life and the morality of practices and choices. Therefore, in order to understand the formation of preferences, we need to understand what ideas available and how people choose among them (Goldstein \& Keohane 1993: 13).

Theories of ideas therefore prove to be potentially effective tools in exploring USVietnam relations, since they shed light to the understanding of how preferences are formed during the normalization process, given the complex and special historical and strategic contexts that were presented to the relationship.

However, there remains some limitation on the literature on the roles of ideas. First, the current literature on ideas restrict its scope by only exploring ideas of individual country (notably ideas of each individual powerful country, as Legro's theory presents) and how these ideas interact with other factors (i.e. power and interests) to form their preferences in international relations. While this is an important account for understanding international relations in general since one state's foreign policy orientation, especially 
those of powerful countries, will certainly have some influence to international politics, the literature shows limitations in explaining international dyadic relationships where discussion of the interaction of the preferences by the two countries is missing. In other words, there are preferences, but there is also interaction of these preferences, which remains unexplored by theories of ideas. This shortcoming of ideational theories can be well supplemented by Power Asymmetry Theory, which will be addressed in the following section.

\section{Theory of power asymmetry:}

The studies of power disparity among states and its applications in international relations have been popular in IR theories (e.g., realism), especially in the realm of warfare in which capacity factor is believed to be the determinant of either victory or defeat in wars. Most security theories concentrate on victory in war, and it is commonly assumed that the more powerful will win. Indeed power asymmetry factor has been studied to explain the Vietnam War and explore how the United States lost the war despite being the stronger side (Fans 2002).

However, traditional theories tend to overlook the structural and characteristic effects that power disparity brings about in asymmetric relationships. While conventional IR theories, i.e. Realism, acknowledge the power asymmetry that exists among states, such disparity is seen as a disequilibrium. Such disequilibrium creates either subordination or a competition for domination. It is assumed that either the weaker state will balance its vulnerability by means of alliances with other states or it will be subject to the hegemony of the stronger state. 
However, there exist many long-term asymmetric relations, and the stronger cannot always impose its will on the weaker. An extreme example for this is the US-Vietnam relations in which the United States being a stronger side could not impose its will on the weaker and more vulnerable side in the relationship and lost the Vietnam War. A similar example can be the asymmetric relations between China and Vietnam, in which for thousands of years the stronger side sought to impose its will by force on the weaker, but failed to do so (Womack 2003 \& 2006). If an asymmetric relationship cannot be solved through force, then it must be managed by both sides (Womack 2006: 2).

The core argument of asymmetry theory is that disparities in capacities create systemic differences in interests and perceptions since "in the real world, states must bloom where they planted...the realities of differences in capacities are reflected in real differences of perspective and role" (Womack 2006: 20). Since disparity of capacities generates a structure and pattern within which interaction take place, power asymmetry therefore affects states' expectations, in which the stronger side expects deference from the weaker, whereas the weaker side expect a respect for autonomy from the stronger one. Crisis might arise in the relationship if this logic is not followed, as in the case of ChinaVietnam relations in various periods in history, or US-Vietnam relations in the post-war periods.

In addition, a great disparity means that the weaker side will be more attentive to the relationship than vice versa because proportionally it is more exposed to its risks and opportunities. It is easy for misunderstanding to arise because the relationship means different things to each side (Womack 2006: 2). 
The above discussion on the existing literature on power asymmetry reveals that theory of power asymmetry has demonstrates its advantage as a theory of interaction. While other IR theories also pay attention to disparity (i.e. Realist schools) or to differences between actors and patterns of misperception, they overlook the linkage between relative capacities and characteristic perspectives which is a very important determinant of the outcomes of such asymmetric relationships. That is part of the reason why conventional theories will find it puzzling to explain the stalemate that exists in US-Vietnam post-war relations that leads to the extremely prolonged process. Since normalcy in an asymmetric relationship is negotiated, it is not simply dictated by the stronger side, as shown in the case of US-Vietnam relations.

In addition, although questions of war and peace provide the strongest illustration of asymmetric relations, asymmetry affects a full range of external activities and therefore will bring a profound test for a comprehensive US-Vietnam post-war relationship under study.

The following section will present the foundation for a synthesis of theory of power asymmetry and theories of ideas in examining US-Vietnam normalization process, as well as the method for testing the validity of the central thesis of the dissertation. 


\section{The Argument and Hypotheses}

As discussed in previous section of literature review, in contrast with realist analysis which typically stipulates but does not explain state's preferences for some outcome, both ideas and asymmetry are important factors that help shape states' preferences. To understand the formation of preferences, we need to understand what ideas available and how they are chosen, and how the structure generated by asymmetry of power help determine such choice.

The remaining question is why we need both ideational accounts and asymmetry theory to explain US-Vietnam normalization, and under which logic do these two theories work together to produce the observed outcomes in US-Vietnam relations?

It is argued that whether a state has success in matching the expectation of its dominant ideas is likely to depend to some degree on the capabilities that it has in hand ${ }^{4}$, which is highlighted in Legro's theory of ideas. However, in an dyadic relationship whether a state has success in implementing its preferences and obtain its preferred outcomes in bilateral relations with the other party will not only depend, to some degree, on its own power in hand, but also on the capability of the other party in the relationship, because it takes the interaction of these preferences to produce the observed outcomes. Power asymmetry therefore creates a structure and pattern within which the different ideas of the two parties interact, and this is where ideas and power intertwine with each other to produce the observed outcomes.

\footnotetext{
${ }^{4}$ Theories that emphasize the roles of ideas do not ignore the importance of power. In fact, that is one of the reasons why Jeffrey Legro chooses to explore ideas of great powers, since they are likely to have the capability to carry out their ideas.
} 
Along this line, I argue further that we need a synthesis of both theories because while ideas shape states' preferences, asymmetry affects their expectation, and therefore determine the interaction of the relationship. In other words, there are preferences, but there are also interactions of these preferences to bring about the observed outcomes: such interactions are affected by the power asymmetry that exists between the two states. The way I see how ideas can be intertwined with asymmetry in the case of US -Vietnam relations is that: things should have worked out differently but they had not, because each country responded differently due to the difference in their attitudes and desires (shaped by ideas), and the difference in their expectations (which are determined by the asymmetric structure of power that exists between them). For example, normalization could have happened in an early stage (1977-1978) when both the United States and Vietnam desired it and the strategic environment at that time was favorable, but it did not because both countries persisted in their different preferences as well as different expectations. Vietnam, being a weaker country but embedded with a victory mindset, insisted on high demands for war compensations whereas the United States, being a much stronger country but a defeated one, stuck to its own high conditions for normalization as a means of keeping face. These differences in expectations, combined with the war mentality that still remained vivid in both sides, led to the missed opportunity for normalization in the early stage.

Since disparities in capacities create systemic differences in interests and perceptions between the stronger and the weaker side of the relationship (especially when the war history is taken into account), US-Vietnam relations are an extreme case of process 
affected by ideas and asymmetry: an archetypal case that brings their effects together in a particularly clear way.

The logic of the intertwining between ideas and power asymmetry can be presented in the following diagram.

Diagram 1 - How ideas and power asymmetry interact to produce outcomes in dyadic relationship.

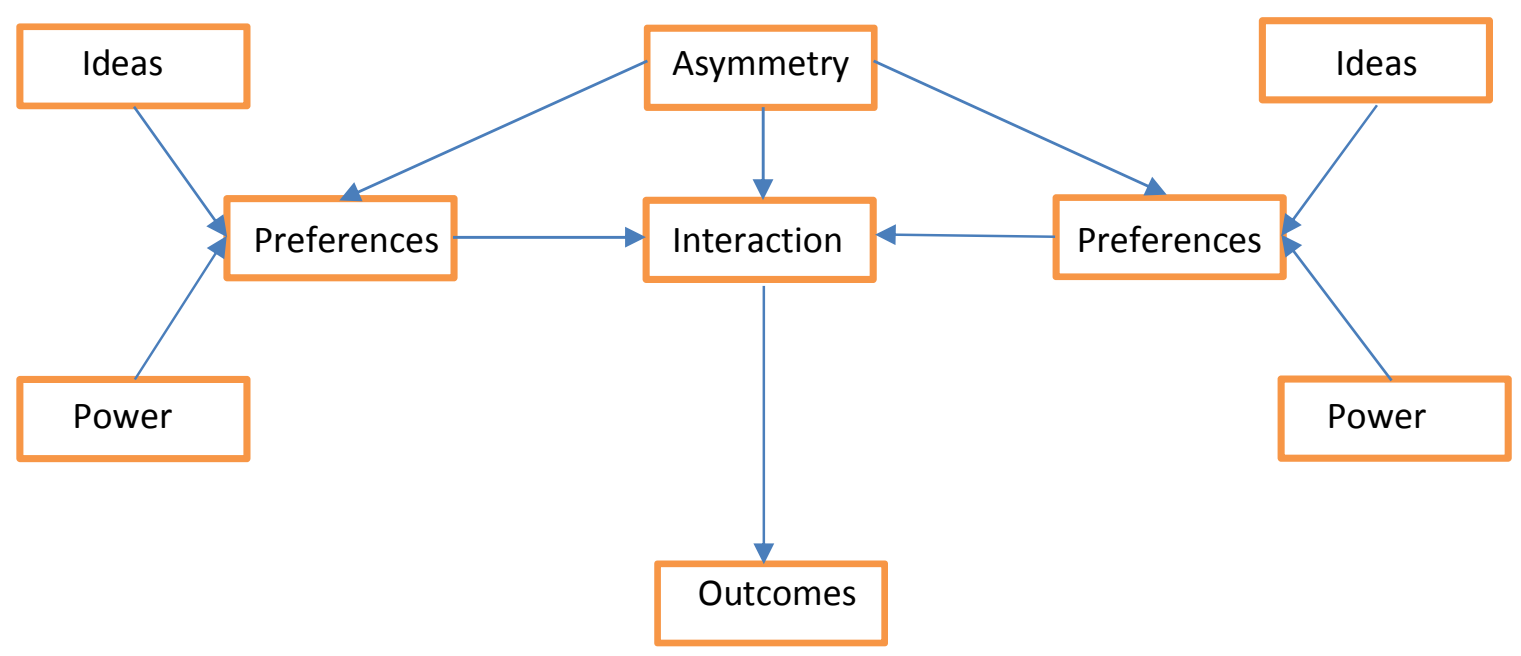

As mentioned in the literature review, the dissertation seeks to study two types of ideas:

(1) national (collective) foreign policy ideas about how to relate to international society (e.g. the Doi Moi (Reform) brought about the "integrationist" idea that resulted in a big shift in Vietnamese policy to the United States), and (2) the war mentality as one type of collective memories/ideas that exists in both American and Vietnamese societies, whose continuity (or change) has significant influence on the relationship. Change in this study 
refers to a significant shift in the way a state conceives of its relations with the world, whereas continuity refers to a basic uniformity of such concept over time. By exploring these certain type of ideas, my argument is distinguished from that suggested by psychological approaches (cognitive approach) whose focus is on psychology of individuals (Jervis 1978, Snyder 1991, Van Evera 1984). It is noted that in focusing on the impact of these ideas, I am interested in the impact of such particular beliefs, not on the relationship between beliefs and objective reality (which psychological approach does). Rather than seeking to explain the sources of these ideas, I focus on their effects instead.

As asymmetry of power generates different expectations by each side in the relationship, asymmetric relationships therefore must be analyzed in terms of their two sub-relations, that of the stronger to the weaker, and that of the weaker to the stronger (Womack 2006: 5). The position of the stronger (the United States) is determined by the fact that the relationship is less important to itself, and therefore is less attentive. The weaker side (Vietnam) is vulnerable to the greater capacity of the stronger side, and therefore it is more attentive. Characteristic patterns of misperception can develop in which the stronger side makes errors of inattention while the weaker makes errors of over-attention, and these misperceptions can amplify one another into a crisis (Womack 2006: 77 - 89).

Similarly, it is necessary for the dissertation to explore both attitudes (ideas) of each side, and the way those attitudes interact through diplomacy within the structure and pattern of interaction that asymmetry of power generates between them. 
Finally, it is noted that the dissertation does not seek to refute Realism and its logic in explaining US-Vietnam relations. In fact, power and strategic circumstances play important role in shaping the normalization process. However, it takes ideas and asymmetry of power to provide a complete and comprehensive picture for the relationship. In other words, the dissertation aims to develop a synthetic theorization that captures the interactive effects of these theories.

The following section will develop a research method to test the validity of the proposed theory of the dissertation.

\section{Research Method:}

Testing the impact of ideas remains one of the biggest challenge for proponents of the role of ideas in international relations theories, since ideas are difficult to assess and seemingly more flexible and subject to change than other factors, such as the number of missiles offered by realists (Legro 2005: 21).

Consequently, the most egregious error that proponents of the role of ideas have made is to assume a causal connection between the ideas held by policy-makers and policy choices. Therefore, it is crucial for a study on ideas to recognize that the delineation of the existence of particular beliefs is no substitute for the establishment of their effects on policy. Since many ideas are available for use, analyst should not assume that come intrinsic property of an idea explains its choice by policy makers, because choices of specific ideas may simply reflect the interests of actors (Goldstein and Keohane 1993: 11). 
However, it is acknowledged that while assessing the existence and content of collective ideas is not simple, it is also not impossible. As Legro observes, by their very nature foreign policy ideas will be in the public realm. They cannot be reproduced unless all have access to them. The symbols and "lessons" of national involvement in international relations, the debates and discourse of states, and the justifications leader give for action are readily available. These can be studied and evaluated, a task that is possible for many aspects of "real time" diplomacy or civic action (Legro 2005: 22)

Therefore, in order to build up a good research framework to measure the impact of ideas and to control the possibility that there might be other factors that can determine both ideas/beliefs and outcomes, the dissertation first and foremost needs to identify the ideas being described and the policy outcomes to be explained. At the same time, in order to provide evidence about the condition under which causal connections exist between ideas and policy outcomes, the hypotheses are designed as below:

\section{The hypotheses:}

Hypothesis 1: (Realist/ Rationalist world): Changes in power conditions and national interests cause the transition in US - Vietnam relations.

This hypothesis will be followed by these observable implications: 
1. Evolving power influences (e.g. the changing contexts of the Cold War) redefine Vietnamese/ US national interests ${ }^{5}$ (i.e. security or economic interests), which cause change in relationship, determining the pace and scope of normalization.

2. Vietnamese/ and US strategic goals (preferences) in normalization are shaped by structural constraints, and the strategic means/instruments to achieve these goals in the normalization process are generally in the form of balancing (e.g. US-Vietnam relations improve to balance against China).

3. US and Vietnam perception about each other is conditioned by their power status in the system and vis-à-vis each other (i.e. whether being an enemy or a friend depends on the existing strategic contexts).

Hypothesis 2: (Ideas and asymmetry of power): Change (and continuity) in ideas, given the asymmetric power structure that exists between the two countries, shapes the transition in US-Vietnam relations. In the world of ideas and asymmetry, we would expect to see:

1. Evolving ideational influences (i.e. national beliefs about best means for achieving foreign policy goals; and the war mentality) redefine Vietnamese and US preferences and perception of each other, which cause change in relationship. (e.g.

\footnotetext{
${ }^{5}$ Specific national interests will be identified in different periods of the normalization process at the beginning of each empirical chapter.
} 
Changes in Vietnam's ideas as a result of the Reform (Doi Moi) resulted in changing Vietnamese perception about the US).

2. The pace and scope of normalization is determined by the interaction between these preferences and expectations.

3. Given the disparity in capabilities, behaviors by the United States and Vietnam will follow some certain pattern in which the stronger side tends to dictate the rule for negotiation while the weaker side tends to be over-attentive to the other party's behavior.

The above research design is structured in the way that enables testing both the hypotheses against empirical evidence and at the same time against alternatives, the two major ways in testing the impact of ideas (Legro 2005: 43).

In testing them against evidence, the impact of ideas can be confirmed if there is the existence of empirical anomalies that can be resolved only when ideas are taken into account. The same logic might apply for testing the validity of realist hypothesis: ideas would be proven of not having any impact if all evidence follows the realist logics. The above analysis framework is also designed in a way that helps minimize the danger of "cherry picking" - finding the history what fits the theory - by comparing the explanations of each theory for the same puzzles/ events in each specific period of the normalization process.

In testing them against alternatives, each of the above hypotheses can serve as the alternative explanation for the other, since there are two competing hypotheses that are 
being tested: If the realist argument is correct, the pace and scope of normalization of USVietnam relations will vary in accordance with the international circumstances that they face, especially if such circumstances relate to security. State in the same structural position should respond to their circumstances in a similar way, and in this case ideas are just epiphenomenal to power factor.

If realism is not correct, states will respond to similar situations in different ways, based not on capabilities or geography but on factors (i.e., ideas and asymmetry of power) exogenous to the material and international determinants found in the realist approach.

\section{Congruence and process-tracing:}

Congruence and process tracing are selected as the main methods for hypothesis testing, both against evidence and against alternative argument as discussed in previous section. Both methods use empirical observations on US -Vietnam relations to test the hypothesis. In case studies, the method of congruence testing attempts to control for all but one independent variable at a time by using theories to create expectations about the dependent variable that can be compared to its actual value (George 1997). By way of congruence, the research makes paired observations of values on the independent variables (power or ideas) and dependent variable (speed of US-Vietnam normalization) of the test hypothesis across different periods of time, then assess whether these values co-vary in accordance with the observable implications. 
Process-tracing is used to explore the chain of events in Vietnam and US decision making process across different periods of time, through which material and ideational conditions are translated into policy outcomes. The process of normalization will be divided into smaller stages for observation. At each period, the stimuli that condition Vietnam's and US decision-making process will be inferred from the historical context. By tracing the process backward, the causal link between a stimulus and its policy outcomes can be explored in the sequence of events in both countries' diplomatic activities and the testimony of Vietnamese and American leaders about the motives underlying their policy responses. It is important that these observations are made in the interaction between the two sides of the relationship.

The stages are divided as below:

- 1975 - 1986: the end of the Vietnam War until the Reform "Doi Moi" was initiated in Vietnam.

- 1986- 1995: Doimoi until initial establishment of diplomatic relations.

- 1995 - 2006: normalization to normalcy.

\section{Data collection and analysis:}

Vietnam side: Data consists of archived documents and interviews. The primary source of Vietnamese data includes policy-making documents such as political reports, policy memoranda, strategic assessments by the CPV and state officials, most of which are unpublished. The documents also include journal articles, books and monographs written 
by officials and academics concerning Vietnam policy toward the US. The second main source of data personal interviews and communications are conducted with retired or incumbent Vietnamese officials that have directly involved in the normalization process and policy making with regards to the US. Tracing the process of Vietnamese decision making and "ideas" formation would mostly depend on the availability of primary sources. It is noted that the concurrent employment of the congruence method would require less primary sources than process tracing.

Because access to Vietnamese archives is particularly difficult due to the sensitivity of the topic and the lack of a defined security classification system in Vietnam, many documents on Vietnam's diplomatic affairs remain compartmentalized and have not been archived (e.g. the Poliburo Resolution 13 of May 1988 has never been made public), I am only able to quote/cite from some reliable sources which partially quote these documents.

US side: The data consists of US official documents on relations with Vietnam, such as the declassified Documents of the State Department on US-Vietnam relations, the Congressional Reports on issues with Vietnam, and records on congressional votes on US-Vietnam relations; public opinion polls on Vietnam, and POW/MIAs materials, policy proposals and recommendations by think tank, and conference reports on Vietnam. The documents also include books and articles written by American scholars on US Vietnam policy and normalization with Vietnam.

The data also include many interviews with high ranking US officials and policy makers on US-Vietnam relations. It is noted that interview data from both sides will be kept anonymous. 


\section{Plan of Dissertation}

As the dissertation covers different periods of the long process of normalization of more than thirty years between the United States and Vietnam, the dissertation is structured accordingly to these different periods in order to highlight the comparison among alternative theories that seek to explain that particular period, as well as for the convenience of readers to follow.

The current section presents the introduction to the puzzles observed in US-Vietnam normalization process and the research question of the study, existing literature and an overview of the central thesis of dissertation with a designed research method to test its validity.

Part I follows includes Chapter 1 and Chapter 2 that explore the first period in the normalization process (1975-1986). While Chapter 1 presents a test for Realist approach in explaining this period, Chapter 2 utilizes the theories of ideas and power asymmetry. Similarly, Part II of the dissertation continues with Chapter 3 and Chapter 4 in exploring the second period in US-Vietnam normalization process $(1986$ - 1995), with the realist logic and ideas and power asymmetry respectively.

Part III continues to explore the last period (1995-2006) of the normalization process with Chapter 5 and Chapter 6 with the same respective theories.

Each of the three main parts of the dissertation will end with a conclusion which evaluates the validity of the hypotheses that have been tested in the part. 
The Conclusion will present an overall summary of findings of the dissertation and a comprehensive evaluation of the tested theories, and suggests implications for USVietnam relations. 


\section{PART I}

\section{US - Vietnam relations 1975 - 1986}

Part I of the dissertation, consisting of Chapter 1 and Chapter 2, seeks to test the validity of the two competing theoretical approaches in exploring US-Vietnam relations since the end of the Vietnam War in 1975 until 1986 when the Doi Moi Reform was initiated in Vietnam: the Realist approach versus the Ideas and Asymmetry approach.

It is acknowledged that US-Vietnam relations during the $1975-1986$ period was the most hostile and chilled episode in post-war bilateral relationship. Following Vietnam's victory in 1975, the U.S. attitude toward Vietnam was antagonistic. Under President Ford's Administration, the United States extended to all of Vietnam the trade embargo against communist North Vietnam that had been ratified under the Trading with the Enemy Act passed during the early years of the conflict. The United States further marginalized Vietnam by halting credits and loans from monetary institutions such as the World Bank, the International Monetary Fund, and the Asian Development Bank. Together with economic embargo, the United States also blocked Vietnam politically by vetoing Hanoi's application for membership in the United Nation for two consecutive years 1975 and 1976.

US-Vietnam relations showed some sign of softening during the first year of the Carter administration as the United States sought to cooperate with Vietnam to solve the issues of POW/MIAs while Vietnam desired to remove the US embargo and receive American war reconstruction aid. Initial negotiations for normalization took place in 1977 and 
1978, but attempts by both sides ultimately failed, and negotiation ended up with no positive result due to sharply different standpoints by each side.

The possibility for normalization faded further when the United States preferred normalization with China to Vietnam in the context of increasing confrontation between Vietnam and China. This development, combined with Vietnam's military intervention and occupation of Cambodia in 1978, its treaty of alliance with the Soviet Union the same year, and a border war with China in 1979 gave more impetus to American hostility toward Vietnam and shut down any possibility for normalization.

Vietnam's long occupation of Cambodia, together with the boat people issue, remained the biggest obstacle in the process of US-Vietnam normalization into the early 1980s under President Reagan Administration, making the 1979-1986 period the most confrontational episode in the history of US-Vietnam postwar relations. Vietnam considered the United States as "the principal and permanent enemy", the statement that was officially written in the Foreword of the 1980 Constitution of the Socialist Republic of Vietnam and in Resolution 09 of the IV Congress of the CPV, while the word Vietnam "as a war, not a country" connotation instantly brought about resentment in many American minds.

What explains the failed attempt for normalization by both sides, and the subsequent hostility and confrontation that overshadowed US-Vietnam relationship for the whole period? 
Chapter 1 and Chapter 2 of the dissertation seek to answer this question via the lens of the Realist approach and Ideas and Asymmetry approach, respectively. Part I will conclude with an overall evaluation and comparison of the two alternative theories. 


\section{Chapter 1}

\section{A Realist explanation for the frozen relationship 1975-1986}

This chapter aims to test the hypothesis that changes in power conditions and national interests given the Cold War contexts and strategic circumstances shaped US-Vietnam relations in the 1975-1986 period, pulling the two countries apart and freezing the normalization process. Realism looks for evidence in the constraints of the strategic environment and their variation that the United States and Vietnam faced in this period to explain the frozen relationship. The following observations are expected to be present in realist lens: Evolving power influences in post-war context redefined US/Vietnamese national interests, causing changes in the relationship and determining the pace and scope of normalization.

The Realist explanation for this period of chill and hostility in US-Vietnam relations points to the cold war contexts and strategic calculations that keep the two countries apart: 1) the US ignorance and lack of interest in Indochina after the war and US high priority in normalizing relations with China instead of Vietnam in the context of increasing confrontation between China and Vietnam; 2) Vietnam's increasing dependence on the Soviet Union and 3) Vietnamese military intervention and long occupation of Cambodia together with the outbreak of Sino-Vietnam border war, all led to a tragic context that prohibited any feasible attempts for normalization from success. The failure of initial attempts for normalization and such compelling cold war contexts lead the United States to full confrontation with Vietnam by continuing and expanding the embargo, prohibiting any types of aid (whether domestic or international, in any 
form) to Vietnam, supporting Khmer Rouge's seat in the United Nation and putting international pressure on Vietnam to withdraw troops from Cambodia. In response, Vietnam shut down cooperation on POW/MIA issue with the United States, and considered the US "the principal and permanent enemy" of Vietnam.

The above-mentioned hypothesis based on such realist assumptions will be tested against evidence obtained in US-Vietnam relations of the 1975-1986 period.

\section{US lack of interest in postwar Vietnam and a high priority for normalization with China.}

After the Vietnam War ended in 1975, Southeast Asia region in general, and Vietnam in particular, received little US attention as "the region was no longer viewed as of vital security" to the United States (Tyner 2007: 163). Indochina for most America was not a crisis but a humiliation better forgotten. It is thus not surprising that, except for a flurry of enthusiasm for normalization with Vietnam in the early Carter years, three US administrations since 1975 have assigned Indochina low priority. For policy makers, Southeast Asia sunk to a third-rank priority on the global agenda, and Indochina became "almost invisible" (Chanda 1986: 142). At the same time, leaders from both political parties were apprehensive over re-involvement, however slight, in the affairs of Indochina, since "the wounds are still fresh and the domestic political risk still evident" (Brown 1989: 3). Therefore, after a short-lived flutter over the Mayaguez ${ }^{6}$ in May 1975, Indochina "sank below the horizon of American consciousness" (Chanda 1986: 142).

\footnotetext{
${ }^{6}$ The United States took military action to rescue the 39 members of an American ship seized by the Khmer Rouge. The cost was 18 marines killed or missing, and 50 wounded.
} 
Consequently, no broad plan for a future US role in Southeast Asia emerged during the first two years after the Indochina disaster. The desire to put Vietnam behind seemed to extend to all of Southeast Asia, despite the fact that the Vietnam War had been fought in large measure to protect US friends from aggression that Washington thought would certainly come without deep American involvement (Brown 1989: 19). The adjustment of US Asian policy to fit the post-Vietnam strategic context therefore seemed unsure and piecemeal. Policies were patched together in response to domestic political concerns, pressures from allies, and a new President's predisposition, but there was no clear statement of the goals and instruments of security policy attuned to the realities of a new era (Stanley 1997: 35). On-again-off-again negotiations with Vietnam, a confusing Korea policy, intermittent expression of concern about human rights in several Asian countries, a slowing of US economic interests in Southeast Asia, bogged down base negotiations with the Philippines, clashes with Japan over energy and trade, and a non-policy on China had all served to reinforce the impression that US security policies in Asia lacked any overall sense of direction. Given this context, it was hardly surprising that the Administration's Vietnam policy seemed difficult to fathom (Stanley 1997: 36).

As Washington developed amnesia about Indochina, the US was not so keen in normalizing relations with Vietnam. This was evident in the postwar years under President Ford's administration when the United States put strict embargo on trade and investment in Vietnam. The embargo, which had been in effect against North Vietnam since 1965, was extended in May 1975 to all of Vietnam. In addition, the South Vietnamese assets of $\$ 150$ million in the US were also frozen. Together with economic 
punishment, the United States also blocked Vietnam politically by vetoing Hanoi's application for membership in the UN in 1975 and again in 1976 (Brown 1989: 21).

The mood in Washington at that time therefore was "for forgetting Vietnam, not forgiving it" (Chanda 1986: 144). The only area that the United States remained interested in relations with Vietnam during this period was the POW/MIAs issue. However, normalization of relations with Vietnam and putting the past behind was a Carter campaign pledge. President Carter's interest in Vietnam was its symbolic importance, because one of the reasons he had been elected was the feeling that he was US post-Vietnam candidate and "he was very interested in normalization with Vietnam as a symbol" (Chanda 1986: 146). To American policymakers, an important means of forgetting the painful past was to get an accounting for twenty-five hundred men lost in Indochina, of whom eight hundred were listed as missing in action (Select Committee Report on POW/MIA's Affairs 1993: 12).

In contrast with American modest interest in the relationship with Vietnam, Vietnamese eagerness to establish ties with the former adversary was strongly felt (Chanda 1986: 142). Even before the end of the war, Hanoi had decided that solidifying relations with the West, and particularly with the US, was a crucial step toward the next phase of reconstruction. Vietnam viewed normalization "as a means of ending isolation, eliminating the embargo, opening up trade opportunities, and reaching closure on some of the more nettlesome bilateral issues" (especially the POW/MIA issue and the refugee related matters) that had dominated relations with the US since the end of the war in 1975 (CPV Resolution\# 5 - 1976). 
As both countries shared certain interests in normalizing relations, negotiations for normalization was initiated in 1977 and early 1978 during which the United States emphasized the need for Vietnam to fully cooperate in seeking American POW/MIAs and Vietnam called for US war reconstruction aid. However, the negotiations took place in the changing strategic context that was unfavorable for success: at the same time the United States was also seeking to normalize relations with China amidst increasing confrontation between China and Vietnam. To the United States, a normalized relationship with China deemed far more strategically important in comparison with that with Vietnam, and as a result normalization with Vietnam was eventually sacrificed because of concerns that positive moves toward Vietnam amidst Sino-Vietnamese confrontation would damage American efforts to improve relations with China.

Since 1972, the US had developed a relationship with the People's Republic of China (PRC), largely based on common anti-Soviet interests. Although US-Soviet détente began in May 1972 when US President Richard Nixon visited Moscow, starting a release of tension between the two superpowers, China still played a strategically important role in the US-Sino-Soviet triangular relationship since both China and the United States shared common interests against the Soviet Union. Given the Cold War context in which Sino-Soviet relations had been increasingly confrontational, a better relationship with China would bring about strategic benefits to the United States. Consequently, normalization with Vietnam, which deemed to be less important in US calculation, would have to be compromised for fear that it would damage possibility of moving forward with China, especially in the context of rising Sino-Vietnamese confrontation. 
President Carter's had set normalization with China as an important goal for his term in office. There were three distinct rationales for the United State to seek to improve USChina relations, especially with regards to security realm, as American policy makers calculated. Enhancing US cooperative security relationship with China would help reduce the possibility of a return to Sino-American confrontation, sustain the collateral benefits to US diplomacy and security policy which had come from past improvements in USChina relations, and minimize the prospect of a Sino-Soviet reconciliation (Department of State 2013: 848).

At the same time, US-PRC relations could be used as a means of gaining some leverage over Soviet behavior. Presuming that the Soviets were sufficiently concerned about the future course of US-China relations either to be more forthcoming in their bilateral relations with the US or to moderate their behavior in order to forestall close US-China security ties (Department of State 2013: 849). US National Security Adviser Brzezinski believed that if there was any leverage to be gained over Soviet actions in the US-China relationship, it was most likely to be in Moscow's anticipation that it could influence the future course of Sino-American relations (Brzezinski 1983).

American policy makers also believed that strengthened US-China security ties could force the USSR to react to what they had already seen as a two front security problem and divert Soviet forces to the Sino-Soviet border, thereby reducing the Soviet threat to NATO and other areas of US interests (Department of State 2013: 849).

Therefore, a shared animosity toward the Soviet Union provided much of the impetus for greater cooperation between the United States and China (Preface, Foreign relations 
Document 1977-1980, Volume XIII: IX). In a memorandum to President Carter, National Security Advisor Brzezinski asserted that:

It is the Soviet Union - not China - that threatens us militarily, that is actively seeking to expand its sphere of influence, that is encouraging war by proxies, and that is conducting a worldwide propaganda campaign against us (Memorandum to Carter July 7, 1978, Doc: 508).

Brzezinski saw the increasing antagonism between China and the Soviet Union an opportunity for the United States to reach out to China:

The Chinese are frightened by recent Soviet advances in Angola, Ethiopia, South Yemen, Afghanistan, and Vietnam. They supported the Shah and invested heavily in Pakistan. Though reluctant to admit their vulnerability, they see themselves endangered by Soviet encirclement. Their counter strategy is to foster a line of containment against Soviet expansionism stretching from Japan through China, Pakistan, Iran, Turkey, to NATO, all backed by the US. They perceive a crumbling middle sector of this line, a vulnerability at the two wings, and a passive United States. (Memorandum to President Carter July 7, 1978: 508).

With the same line of thought, US Secretary of Defense Harold Brown also support improving relations with China as he desired to prevent a renewed Sino-Soviet alliance. Secretary of State Vance and his Assistant on Asian Affairs Holbrooke initially desired to promote normalization with Vietnam, but failed to convince President Carter in the context of worsening Sino-Vietnam relations (Chanda 1986: 286). 
On the other end of the relationship, China viewed US-PRC security relations in geopolitical terms: Chinese leaders saw the United States as a strategic counter weight to the Soviet Union and seek to use security relations with US as a means of containing the USSR. In addition, Chine wanted to use the recently strengthened ties with the US, Japan and Europe not only to enhance China's economic and military modernization program, but also to stimulate sufficient tension in Moscow's relations with the United States to divert Soviet pressures away from China, and to use Indochina developments to worsen US-Soviet relations (Weinstein 1978).

As both sides had strong incentives to promote relations, negotiations on normalization of relations between the United States and China took place at different levels, including meetings between Chinese Vice Premiers Li Hsien-nien and Deng Xiaoping with top American officials in both Beijing and Washington. Talks on normalization with China occurred at the time that US negotiations with Vietnam were taking place.

However, as Sino-Vietnam antagonism increased to the point that a war might break out between the two countries (including China's concerns about Vietnam's leaning toward the Soviet Union and Vietnamese plans for military intervention into Cambodia), the United States was concerned that moving ahead with normalization with Vietnam might seriously interfere and damage the process of normalization with China, especially when China openly expressed its dissatisfaction about US-Vietnam improved relationship.

With such significant concerns, US CIA Director Stansfield Turner indicated in his report titled "US observation on China-Vietnam conflict" in June 1978 to President Carter: 
The Vietnam situation, where I fear that the rush of events may lead us to move ahead with Vietnam so rapidly that it will interfere in our China policy (CIA Report to President Carter, June 1978: 523)

Sharing the same concern about dissatisfying China, in a memorandum to President Carter, Security Advisor Brzezinski indicated that normalization with Vietnam had become incompatible with normalization with China, a process moving toward fruition but still in the balance. For the US, the China gambit was far more valuable than a relationship with Vietnam (Memorandum from Brzezinski to Carter on July 7, 1978). Brzezinski believed that normalization with Vietnam, the ancient enemy of China that was about to attack China's ally Cambodia, would damage and perhaps derail establishment of full diplomatic relations with China:

This willingness (to normalize with Vietnam) comes at the wrong time and in the wrong context. It will reinforce Chinese concerns, and thus needlessly complicate the more important task - normalizing with Peking. You (President Carter) need to choose: Vietnam or China, and China is incomparably more important to us (Department of State 2013: 509).

US concerns of upsetting China was also evident in the policy making process. In a memorandum on November 11, 1978 to President Carter and Security Advisor Brzezinski, the CIA Director Turner observed that recent comments by top Chinese officials demonstrated that Peking's opposition to the normalization or improvement of relations between US and Vietnam was growing: 
As the dispute between China and Vietnam escalated this summer, some Chinese officials began to convey different signals. Since last August (1978), comments on US-Vietnam normalization have been generally negative. This shift over time in China's position clearly reflects Peking's growing belief that Hanoi had embarked on a course totally opposed to Peking's. Vietnam's entry into CEMA, its military action in Kampuchea, the dispute over ethnic Chinese in Vietnam and finally the Soviet-Vietnam treaty of friendship and cooperation (which was signed in November 3, 1978) are the outstanding benchmarks (Department of State 2013).

American concerns about dissatisfying China obviously increased as shortly after the Soviet-Vietnam treaty of friendship and cooperation was signed, China's news agency took the unusual step of publishing Chinese Vice Premier Li Hsien-nien's attacks on Vietnam during talks with American guests, intended to convey Chinese displeasure over the possibility of normalization. On Nov 3, Vice Premier Li had also raised the subject of normalization in a conversation with Secretary Schlesinger: recited in an irritated fashion the China's belief that it is no use trying to draw Vietnam economically or politically away from the Soviet (Department of State 2013).

Chinese officials in fact had returned to the theme of US economic assistance to Vietnam almost every time they discussed the question of US-Vietnam normalization. In meeting with US officials, Vice Premier Li Hsien-nien argued vehemently against US economic aid, asserting that it would relieve the Soviet Union of a "great burden" while having no effect on Vietnam's close ties to the USSR. When Chinese officials talked about 
economic assistance, they consistently cite their own record of aid to Hanoi and claim that even their "\$20 billion" was not enough to check Hanoi’s gravitation to Moscow. Such statements were because China had terminated aid to Vietnam before as a punishment, and therefore was concerned that such punishment would become less effective if Vietnam would receive aid from the United States instead. Although the United States had affirmed China that there would be no aid to Vietnam because Congress had already blocked such possibility, China still attempted to link the improving US-Vietnam relations with aid issue to highlight their dissatisfaction and concerns. Aid to Vietnam, said Deng Xiaoping when meeting with his US counterparts, "would be like assisting the Soviet Union in dominating Asia" (Department of State 2013).

Beside its rising campaign against Vietnam, China was also disturbed/ worried that normalized US-Vietnam relations would be viewed as taking sides against Kampuchea. Chinese leaders (both Li and Deng) had linked the question of US relations with Vietnam to the American attitude toward Kampuchea (CIA Report June 1978). Such increasing Chinese pressure reinforced American hesitance to move forward in normalization with Vietnam.

Under Chinese pressure for halting the normalization process, and with his own strategic calculations, National Security Advisor Brzezinski convinced President Carter that "if we normalize with Vietnam before normalizing with China, we will leave our relations with China anomalous while coupling SALT with recognition of a pro-Soviet state with whom the Chinese currently have bad relations" (Department of State 2013: 570). 
Disappointment over US normalization with Vietnam at this time could provide ammunition to those in China who might eventually oppose China's opening to the US, and US recognition of Vietnam clearly would chill the climate of the relationship (between US and China) and would be seen in Peking as inconsistent with the development of a cooperative, strategic link between China and the US.

Therefore, in this regard, the Carter Administration calculated that the timing of any US move to recognize Vietnam would be instrumental in determining the depth of Chinese displeasure. US-Vietnam normalization in the immediate aftermath of the recently concluded treaty between Vietnam and Moscow, and amidst indications of a new round of Vietnamese military action in Kampuchea would almost certainly be construed by Peking at best as US indifference to fundamental Chinese interests and policies in Southeast Asia.

In the event that the situation in Indochina finds its own level and the threat to the Kampuchean regime lessens in Chinese eyes, Peking may find it less difficult to swallow US-Vietnam normalization. On the other hand, if the situation in Indochina worsens dramatically in the next months, Peking's opposition to normalized US-Vietnam relations can be expected to intensify (Memorandum from Brzezinski to Carter, July 1978).

In fact, establishing diplomatic relations with Vietnam would have been much less complex and difficult than with China: the United States could set up relations with Hanoi only if the Vietnamese agreed to cooperate on the search for the missing in action and dropped their reparation demand, but to go ahead with China would require an 
important concession on the part of the Americans - the issue of Taiwan (Weinstein 1983). However, with China receiving much more significance in terms of strategic interests, normalization with Vietnam was eventually sacrificed. Although some parts of the US government sought to address human rights in the Sino-US dialogue, this issue was generally subordinated to the effort to improve relations between the US and China.

As a result, on October 21, 1978 President Carter officially decided to postpone normalization with Vietnam, and publicly announced on December 15, 1978 that the United States and the People's Republic of China were establishing formal diplomatic relations. Bilaterally, when normalization diplomacy between the United States and Vietnam ceased in 1978, Vietnam also ceased any semblance of cooperation on MIAs. Consequently, "normalization was dead in the water" (Brown 1989: 34).

\section{Vietnam's dependence on the Soviet Union}

Opportunity for improving relations with the United States faded further when Vietnam became more and more dependent on the Soviet Union, and thus widening the distance between itself and the former enemy - the United States. After 1975, Vietnam had virtually nowhere to turn but to the Communist bloc for the necessary economic assistance to build and rebuild the backward and war-ravaged country. Le Duan, First Secretary of the Vietnamese CPV, signed a number of highly significant economic agreements in Moscow in late 1975. One pledged "coordination of national economic development plans" of the two countries, while another promised a major Soviet underwriting of Vietnam's forthcoming five-year plan (1976-80) (Horn 1978: 586). Not

only had the U.S.S.R. been Vietnam's major aid donor by far, but it had also been its 
largest trade partner. Moreover, Vietnam increased its exports to the Soviet Union by 157 per cent in the first six months of 1977 in an apparent effort to pay off Soviet loans which had financed Hanoi's huge trade deficit. Finally, aside from the small arms which came largely from China until the end of the war when Beijing cut off the flow, and the $\$ 5$ billion worth of equipment left by the fleeing U.S. forces in the spring of 1975 (for which spare parts are unlikely to be obtainable), Vietnam 's military hardware mostly came from the Soviet Union (Horn 1978: 588).

As Sino-American relations were getting warmer and hope for normalization with the United States for reconstruction aid was fading, together with serious security threat coming from Khmer Rouge Cambodia, and increasing confrontation with China associated with a Chinese completely cut off of aid, Vietnam had no other choice but to lean toward the Soviet Union and thus became increasingly dependent on the Soviet (CPV Documents). Although during the first 2 years after 1975 Vietnam hesitated to join the Council for Mutual Economic Assistance (COMECON) because of concerns about China's reaction, Vietnam ended up joining the organization (June 1978). This may have reflected disappointment over the course of normalization talks with the US, but it also reflected Hanoi's recognition that only the Soviet Union could provide quick help to a Vietnamese economy that had gone from bad to worse since 1975.

The Soviet Union was most likely to benefit from the situation, at least over the short term, by taking advantage of the opportunity to make Vietnam dependent on Moscow, thereby establishing a sphere of influence on China's southern boundary (Interagency Intelligence Memorandum, Nov 14, 1978: 591). The Soviet Union also found its long- 
sought cooperation with Hanoi even more crucial in the light of an emerging SinoAmerican connection. For Moscow, it was a time of opportunity (Brown 1989:33). The beginning of the public quarrel between China and Vietnam came as a long-awaited opportunity to draw Vietnam firmly into its embrace. Moscow took advantage of the overseas Chinese issue to belabor its favorite theory of Chinese fifth column and win propaganda points in Southeast Asia. It twisted the knife into China by a full denunciation of Peking's "great power hegemony" and its interference in Vietnam.

Becoming more dependent on the Soviet, Vietnam signed the Treaty of Friendship and Cooperation with the Soviet Union (November 3, 1978), with Article 6 provided for consultation on security threats to the contracting parties and appropriate measures to counter them. Thus was established a strong Soviet-Vietnamese alliance. The Soviet Union was allowed to use Cam Ranh Bay, one of the best naval bases in the world due to its strategic location and advantageous features as a deep water bay, which used to be the most important naval base in the region for the Americans during the Vietnam War. On March 27, 1979, the first Soviet fleet entered the bay, which was developed into Moscow's largest naval base and staging area outside the Soviet Union and a key outpost for greater Soviet power projection in the South China Sea and the Indian Ocean, helping the USSR to emerge as a major naval power in Asia (Chanda 1986: 398) US Department of Defense Report to the President estimated that the Soviet Union's Pacific forces could push south 4000 kilometers from Vladivostok to use Cam Ranh Bay as its base. The USSR therefore obviously gained a new favorable strategic position (Department of State 2013: 552). 
From 1979 Soviet economic aid to Vietnam was estimated by US intelligence to be worth 1 billion a year (CIA Report 1979). The number of Soviet military advisers stationed in Vietnam in 1986 was estimated to be around two thousand compared with just twentyfive in early 1977. In the two years following the Chinese invasion Moscow supplied Hanoi with weapons worth $\$ 2$ billion - a more than tenfold increase over 1978. Although the arm deliveries slackened in subsequent years, aid was still estimated at an annual average of $\$ 750$ million (Chanda 1986: 397). In addition, there were three thousand Soviet experts working on aid projects, including offshore oil exploration. The Soviets simultaneously increased their economic and military aid to Laos and Cambodia and expanded their presence.

Vietnam's leaning to one side policy and its overdependence on the Soviet Union while China and the United States were getting closer in the context of increasing SinoVietnamese confrontation indeed narrowed down any possibility for US-Vietnam normalization of relations. The decision to join COMECON and the signing of the Treat by Vietnam was therefore “another nail in normalization's coffin” (Brown 1989: 28).

\section{Vietnam's military intervention and occupation of Cambodia and the Sino- Vietnam border war}

The strategic context of the Cold War became increasingly unfavorable for US-Vietnam relations as the Cambodia issue arose and the border war between China and Vietnam broke out. 


\section{Vietnam's invasion and occupation of Cambodia:}

After the war with the United States ended, the strategic environment in Southeast Asia had evolved negatively to the degree that once again threatened Vietnam's national survival. Conflicts between China and Vietnam, the two allies during the American war, had been escalating beyond control. In 1974, China attacked the forces of the Republic of Vietnam in the Paracels and occupied the entire archipelagos. In 1978, ethnic crisis involving the Hoa (overseas Chinese) people inside Vietnam broke out. Immediately after the fall of Phnom Penh in April 1975, Khmer Rouge forces, backed by China, launched a series of irredentist attacks on Vietnam's southwestern border. By the end of 1977, Vietnam's conflicts with the Khmer Rouge had escalated to a status of warfare. Since the Chinese invasion of Vietnam in 1979 in response to the latter's overthrow of the Khmer Rouge, Vietnam was at war again in both fronts.

Vietnamese and Khmer Rouge communists used to form an alliance to fight U.S.-backed regimes in their respective countries during the Vietnam War. While appeared to be cooperative to Vietnam, the Khmer Rouge leadership feared that the Vietnamese communists were scheming to form an Indochinese federation with Vietnam as the dominant force in the region (Weinstein 1978). In order to preempt an attempt by the Vietnamese to dominate them, the Khmer Rouge leadership began purging Vietnamesetrained personnel within their army, and began waging a war against Vietnam.

Border clashes, provoked by the Cambodian Khmer Rouge, occurred along the frontier on an ever increasing scale during 1977. Since April 1977 Cambodia used several divisions supported by artillery units to carry out senseless attacks against almost every 
area located along the Vietnamese border, and particularly against the settlements of the new economic zones in the southern part of Vietnam (Leighton 1978: 1). During the winter of 1977-78, intelligence became available on the brutal incursions into Southern Vietnamese border provinces by the Chinese-backed Khmer Rouge regime of Pol Pot. By early summer 1978, ominous evidence surfaced that indicated that Vietnam, stung by thousands of casualties (mostly civilians) on its own territory, was preparing to invade Cambodia with the intent of deposing Pol Pot (Brown 1989: 26).

By mid-1978, Vietnam had decided that the Khmer Rouge was intolerable and that military action to remove them from power was the only cure. By the summer, Hanoi was moving quickly to organize a Cambodian liberation front, the precursor of the People's Republic of Kampuchea (PRK) under Heng Samrin and Hun Sen. At the same time, China gave up efforts to moderate and restrain the Khmer Rouge excesses against Vietnam, and decided to back its murderous ally to the hilt against Soviet sponsored Vietnamese "hegemonism”. This served, in turn, to harden Vietnam's position (Brown 1989: 27).

In Vietnam's view, the Khmer Rouge was a Chinese proxy aiming to destabilize Vietnam from the southwestern front. In fact, Vietnam tended to view the "Kampuchean issue" as entirely masterminded by Beijing in its strategy of "playing the barbarians against the barbarians" (Truong Chinh 1979). Vietnamese leaders believed that the attack initiated by the Khmer Rouge was an integral part of China's traditional strategy to invade Vietnam with a pincer movement: 
The war of aggression by the Pol Pot - Ieng Sary clique against Vietnam is in fact waged by the reactionary ruling circle in Beijing, a war organized, nurtured and directed by Beijing. It is part of a strategy aiming to gradually contain, weaken and subdue Vietnam. It is to implement Beijing's chauvinist expansionism and hegemony, under the cover of Cambodia's "defensive counter-attack" against "Vietnamese aggression"...In conformity with a law in Chinese chauvinist behavior towards Vietnam, Beijing repeated its offensive strategy employed by Chinese feudalist dynasties many times in history: launching frontal assaults in coordination with attacks from behind (Truong Chinh 1979: 13-17).

As a result, following increasingly vicious border skirmishes, to protect itself from increasing security threat by Democratic Kampuchea (the Khmer Rouge) and to stop the genocide initiated by Pol Pot in Cambodia, Vietnam launched a full attack into Cambodia in December 1978 and captured Phnom Penh in January 1979.

At the outbreak of the war, the United States strongly condemned Vietnam for its invasion of Cambodia. In American strategic calculation, Vietnamese military adventure in Cambodia was "the proxy war between China and Soviet", and since supporting China was more strategically beneficial to the United States, the United States gave its supportive voice to the Chinese and Khmer Rouge. American National Security Advisor Brzezinski advised President Carter that the United States should help China to remain confident of its continued ability to deter a Sino-Soviet conflict in the face of continuing Soviet military buildup on the Chinese border: "We (Americans) have no interest in a 
Sino-Soviet accommodation secured through Chinese submission to the Soviet pressure" (Department of State 2013: 721).

On May 1979, State Department Deputy Assistant Secretary Robert Oakley warned Vietnam Ambassador to the United Nations Ha Van Lau that Hanoi should "act with restraint in Southeast Asia, especially regarding Thailand" and made plain US concern "about the long term implications of the growing Soviet military presence in Vietnam". Subsequently the United States publicly rejected normalization as long as Vietnam occupied Cambodia and threatened its neighbors (Department of State 2013: 725).

Consequently, Cambodia issue remained the biggest hurdle throughout US-Vietnam normalization process, putting the two countries in confrontation and hostility once again after the Vietnam War.

US strong opposition to Vietnam's occupation of Cambodia, and especially American open support for China in the face of a Chinese invasion of Vietnam, all together completely shut down any possibility for normalization. The Sino-Vietnam War in 1979 therefore brought about severe consequences for the existing incremental steps toward normalization of US-Vietnam relations.

\section{Sino-Vietnamese border war}

Relations between China and Vietnam were once as close as "lips and teeth" in the 1950s, but irritants developed in the 1960s and into the first half of the 1970s as the end of the 
war in Vietnam drew closer ${ }^{7}$. After 1975 the relations deteriorated sharply, bringing the differences between China and Vietnam out into the public arena, among which were China's uneasiness about Vietnam's relations with the Soviet Union, China's diminishing aid to Vietnam and the dispute over the Paracel and Spratly archipelagoes in the South China Sea where both claimed sovereignty. This became apparent during a visit by the secretary- general of the Communist Party of Vietnam (CPV) Le Duan, to China in September 1975 during which, for the first time in discussions between Vietnam and China, Le Duan officially raised the issue of sovereignty over these islands (Amer 1994: 357-383).

Despite the many disputed issues which plagued the relations between China and Vietnam up to the beginning of 1978, it was the exodus of the ethnic Chinese from Vietnam to China in the spring of 1978 and the Vietnamese military intervention and removal of the Pol Pot regime and occupation of Cambodia in December 1978 that triggered the public deterioration of relations, which were used by China as excuses to initiate a border war with Vietnam ${ }^{8}$ (Interview data).

In the early morning of February 17, 1979, China launched a massive attack on Vietnam across large border areas of six Vietnamese northern provinces in an attempt to "teach Vietnam a lesson". The war lasted in more than three weeks with heavy casualties in both

\footnotetext{
${ }^{7}$ Chinese move toward the United States in 1972 and intervention in the negotiation process for the Paris Accords in favor of the United States that ended the Vietnam War, for which Vietnam accused China of compromising with the United States on the back of Vietnamese revolutionary cause (CPV documents 1978).

${ }^{8}$ China accused Vietnam of ill treatment of the Chinese minority in Vietnam while Vietnam blamed China for instigating the Chinese groups in Vietnam to flee the country to destabilize Vietnam's economy (interview data).
} 
sides. The Sino-Vietnam border war was a result of strategic calculation on Chinese side, which had important implication for US-Vietnam relations.

Viewed from Peking, the Vietnamese treatment of the ethnic Chinese was neither part of Socialist transformation nor simple racial discrimination, but an integral part of Moscow's policy of encircling China. Vietnam's conflict with Cambodia was increasingly seen as part of a Soviet drive against Peking's regional leadership by using the "lesser hegemonist" Vietnam.

Consequently, China upgraded the significance of the Vietnam - Cambodia conflict from purely regional to global significance by claiming the linkage between Vietnamese expansionism and Soviet drive for supremacy (Chanda 1989: 258). They no longer viewed the Cambodia or overseas Chinese issue as disputes between two Socialist countries that could be settled through negotiations, seeing these as "a component of the whole plot", in which the Soviet superpower with its own hegemonistic aims provides cover and support for the Vietnamese authorities' regional hegemonism, while the Vietnamese authorities serve as a junior partner for the Soviet Union. (Chanda 1989: 259). Beijing also contended that the Vietnamese occupation of Kampuchea and its domination of Laos was not an "isolated event" or "local issue," since it not only revealed Hanoi's ambition to dominate all of Indochina but also represented "an important component of the Soviet attempt to further its strategy of seeking world hegemony."

Meeting with US President Carter in his trip to the United States in January 1979 to seek for American support for the Chinese coming military action against Vietnam, Deng asserted that: 
Vietnam is playing the role of Cuba. Of course, the Soviet Union will make use of Vietnam to harass China. Vietnam is also an important factor in the Soviet "Asian collective security system”. Proceeding from global strategic as well as from Asian considerations, we consider it necessary to put a restraint on the wild ambitions of the Vietnamese and to give them an appropriate limited lesson (Memorandum of Conversation with Deng, Jan 29, 1979: 768).

In Deng's calculation, the lesson would be "limited to a short period of time":

We intend a limited action. Our troops will quickly withdraw. We will deal with it like a border incident. What we plan to do is a limited short time action, to give them a lesson. A lesson along the border might bring about changes in Vietnam also. There is not too much difficulty in giving them a lesson along the border. Action will be quick, lasting 10-20 days, to be followed by withdrawal (Memorandum of Conversation with Deng, Jan 29, 1979: 768).

Deng calculated that a "self-defense counter attack" on Vietnam was unlikely to provoke a large-scale Soviet attack on China. Citing US military intelligence estimates of Soviet troop strength along the Chinese border, he argued that they would be unable to drive rapidly toward Peking. A small-scale attack by them could be handled by China. Second, an attack on Vietnam as an act of "self-defense", instead of an intervention on Cambodia, would not invite an unfavorable international reaction. Third, the punitive measure would not interrupt China's Four Modernizations and in fact would deter Vietnam from disturbing it in the future. He argued that if China achieved even 70 percent of its war objectives, the 30 percent failure would serve as a stimulus for military improvement. 
Most important, he argued, China's invasion and withdrawal from Vietnam would demonstrate to the Soviet Union and Vietnam China's determination and ability to break their encirclement. Soviet global strategy would suffer a setback in Asia (Memorandum of Conversation with Deng, Jan 29, 1979: 768).

Besides seeking American support, Chinese diplomacy also attempted to legitimize its military action against Vietnam by condemning Vietnam's invasion and occupation of Cambodia at international arenas. Beginning with the emergency UN Security Council meeting in early 1979, Beijing in all international forums or debates on Kampuchea repeatedly stressed that the Vietnamese occupation of Kampuchea was an act of "naked aggression" across international boundaries and a "colonial war in which the strong bullies the weak with the aim of subjugating a small independent nation" (Chang 1983: 599). As such, it had trampled underfoot the UN Charter and fundamental principles of international law" and must not be condoned. For this reason, the UN also had "an unshirkable responsibility" to take effective measures to resolve the Kampuchean issue. Moreover, since the Heng Samrin regime in Kampuchea was no more than a "puppet" created "at bayonet point" by the Vietnamese army, Beijing also insisted that continuing recognition of Democratic Kampuchea was "a matter of principle," since it was upholding the sovereignty and independence of a member of the United Nations. To do otherwise would be to acknowledge that military aggression and interference in another country's internal affairs was permissible, which could only throw the inter-national community into chaos (Chang 1983: 560). 
In China's strategic calculation, although China was unhappy with some of the policies of the Khmer Rouge regime, it considered an independent Kampuchea allied with Peking an essential buffer against the expansion of Vietnam, and by extension Soviet, influence in the area. (Interagency Intelligence Memorandum, Nov 14, 1978: 591). In fact, China hoped to thwart Vietnamese ambitions by providing strong support for the Democratic Republic of Kampuchea (Khmer Rouge) while undertaking a diplomatic and propaganda campaign to portray Vietnam as a Soviet cat's-paw and to arouse suspicions about Hanoi among non-Communist Southeast Asian states.

Supporting Pol Pot to continue the battle against Vietnam by proxy seemed a good enough medium-term objective for Chinese foreign policy goals. The Soviet invasion of Afghanistan in December 1979 gave additional weight to China's anti-Soviet stance. China wanted to leave the conflict in Cambodia unsolved because it feared that a quick settlement of the issue could only be favorable to Hanoi: If a pro-Vietnamese regime were legitimized in Cambodia and an Indochina bloc were consolidated under Hanoi, a severe blow would be dealt to China's regional power, and a resolution of the Cambodia conflict and restoration of amity between Hanoi and ASEAN would also end the uneasy coalition between China and ASEAN (Chanda 1986: 379). Vice Premier Deng said "it is wise for China to force Vietnam to stay in Kampuchea because that way they will suffer more and more and will not be able to extend their hand to Thailand, Malaysia and Singapore.” (Memos of Conversation Deng - Carter January 1979)

The Sino-Vietnamese conflict therefore had important implications on US-Vietnam relations. In US view, which was increasingly colored by the Manichean anti-Sovietism 
of Brzezinski - the Vietnam-Cambodia conflict as a proxy war between Moscow and Peking in which China deserved America's strategic support (Chanda 1986: 259). With such mentality in mind, the United States ended up taking sides with China in the war, condemning Vietnam's occupation of Cambodia.

For the United States, a conflict between the Soviet Union and China was more beneficial: making China more dependent on the US support, and at the same time weakening the Soviets and the communist bloc. A better relationship with China also gave the US a better leverage in dealing with the USSR (Department of State 2013: 719). It was therefore in the interest of the United States to exploit Soviet-Sino conflict, and the United States opted for supporting China in the Cambodia war. The United States taking sides with China in its invasion of Vietnam consequently made Vietnam become more dependent on the Soviet Union. The strategic situation of such Cold War context therefore, once again, created another step further away from normalization of relations between Vietnam and the United States.

In addition to the above-mentioned strategic environment that hindered the normalization of US-Vietnam relations, the boat people issue was another factor that contributed to the widening gap between the United States and Vietnam. In 1978-1979 a massive wave of Vietnamese refugees took to the sea to flee from Vietnam. These refugees fled from the newly formed Socialist Republic of Vietnam due to a combination of factors, including political, social, and economic persecution under the new regime (Tran Tue Quan 2012: 80). These refugees were known as "boat people" because they had crossed the treacherous South China Sea in inadequate and overcrowded boats to reach refugee 
camps in neighboring countries including Malaysia, Thailand, Indonesia, the Philippines and Singapore, and also Hong Kong. The mass flight of hundreds of thousands of boat people from Vietnam in 1978 and 1979, reaching the level of 75,000 refugees per month by early 1979, caused an international humanitarian crisis with the Southeast Asian countries increasingly unwilling to accept ever more boat people on their shores (Shivakumar 1995).

Figure 1: Boat people outflow 1975 - 1995

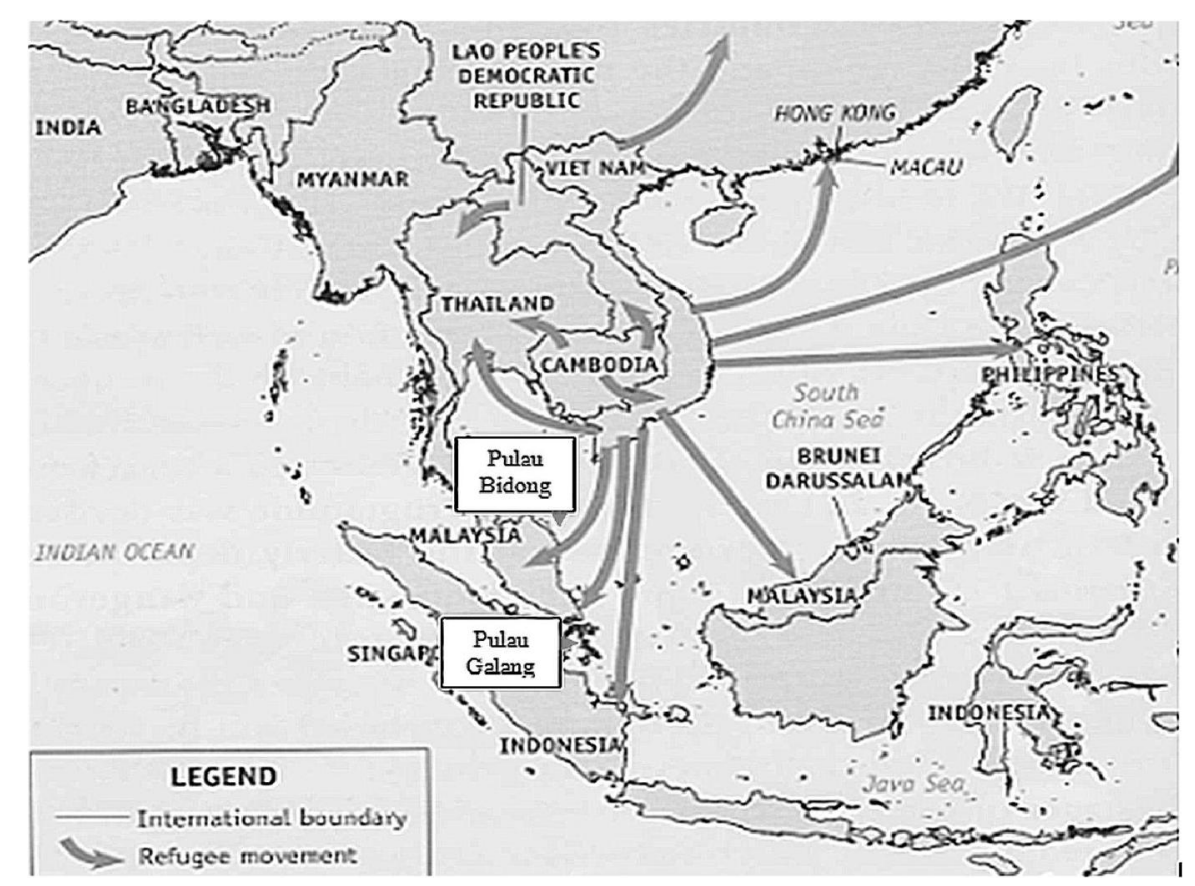

(Source: UNHCR. State of the World's Refugees: Fifty years of humanitarian action (Oxford: Oxford University Press, 2000), adapted from Tran 2012)

Hanoi's policy of callous expulsion added weight to the arguments in Washington against normalization of relations in the summer of 1978 (Brown 1989: 39). The outflow of boat 
people and the crisis that it created aroused strong American public opposition to Vietnam's handling of the situation, blaming the communist regime for mistreating their people. Such strong anti-Vietnam sentiment entered US Congress while debate on normalization with Vietnam was intensive, adding strength to the opponents of improving relations with Vietnam (Slabey 1996).

In summary, the Soviet-Vietnamese treaty had been followed by Sino-American normalization, which in turn had been followed by the Vietnamese invasion of Cambodia and the Chinese invasion of Vietnam, all drifted away any hope for normalization of relations between the United States and Vietnam in the 1975-1986 period, as observed by the Realist approach. These developments effectively ended substantive US-Vietnamese contact.

Together with the boat people issue, and at the same time the US government was occupied with other urgent issues (negotiation for SALT II, signing the disputed Panama Treaty), Vietnam became less and less present in US foreign policy priorities. For the United States, Vietnam was no longer an American problem except as the aggressor in Cambodia. The United States continued its embargo on Vietnam, blocking international aid to Vietnam to lever pressure for Vietnam's withdrawal from Cambodia and at the same time supporting forces that fight against the government established by Vietnam in Cambodia, including supporting the membership of Khmer Rouge in the United Nation as legal representative of Cambodia. The American hostile attitude to Vietnam remained 
through the rest of the 1975-1986 period, although there were a few modest and unsuccessful gestures for resuming cooperation on POW/MIA issue ${ }^{9}$.

In summary, the above analysis reveals that events in US-Vietnam relations during the 1975-1986 followed the logic that Realism predicts: The evolving strategic circumstances and the power structure in such Cold War contexts resulted in the hostility and confrontation in the bilateral relationship that led to no hope for normalization. Realist account proves to be especially valid in explaining US-Vietnam relations in the early years right after the Vietnam War ended (1975-1976) under the Ford Administration when Vietnam ranked low in US interests, and from late 1978 onward after the strategic situation evolved to the point that became impossible for normalization to happen: US normalization with China when Vietnam was at war with China, and the invasion and occupation of Cambodia by Vietnam, together with the Vietnam's taking side with the Soviet Union, all of which put the United States and Vietnam at confrontation line.

However, historical evidence of the short period from 1977 to mid 1978 reveals a central puzzle that remained unanswered by realist logic: the missed opportunity for normalization while both countries shared interests for an early normalization, and the strategic circumstances at this particular moment of history proved to be favorable for normalization.

\footnotetext{
${ }^{9}$ There were some initial contact with Vietnam for POW/MIA issue at the start of the Reagan Administration, but these efforts turned out to be symbolic rather than realistic.
} 


\section{The missed opportunity for normalization- a puzzle unanswered by Realism}

A window of opportunity indeed opened for normalization of relations for both the United States and Vietnam in 1977 and early 1978. First, it appeared that both the United States and Vietnam shared strategic interests for an early normalization: for the United States, it was the settlement of the legacies of the war with regards to POW/MIA issues, which was one of the top priority of the Carter Administration in office, and the strategic incentives to use Vietnam in the power competition game with the Soviet Union and China in the Cold War context; for Vietnam, it was for both the economic and political incentives that normalization with the United States was desired. Second, the strategic environment of the 1977-1978 was favorable for normalization when both China and ASEAN did not oppose the process, but in fact showed support for US-Vietnam normalization.

First, the United States proved to have strong interests in normalization with Vietnam in 1977. One of the top priorities for the Carter Administration was to have normalized relations with both Vietnam and China, a target that was clearly set during the presidential election campaign. To American policymakers under Carter Administration, normalization with Vietnam was one way to put the past behind, and an important means of forgetting the painful past was to get an accounting for twenty-five hundred men lost in Indochina, of whom eight hundred were listed as missing in action (Select Committee report on POW/MIA's Affairs 1993: 12). 
In fact, President Carter had a better position than President Ford in promoting relations with Vietnam when he had a report prepared by the House Select Committee on Missing persons in Southeast Asia headed by Republican Congressman Sonny Montgomery.

The Montgomery commission, including members of the MIA subcommittee, traveled widely throughout Vietnam. The mission met with Vietnamese highest officials including the Prime Minister Pham Van Dong. During the meeting, Vietnam committed to fully cooperate on searching for POW/MIAs and showed strong desire for normalization with the United States. Since their return, numerous members of the mission urged the Carter Administration to revive stalled talks with Hanoi about normalizing relations. Congressman Montgomery, who was a strong supporter of United States intervention in Vietnam during the war, became one of the most outspoken members of Congress favoring United States resumption of relations.

The commission concluded that improving relations with Vietnam, including reducing the embargo, was the best hope for obtaining accounting for MIAs. The report not only concluded that "no Americans are still being held alive as prisoners in Indochina or elsewhere, as a result of the war in Indochina, but also stated that a total accounting by the Indochinese governments was not possible and should not be expected. This report was very useful to gain support for normalization with Vietnam, from both the US Congress and the American public. In fact, the MIAs issue was not only the humanitarian question for the US government, it was the question of money as well, because the United States had to keep the lost men on the payroll and give them periodic promotions until they were declared dead. Normalization therefore represented an opportunity to 
unfreeze the dialogue over a myriad of bilateral issues, especially POW/MIAs - related matters.

Beside POW/MIA issue and the goal of putting behind the past, the United States also had other interest in normalizing relations with Vietnam. In American strategic calculation, a good relationship with Vietnam would be useful to resume the US role as the key balancing force in the region, and to re-energize Washington's efforts to prevent China from isolating Southeast Asia. In an October 1976 memorandum setting out specific goals and priorities for Carter Administration foreign policy, State Secretary Vance placed heavy emphasis upon normalizing relations with Vietnam as "an opportunity for a new initiative":

The Vietnamese are trying to find a balance between overdependence on either the Chinese or the Soviet Union. It is also in the interest of the US that Vietnam not be so dependent". (Department of State 2013s - Memorandum from Vance to Carter, October 1976)

Along this line, Secretary Vance and Assistant Secretary of State for East Asia and Pacific Affairs Richard Holbrooke calculated that Vietnam would prefer to have balanced relations with the superpowers than be wholly dependent on the Soviets. They saw the absence of an American diplomatic presence in Vietnam as an important factor inhibiting US ability to counter Soviet influence in Southeast Asia. With that in mind, Secretary Vance wrote in his memoirs that "normal diplomatic relations with Hanoi, strongly supported by our Asian friends, could increase our influence with Vietnam and offer it alternatives to excessive political and military dependence on the Soviet Union and China 
(Chanda 1986: 150). In addition, development of positive bilateral relations with Vietnam will be one strategic option among many that would remind China of the rules of behavior, and communicate US willingness to resume its leadership role in Asia in the aftermath of the war (Stern 2005: 8).

The above-mentioned discussion reveals that although the United States did not have significant interests in Southeast Asia in general after the Vietnam War, the Carter Administration did have strategic incentives to establish diplomatic relations with Vietnam in his early years in office, both in settling the legacies with regards to POW/MIAs as a means to heal the wound of the war, and in using normalized relations with Vietnam as a means to balance against the Soviet Union in the complicated triangular relationship among the United States, the Soviet Union and China in the Cold War context of 1977-1978.

For Vietnam, there was also a strong incentive in having normalized relations with the United States. Even before the end of the Vietnam War, Hanoi had decided that solidifying relations with the West, and particularly with the US, was a crucial step toward the next phase of reconstruction. Vietnam viewed normalization as a means of ending isolation, eliminating the embargo, opening up trade opportunities, and reaching closure on some of the more nettlesome bilateral issues (especially the POW/MIA issue and the refugee related matters) that had dominated relations with the US since the end of the war in 1975.

Addressing the National Assembly on June 3, 1975, only a month after the fall of Saigon, Vietnamese Chairman of the Ministers Council (Prime Minister) Pham Van Dong 
extended a formal invitation to the US to normalization with Vietnam and to honor the Paris Peace Agreement by giving reconstruction aid to Vietnam. That call was rejected by Washington. "At festive occasions in Vietnam we have wrestling games; at the end we embrace. Vietnam is ready, but Ford is not" (Hoang Tung 1975).

It also seemed to some observers that Vietnam's attempt for normalization during December 1977- September 1978 was an effort to "balance" its increased reliance on the Soviet Union with a more crucial, potentially lucrative new relationship with the United States, Moscow's chief rival (Stern 2005: 8). At the same time, Hanoi calculated that a normal relationship with the United States would at least telegraph the message to China that American interests were now part of the equation, so that any attempt by China to bring pressure to bear on Vietnam would have to take into account the possibility of American reaction that could be inimical to Bejing's interests (Stern 2005: 8).

In addition, in 1978 Vietnam also approached the possibility of normalization with the United States as an opportunity to demonstrate its sovereign strength and diplomatic prowess. From Hanoi's perspective, entering into relations with Washington would enhance Vietnam's reputation as a powerful, confident Southeast Asian country, and drive home the point that Hanoi could hold its own in direct negotiations with the United States (Brown 1989: 22). In the mid-1970s, this was referred to as "consolidating the international rear" and involved a commitment to winning friends, reducing foes, and developing sympathy and support in both the "revolutionary" and the "progressive" forces of the world (CPV Resolution 1977). 
With the above-mentioned rationales, both the United States and Vietnam indeed made some initial moves toward improving bilateral relationship. On the US side, President Carter made positive initiative to normalization with Vietnam by changing US condition for normalization from asking for "full accounting for MIA", which was a persistent policy of the former administration initiated by President Ford ( which was deemed impossible) to for "fullest accounting possible". This was considered a significant move, paving the way for a possible enhancement of cooperation between the two former enemies.

In an additional effort to speed of the normalization of relations with Vietnam, President Carter sent Leonard Woodcock Commission to Hanoi for cooperation on POW/MIA in March 1977. On one level the Woodcock mission was a remarkable success. It had broken the ice on the US-Vietnam relationship, given hope of further progress on sensitive American domestic concern, and apparently established a favorable atmosphere for formal negotiation toward diplomatic relations (US Department of State 2013s). The Carter administration also agreed to drop its opposition to Vietnam's entry into the UN and pledged to end its trade embargo once diplomatic relations had been established (Department of State 2013s).

In return, Vietnam promised to intensify efforts to provide an accounting of Americans listed as MIA in the war, and Hanoi negotiators went on to say that Vietnam was asking the US not for "war reparations", but for "contributions" to the reconstruction of the country (Stern 2005). Broadcasts over Radio Hanoi indicated that the government was in fact preparing the populace for normalization of relations with the US and for a stepped- 
up effort to gather information about the American's MIA's. Both sides consequently appeared to share the objective of an early normalization of relations (Weinstein: 1).

Second, the strategic circumstances of the Cold War in 1977-early 1978 appeared to be favorable for normalization when both China and ASEAN countries showed their support for US-Vietnam normalization of relations. In the early period, China did not oppose USVietnam normalization. Indeed, from the end of the Indochina war until early 1978, China appeared to support US-Vietnamese normalization in the hope that it would counter growing Soviet influence in Hanoi (Weinstein 1978). In a meeting between Secretary Vance and Chinese Ambassador Huang in 1977, as a result of Woodcock's mission to Vietnam, Vance told Huang that US may normalize with Vietnam, Huang "interjected that he had just heard on the radio that President Carter had decided to accept the invitation to resume negotiations in Paris with Vietnam", and said it would not run against Chinese interest that normalization may happen (Department of State 2013: 509). Assistant Secretary for Asian Affairs Richard Holbrooke recalled:

In 1978 in the UN General Assembly meetings the Chinese saying to us: "What you do with the Vietnamese over normalization is your affair. We do not oppose normal diplomatic relations between you and any socialist country" (Chanda 1986: 289).

In fact, China was aware of how normalization of US-Vietnam relations might help blunt Vietnam's growing dependence on the Soviet. 
At the same time, the ASEAN countries were not opposed to normalization "if it helped tame the Vietnamese tiger", and indeed its member warily pursued the same track, since there was unanimity among the Southeast Asians interviewed that it would be desirable for the US to have normal diplomatic relations with Vietnam (Weinstein 1978: 45). There was also virtual unanimity on the desirability of US's providing economic assistance to Vietnam, as long as: (1) aid should not be so substantial that it makes the Vietnamese too strong, and (2) it should not come at the expense of aid to the ASEAN countries (Weinstein 1978: 46).

In summary, there appeared to be obviously favorable conditions for normalization in the 1977 -early 1978 period and both the United States and Vietnam would have been better off if they went ahead with normalization. In 1977, the time was ripe for Vietnam and the United States to get together since a sympathetic new American administration was in office with some latitude in foreign affairs; feeling about MIAs was strong but had not coalesced; and there was adequate support on Capitol Hill for normalization (Weinstein 1978; Brown 1989). In addition, in 1977 and early 1978, Vietnam was pro-Soviet but had not taken the plunge into COMECON or signed a security pact (not until November 1978), and China and ASEAN did not oppose normalization.

Given the incentives and favorable conditions for normalization, the failure for normalization of US-Vietnam relations appears to be at odd with the Realist logic. 


\section{Conclusion:}

The above analysis reveals that events in US-Vietnam relations during the 1975-1986 mostly followed the logic that Realism predicts: The evolving strategic circumstances and the power structure in such Cold War contexts resulted in the hostility and confrontation in the bilateral relationship that led to no hope for normalization. The realist account proves to be especially valid in explaining US-Vietnam relations in the early years right after the Vietnam War ended (1975-1976) under the Ford Administration when Vietnam ranked low in US interests, and from late 1978 onward after the strategic situation evolved to the point that became impossible for normalization to happen: US normalization with China when Vietnam was at war with China, and the invasion and occupation of Cambodia by Vietnam, together with the Vietnam's taking side with the Soviet Union, all of which put the United States and Vietnam at confrontation line.

However, realist logics fall short in explaining the period of 1977-1978 during which both countries showed strong preferences for an early normalization, and at the same time the strategic environment was favorable for a normalized relationship when China and ASEAN countries indeed showed their support for normalization of US-Vietnam relations. By only looking at the "big picture", Realist approach therefore fails to adequately explain the actual process of interaction of the preferences made by the involving parties that realism considers as given and takes them for granted. The following Chapter 2 will go beyond realist logic to explore how Ideas and Asymmetry of power offer answer to the puzzling question that remains at odd to realist logic. 


\section{Chapter 2}

\section{Ideas and Asymmetry of Power explanation}

This chapter seeks to explore the role of ideas and power asymmetry in shaping USVietnam relations in 1975-1986 period. The chapter aims to test the hypothesis that ideas (the war mentality that vividly embedded in both countries) and the disparity of capacities between the United States and Vietnam that resulted in different interests and expectations from both sides were the factors that contributed to the failed attempt for normalization and the hostility and confrontation that preceded it. In the lens of Ideas and Asymmetry approach, we will expect to observe:

a) The war mentality and resentment mindset have strong influence in the policy making process of each country, leading to antagonism and unexpected consequences.

b) Given the disparity in power, behaviors by the US and Vietnam will follow some certain pattern in which the stronger side tends to dictate the pace and scope of negotiation while the weaker side tend to be over-attentive to the other party's behavior.

The influence of ideas and asymmetry of power will be tested against empirical evidence in three main areas: 1) Negotiation over POW/MIA and war reparation aid issues; 2) US collusion with China against Vietnam; and 3) US and Vietnam antagonism over the Cambodia issue. 
As ideas are difficult to assess, and in order to avoid assuming a causal connection between the ideas held by policy makers and policy choices, the chapter has identified the ideas being described (the war mentality as part of collective memory by both sides) and the policy outcomes to be explained. The war mentality will be assessed in the debates and discourse of both US and Vietnamese policy makers and official documents issued by both sides. Findings of the Chapter will be pooled together for assessment at the conclusion.

\section{Uncompromising conditions for normalization: POW/MIA issue and War Reparation Aid}

\section{Full accounting for MIA as an ultimate precondition for normalization:}

In the aftermath of the traumatic events of early 1975, the United States under President Gerald Ford addressed the question of normalization of relations with Vietnam guardedly (Brown 1989: 20). The only interest that the Ford administration had with Vietnam was the settlement of the legacy of the war: the POW/MIA issue. The POW/MIA issue has a high profile in American politics and clearly represents the most important US policy concerning Vietnam in post-war era. It was the "highest national priority by the Executive branch" and has been the main impediment to the normalization of relations with Vietnam (Senate Select Committee on POW/MIA Affairs 1993: 15).

In negotiations with Vietnam, Washington maintained that a complete accounting for the MIAs was the "absolute precondition" for any real steps toward normalization. 
Washington position was that the Paris Agreement 1973 to end the Vietnam War was still binding, in which the Article 8(b) stated Vietnam's responsibility to solve the POW/MIAs issue (Appendix A). Robert Funseth, spokesman of the US State Department, on May 29, 1975, said:

The US State Department regards this Agreement as still binding where it is applicable...Hanoi must bear the main responsibility for the missing personnel issue (Department of State 2013).

In an obvious hardening of American position, Secretary of State Henry Kissinger announced on April 22, 1976 that Vietnam's "full accounting for the missing in action" is "the absolute precondition" for US consideration of any other moves in its relations with Vietnam (State Department Doc). Furthermore, in a May 8, 1976 diplomatic note, the US State Department once again made its position clear:

Talks on the basis of the selective application for past agreements would not be fruitful...The US believes it would be more useful to discuss issues affecting future relations between our two countries. The humanitarian concern for a full accounting of our missing men will be one of the primary issues of the United States in such discussions. Until this issue is substantially resolved, there can be no real progress toward normalization of relations (Stern 1995: 21).

A July 19, 1976 diplomatic note went further in stating that: 
A full accounting for those Americans missing in action and the return of the remains of those killed in action is a matter of primary concern to the United States...United States does not consider that it has an obligation to provide reconstruction assistance to Vietnam (Stern 1995: 22).

Clearly, a full account of these last "discrepancies" is not possible. Compared with the US experience in other recent wars, the number of 1172 cases is, in fact, remarkably low. Although data are only roughly comparable, the number of servicemen and women still unaccounted for in World War II is 78,794 and in the Korean War is 8,177 (Morely 1992: 18).

Table 1 - Americans Unaccounted for in Southeast Asia

\begin{tabular}{|l|c|c|c|}
\hline Country of Loss & POW/MIA & KIA/BNR $^{\mathbf{1 0}}$ & Total \\
\hline North Vietnam & 348 & 233 & 581 \\
\hline South Vietnam & 450 & 625 & 1075 \\
\hline Laos & 333 & 193 & 526 \\
\hline Cambodia & 37 & 46 & 83 \\
\hline China & 4 & 2 & 6 \\
\hline Total & $\mathbf{1 1 7 2}$ & $\mathbf{1 0 9 9}$ & $\mathbf{2 2 7 1}$ \\
\hline
\end{tabular}

(Source: Defense Intelligence Agency, Monthly POW/MIA Statistical Report, November $12,1991)$

Moreover, it is officially acknowledged that the circumstances of the Vietnam War make a "full" accounting particularly difficult (Senate Select Committee on POW/MIA Affairs 1993: 16). Most Americans unaccounted for from the Vietnam War were Air Force and Navy aircrew lost over North Vietnam, Laos and Cambodia, or thinly populated areas of South Vietnam. Problems in recovering these men, alive or dead, were formidable, due to

\footnotetext{
${ }^{10} \mathrm{KIA} / \mathrm{BNR}$ : Killed in action/body not recovered.
} 
inhospitable terrain, enemy action, and the fact that US ground forces never occupied North Vietnam and Laos and lost access to South Vietnam after the Communist victories of 1975. Other POWs and MIAs were Army and Marine Corps personnel lost on the ground in South Vietnam, as individuals or in very small groups. Recovery of the remains of Americans lost on the ground was hampered by insufficient information being given or available to US ground units who fought in areas where the US personnel had been lost (Morely 1992: 19).

In fact, these difficulties in searching for MIAs were known to the American government. On September 30, 1975, Dr. Roger Shields, US Deputy Assistant Secretary of Defense, chief spokesman for POW/MIA affairs at the Defense Department, speaking at a hearing of the House Select Committee on Missing Persons in Southeast Asia, said:

In the Korean War and in World War II, about 22 percent of our casualties were ultimately declared dead and were never recovered. In the Vietnam War, we are talking about less than 5 percent". (MOFA, On the question of Americans missing in the Vietnam War 1980: 14)

A "full accounting" for MIAs was therefore virtually impossible, as later proved by the report of Representative Montgomery's House Select Committee on Missing persons in Southeast Asia after he came back from Vietnam in January 1976, rejecting the possibility of live Americans being held captive in Indochina, and it had stated flatly that "a total accounting by the Indochinese government is not possible and should not be expected". The final report of the House Select Committee on Missing Persons in Southeast Asia, on December 13, 1976, also concluded: 
Due to the passage of time, ravages of climatic conditions, and uncertainty of site location in some 54 percent of the incidents, crash site investigations could add only negligible information and a small percentage of identifiable remains beyond what the Indochina governments are now capable of furnishing...

Such conclusion was reaffirmed by the Woodcock Commission report in 1977 after the visit to Vietnam (Woodcock Mission Report to Carter 1977).

However, while being fully aware of the impossibility of the demand for a full counting for MIA, the Ford administration still firmly maintained such ultimate condition for normalization with Vietnam during the first two years after the war ended. Regardless of lobby/pressure from oil companies to normalize relations with Vietnam (since 1975 oil company representatives had been having unpublicized meetings with Vietnamese officials in Paris for the resumption of exploration, and in Feb 1976, some of them were invited to Hanoi to submit proposals - Chanda 1986: 145), the Ford administration persistently refused to lift the trade embargo without a full Vietnamese accounting of the MIAs.

Such unreasonable conditions for normalization by the United States provoked strong reaction from the Vietnamese side. Vietnamese official media went on to criticize the United States in hash terms:

While rejecting the legality of the 1973 Paris Agreement, regarding it as "dead in order to evade its obligation to contribute to post-war reconstruction in Vietnam, the United States demands that Vietnam implement those provisions benefiting 
the US side, imposes on Vietnam "obligations" to carry out Article 8 (b), although the Government of Vietnam has so far unilaterally and consistently carried out a humanitarian policy on the missing American personnel (Tap Chi Cong San December 1976: 25)

The US hardline policy on normalization was further perceived by Vietnam as "American plot to harm the revolutionary cause of the Vietnamese people" (CPV 1976).

Consequently, by insisting on an unrealistic demand for a full accounting before normalization, the Ford administration had virtually shelved the issue. Together with hardening American policy on the POW/MIA issue, the United States also froze the Vietnamese assets and vetoed Vietnam's application for membership in the United Nation in two consecutive years from 1975 to 1976 , all led to a completely frozen relationship with the former enemy.

\section{Confrontation over war reparation aid}

While the United States stuck to its firm stand in setting unfeasible conditions for normalization, Vietnam appeared to be equally consistent and resolute in its unswerving demands for US war reconstruction aid in return for normalized relations.

Obtaining reparation aid from the United States was one of the priorities Vietnam had in developing relations with the United States. While the US government regarded the 1973 Paris Accords as still binding, especially in regard to the responsibility of accounting for MIAs, Hanoi took the position that the responsibilities regarding MIA information and 
repatriation spelled out in Article 8 (b) were "no more binding than the fulfillment of Article 21 on reconstruction aid" which stipulated that the United States "will contribute to healing the wounds of war and to postwar reconstruction of the DRV and throughout Indochina”. Tran Hoan, representative of Vietnam at the October 24, 1976 meeting with American negotiator reiterated Hanoi's basis position:

We are ready to carry out fully, and I repeat fully, our obligations regarding the provisions of Article 8 (b) of the Paris Accord...but the American side must also assume its obligations regarding the contribution to healing the wounds of war and to post-war reconstruction in Vietnam and to carry out what was agreed at Paris in 1973 in the Joint Economic Commission. It is not only a question of law or of legality, but also a question of honor, responsibility and conscience (Stern 1995: 22).

In response to Vietnam's demand for reparation aid as precondition for normalization, the United States strongly rejected any possibility for paying war reconstruction (Chanda 1986: 153). There was a strong American distrust of Vietnam as US officials argued that the United States would not need to abide by the 1973 accord regarding aid to Vietnam when Hanoi had violated the 1973 agreement in taking South Vietnam by force (Interview data).

However, while making no compromise on the aid issue, the United States under the Carter Administration adopted a more flexible approach to the POW/MIA issue in an attempt to enable normalization happen. Instead of asking for "full accounting" (as once insisted by the Ford Administration), President Carter then only asked for the "fullest 
possible accounting" for MIAs as precondition for normalization. On March 13, 1977 , President Carter, talking to the US Presidential Commission led by Woodcock before its departure for Vietnam, stressed:

There might never be enough information about all the missing. What's important is that there must be a realistic attitude towards what could be obtained. Some dropped on water or in the jungles and the mountainous terrains where they might never be found or the search would take a long time (Department of State 2013)

In part of this more flexible view on the possibility of improving relations with Vietnam, in the talks with Vietnamese Deputy Foreign Minister Phan Hien in Hanoi on March 17, 1977, Leonard Woodcock, head of the US Presidential Commission, stated that:

Let me stress we are not unrealistic in our expectations. We recognize that no information may ever be recovered on many of the missing. From our own experience we know that the remains of the dead are often difficult or impossible to find, in many cases having been virtually swallowed up by the earth or the sea or ravaged by time and other elements...We recognize that a search and accounting for further information could take more time and be a continuing process" (Department of State 2013).

However, such more flexible condition by the United States was not equally responded by Vietnam. In the first months of 1977, Hanoi continued to call on the US government to fulfill its obligation to "contribute to binding the wounds of war and the reconstruction 
of Vietnam' and to carry out the commitments to which the Joint Economic Commission agreed in 1973. During the Woodcock mission to Hanoi on March 16, 1977 to start negotiation for POW/MIAs cooperation and discuss possibility for normalization, Vietnamese Deputy Foreign Minister Phan Hien representing Vietnam in a meeting with Woodcock told his American counterpart that "aid was an obligation to be fulfilled with your conscience and all your sense of responsibility", and "As to the form US aid might take, the Vietnamese are flexible" (Stern 1995: 140).

Such persistent demands for reconstruction by the Vietnamese government led to the stalemate and failures of three rounds of negotiation on normalization. In the first round of negotiation for normalization in Paris in May 1977, although the US showed some eagerness to move forward with normalization by dropping the linkage between diplomatic recognition and information about MIAs (Schulzinger 2006: 10), and Assistant Secretary Richard Holbrooke proposed unconditional establishment of relations after which the US trade embargo would be lifted, Vietnam was still persistent in its stand for reparations as precondition for normalization. During this round of talks with Richard Holbrooke, Vietnamese deputy foreign minister Phan Hien again placed economic assistance front and center as a precondition to normalization, linking it to cooperation on the missing in action by bringing up the issue of President Nixon's 1973 letter to Vietnamese Premier Pham Van Dong, in which the US President had promised 3.25 billion in reconstruction aid in addition to commodity aid in the range of $\$ 1.5$ billion (Stern 1995: 152). 
In response, Assistant Secretary Holbrooke told Phan Hien that the US would not provide aid, but offered to lift the trade embargo once the United States and Vietnam restored diplomatic relations, stating that "the US has no preconditions. After our embassies are established we'll lift the trade embargo" (Schulzinger 2006: 10). This was considered another flexible move by the United States to put forward normalization of relations with Vietnam.

However, Phan Hien resented the American's dismissal of reconstruction aid, indicating that Vietnam would be willing to drop the characterization of reparations, but insisted that both the Paris Accords and Nixon's letter committed the US to rebuild Vietnam, and the Paris Accords (Article 21, see Appendix A) still governed relations between the two countries. Consequently, the meeting broke up without an agreement (Schulzinger 2006: $10)$.

On May 19, 1977, in another attempt to put pressure on the United States, Hanoi released the secret Nixon's letter to the public, highlighting a quotation from the letter that said "the government of the United States of America will contribute to the postwar reconstruction in North Vietnam without any political conditions. The US contribution will fall in the range of $\$ 3.25$ billion in grant aid over five years" (Nixon's letter to Pham Van Dong 1973). The release of the Nixon letter amidst negotiations on normalization were taking place resulted a setback in the process, reconfirming Vietnam's hard stand on the precondition for normalization to move forward.

The release of President Nixon's letter and Vietnam's persistent demand for compensation for the war resulted in negative US response. Vietnamese negotiators 
claimed that Nixon had secretly pledged them aid, and the suggestions of possible indirect US aid "had touched many a raw nerve in the US Congress" (Chanda 1986: 325). Although Carter had consulted the Congress before sending Assistant Secretary Holbrooke to Paris for talks with Vietnam, there was considerable opposition to an move seen as leading toward normalization (Slabey 1989: 83). The House of Representatives was in the midst of debating the foreign aid bill when the report of Phan Hien's remarks about America's aid obligation to Vietnam at the May 41977 press conference in Paris "clattered on the teletype machine" of the House Foreign Affairs Committee. Republican Congressman William Ashbrook waved a copy of the wire service report to call for a measure to stay the hand of the State Department. His amendment prohibiting the US administration from "negotiating reparations, aid, or any other form of payment" to Vietnam was passed on the same day by 266 votes to 131 . Bowing to anti-Vietnam mood of the Congress, Secretary Vance announced "we made clear to Vietnam that we will not pay any reparations" (Chanda 1986: 153).

The second and third rounds of negotiation in June and December 1977 respectively also came up with no agreement as both Vietnam and the United States stubbornly stuck to their own terms. Vietnam continued to operate on the presumption that the United States owed Vietnam economic assistance legally and morally whereas the United States firmly refuted the demand. (Brown 1989: 24).

As the second round of talks between Vietnam and the United States was taking place in Paris in June 1977, the House of Representatives overwhelmingly approved an amendment to the foreign aid bill, introduced by Democratic Congressman Lester Wolf, 
to formally renounce Nixon's promise of $\$ 3.25$ billion to Vietnam. By a massive vote the House repudiated the President and adopted an amendment that barred US funds from going “directly or indirectly" to Vietnam (Chanda 1986: 155). Vietnam's flat demand for economic assistance as a precondition, no matter how justified in the eyes of the Vietnamese Politburo, therefore prevented consummation during the first six months of the Carter administration when the window was wide open, since "after Hanoi's 1975 military conquest, reparations by any other name were never in the cards"(Brown 1989: 31). Hanoi's demands consequently served to arouse conservative criticism of the normalization gambit, and congressional actions narrowed still further room for maneuver - the possibility of even humanitarian aid after normalization become remote. Woodcock, who led the US Commission to Hanoi in March 1977 to seek for Vietnamese cooperation on POW/MIAs issue, admitted later that the administration simply had not gauged how deep was the feeling among congressional leaders, even among liberals, against giving money to Vietnam (Chanda 1986: 155). As a result, the window for normalization had begun to close earlier than expected.

During the third, and also the last round of talks in early December 1977 held by Assistant Secretary Holbrooke with Vietnamese deputy foreign minister Phan Hien, being aware of the faded possibility for reparation aid that had been barred by the US Congress, Vietnam instead required American private pledge about an aid package after normalization may happen. However, since the money issue was no longer negotiable in the United States and given the strong opposition in Congress, negotiation for normalization once again ultimately failed. 
Possibility for normalization faded further in early 1978 after all talks had been cancelled due to an espionage incident occurred in which the Vietnamese ambassador to the United Nations Dinh Ba Thi was named as an unindicted coconspirator (Chanda 1986: 268-271; Brown 1989: 27). Although the spying case was of limited importance - the stolen cables had the lowest classification and some were not classified at all, the Vietnamese ambassador was expelled from the United States. The case was not significant in the scale itself, but it proved to be a turning point in the checkered history of US - Vietnam relations since it happened at a wrong time for normalization: "it just froze everything" (Interview data).

US-Vietnam series of negotiations for normalization in Paris in 1977 and early 1978 therefore ultimately failed as both sides stubbornly stuck to their own terms. The failure of the talks in Paris to bring about agreement on normalization and the emotions it provoked among the conservatives virtually meant the end of Carter's first foreign policy initiative.

In September 1978, Vietnamese Deputy Foreign Minister Nguyen Co Thach met with Assistant Secretary Richard Holbrooke in New York in the final efforts by Vietnam to seek normalization. As a compromise to American opposition, Vietnam had indicated its willingness to drop the demand for reparations as precondition for normalization in earlier unofficial meetings with American diplomats ${ }^{11}$. To confirm such compromise in negotiation, Thach made the official announcement about Vietnam's decision to remove

\footnotetext{
${ }^{11}$ During an informal meeting with Fred Brown in Hawaii in early 1978, Vietnamese diplomat Hoang Tung hinted his counterpart that Vietnam might be willing to drop demand for reparation as precondition for normalization.
} 
aid as precondition for normalization to Holbrooke and his colleagues at the meeting, paving the way for some initial positive signs for normalization to happen (Interview data).

However, to the Vietnamese disappointment, in the face of increasingly strong Congressional opposition, the US administration later in October 1978 not only refuted Vietnamese proposal, but also decided to raise the conditions for normalization. Robert Oakley, US Deputy to the Assistant Secretary of State for East Asia and Pacific Affairs, presented US new additional conditions for normalization during his two trips in October 1978 to the Vietnamese counterparts Deputy Foreign Ministers Nguyen Co Thach and Tran Quang Co, indicating that normalization would have to wait, pending a satisfactory Vietnamese answer to three problems:

(1) Vietnamese hostility toward Cambodia,

(2) Soviet-Vietnamese ties, and

(3) the increasing number of boat people coming out of Vietnam.

These new conditions were obviously unrealistic, and proved to be used as excuses for US cancellation of normalization with Vietnam (Interview data). The US Statement Department later explained to the Congress for why normalization failed by pointing to Vietnam's alliance treaty with the USSR and the invasion of Cambodia and the surge of boat people, but the fact was that these events flew in the face of chronology, because the 
first two developments took place well after the October 11, 1978 decision by Carter to postpone normalization with Vietnam ${ }^{12}$.

Consequently, Vietnam expressed its strong frustration to these new conditions for normalization. The Nhan Dan Daily and Tap chi Cong san issues in early November 1978, the official newspapers of CPV, went on to strongly criticize US new demands, accusing the US of "bluntly breaking promises and attempting to refute responsibilities for their crimes committed against Vietnamese people" (Nhan Dan Daily November $1^{\text {st }}$, 1978). From the Vietnamese standpoint, Vietnam needed US aid to have excuse to explain to Vietnamese people for why Vietnam should normalize with the US: "we must explain to our own people why the Americans are now being welcomed - that requires some indication that the US wishes to help Vietnam recover from the war's destruction (Tap Chi Cong San, November 1978).

The hardening policy of the United States also resulted in an internal debate by party followers of two political lines in the CPV about whether Vietnam should move forward with normalization with the United States in particular, and improve relations with the West in general. Moderates led by Premier Pham Van Dong favored a close cooperation with Western industrialized countries and gradual transformation of South Vietnam, which would permit better utilization of capital and management resources, whereas the hardliner/conservatives led by politburo member Truong Chinh (former First Secretary of $\mathrm{CPV}$ ) were most concerned about building socialism, maintaining ideological purity, and protecting the social system from "enemy infiltration and sabotage" (Interview data).

\footnotetext{
${ }^{12}$ These are strong counter-evidence against Realist explanation for the failure of normalization that gives credit to Vietnam's dependence on the Soviet Union and the invasion of Cambodia.
} 
The conservatives in CPV tended to view international relations through a MarxistLeninist prism. From this "old thinking" perspective, Vietnam viewed the world as split into two irreconcilable camps, socialist and capitalist. Capitalism was deemed inherently violent and imperialist, prone to seeking domination over other countries, especially socialist ones. Driven by the revolutionary tasks and the strength musters of the two rival blocs, the priority in Vietnam's foreign policy was given to its bonds with the socialist countries of which its relations with the USSR was the cornerstone, and "socialist internationalism", which held that socialist parties and countries would align and support one another, was the guideline for external relations.

This old thinking orthodoxy was a basic lens through which Vietnamese leaders understood international relations and planned foreign policy. Under this lens, Vietnam placed top priority in developing external relations within the socialist camp and isolated itself from the capitalist world. Its emphasis on socialist internationalism made it extremely dependent on Soviet aid and led to confrontation with the West and noncommunist neighboring countries.

The fact that the United States stubbornly refused to admit that any moral responsibility for the devastation of Vietnam only helped to confirm the hardliners in their view of the innate hostility of the United States and reinforced the continuity of the "old ideas" about international relations in which the United States was placed on the other side of the friends/enemies divide. As a result, a pro-Soviet approach was further enhanced, and US persistent stand pushed Vietnam further into alliance with the Soviet Union later in November 1978. 
The failures of negotiations in 1978 due to US overwhelming opposition to reparations, and additional unreasonable conditions for normalization, served as the final benchmark for an opportunity for normalization that had been completely missed. Bilaterally, when normalization diplomacy ceased in 1978, Vietnam also ceased any semblance of cooperation on MIAs.

In conclusion, the above analysis indicates that despite the strong incentives and preferences for normalization by both sides and the strategic circumstance of 1977-1978 that was favorable for an early establishment of diplomatic relations, the American unreasonable request for accounting of MIAs and Vietnam's stubborn stand in demanding reparation aid as preconditions for normalization were the major reason for why opportunity for normalization drifted away. With a victory mindset, Vietnam expected US reparation aid not as a reward for cooperation on the MIA issue, but as an act of moral obligation. For the United States, setting the rule for normalization and refusing to pay reparations, which might be considered admitting the moral responsibility for the war, proved to be a way of keeping face followed by the defeat.

\section{US collusion with China and Vietnamese sentiment.}

In a lasting irony of history, China went to war against Vietnam with discreet American blessing (Chanda 1986). In January 1979, Deng Xiaoping went to the United States to foster US-China relations and seek American support for Chinese plan for invasion of Vietnam. In his meeting with President Carter, Deng revealed China's plan to disrupt Soviet strategic calculations (implying that the Soviet Union was behind Vietnam's invasion of Cambodia), saying that "we consider it necessary to put a restraint on the wild 
ambitions of the Vietnamese and to give them an appropriate limited lesson" (Department of State 2013).

While Deng publicly denounced the Soviet Union, questioned the value of the SALT II agreement that the United States had patiently worked out with Moscow, and issued threats against Vietnam, Carter made no effort to contradict or even disassociate himself from Chinese statements (Chanda 1986: 352). During his restricted meeting with Deng on Jan 29, Carter made a very modest attempt to discourage the Chinese leader from attacking Vietnam, but he never hinted that the contemplated Chinese action would affect Sino-American ties (Department of State 2013).

In contrast with Washington's earlier condemnation of the Vietnamese invasion of Cambodia as "a threat to regional peace and stability that raises the danger of wider conflict", the United States implicitly justified the Chinese action. President Carter reported to Vice Premier Deng that "in the last few weeks, we have seen a Vietnamese invasion of Cambodia, and as a result, a Chinese border penetration in Vietnam. The American spokesman called for immediate withdrawal of Vietnamese troops from Cambodia and Chinese troops from Vietnam (Chanda 1986: 359). In this context, such formulation was interpreted at the same time as implying the United States would not object to the Chinese troop's staying in Vietnam as long as the Vietnamese were in Cambodia. President Carter went further to promise Deng that the United States would give China intelligence briefing (Memorandum of Deng and Carter meeting, January 29, 1979). In fact, Washington had quietly helped China by providing satellite intelligence 
about Soviet troop deployment along China's border and informing China when Soviet forces in Siberia were put on a state of alert after the Chinese invasion (CIA Report).

In addition, at a meeting with Chinese Foreign Minister Huang Hua during Deng's visit to the United States, Security Advisor Brzezinski indicated that the only real US concern was possible Soviet reaction to the Chinese move. He tried to "encourage the Chinese to concentrate on a swift and decisive move and not undertake a prolonged engagement", something that Deng already promised to Carter (Memorandum of conversation between Huang and Brzezinski January 1979).

In another sign of American strong support to Chinese plan of invading Vietnam, US congressional leaders were straightforward in their favorable statements for Chinese plan of action. During a meeting on Capitol Hill, House Speaker Tip O'Neill even went on to tell Deng that "if adventurous Vietnam was not restrained, there might be a Third World War" (Chanda 1986: 353). Although the Congress was not in total uniform in supporting of China's invasion of Vietnam, such open proponent voice by important congressional figures did indicate American support for China's invasion plan against Vietnam.

With all these implied support to China in its plan of invading Vietnam, the United States was giving China "a formal opposition and a wink" (Chanda 1986: 354). In fact, The US was indeed the only Western country that came close to endorsing China's war.

In addition, the United States indeed still planned the trip for Secretary of Treasury Michael Blumenthal to visit China during the time China was invading Vietnam, which could have been cancelled to show American displeasure at the Chinese attack, indicating 
to the Vietnamese that the United States was indeed supporting China in its invasion course (Weinstein 1978: 18).

Before Secretary Blumenthal made the trip, a Special Coordination Committee was formed to discuss whether Blumenthal should go ahead with the planned visit. The Special Coordination Committee Meeting in Washington February 19, 1979 considered five options with respect to the trip: (1) persist with original plans; (2) persist with the trip, but alter the instructions to take into account the new situation; (3) postpone the trip for a week; (4) postpone the trip until Chinese have withdrawn forces from Vietnam; (5) keep the trip on schedule but have a lower level representative. Considering these options, Brzezinski argued that the trip should go forward, since "the trip is part of the normalization process (with China), and we seek that to go forward in spite of the Vietnam conflict" (Summary of Conclusion of a Special Coordination Committee Meeting, Washington, February 18, 1979). Such argument was also supported by the US Vice President Mondale when he believed that delaying Blumenthal's trip would be to tip in the Soviet-Vietnamese favor. Along the same line, Secretary of Press Jody Powell supported the trip to take place as originally scheduled, and anticipated that the basic US public reaction would be that "Vietnam deserves to be beaten a little bit over the head" (Summary of Conclusion of a Special Coordination Committee Meeting, Washington, February 18, 1979).

In a report to Carter after the trip in early March 1979, Blumenthal recalled that China made an tremendous effort to be accommodating, to settle the claims/assets issue, and to insure that the visit be successful: they clearly saw it to their advantage, both as regards 
US-Sino bilateral relations and in terms of the overall impact worldwide, to come up with an agreement (to elevate the US liaison office to embassy status) (Memorandum from Secretary of the Treasury Blumenthal to President Carter, March 5, 1979).

The Blumenthal trip to China during Chinese invasion of Vietnam therefore indicated a clear signal of US support to China in its war against Vietnam. Such American support to China was interpreted by Vietnam as "the American plot to play the China card against Vietnam", drifting the two countries further apart away from normalization and put them deeper in hostility and confrontation in this period.

Since Vietnamese thinking about China had always been overshadowed by suspicion, even during the period of intimate relationship in the 1950s and early 1960s, the idea that the United States was supporting China inevitably generated strong anti-American sentiment in Vietnam. As stated in Politburo Resolution 9 of July 1978, "the Chinese leadership is the biggest international reactionary force, an ally of America, performing the role of the most dangerous reactionary assailant, plotting to eradicate MarxismLeninism and socialism, and exercising chauvinist expansionism and hegemony in the world, first and foremost in Southeast Asia" (Dao Huy Ngoc 1999).

It is noted that in the past, the Sino-American rapprochement in 1972 already came as a shock to Vietnam, and Beijing's decision to negotiate with Nixon was viewed by Hanoi as a betrayal (CPV Political Report 1972). Immediately after Nixon had returned to the United States from China, Hanoi assailed Nixon as a "bellicose, ferocious, ruthless and tricky imperialist ringleader," and declared the United States as the "biggest enemy of all nations in the world" (The Nhan Dan Daily, Dec 1972). Therefore, the idea that the 
United States was colluding with China - "the most dangerous and permanent enemy" against Vietnam - deeply embedded in Vietnamese thinking about the United States, worsening the bilateral relations which had already been confrontational.

US-Vietnam relations became more hostile when Vietnam perceived that the United States was supporting the Khmer Rouge forces to fight against Vietnam.

\section{Cambodia issue and American antagonism}

Together with "playing the China card", the United States took various measures against Vietnam's military intervention and occupation of Cambodia by (1) supporting China and ASEAN's efforts to strengthen the Khmer Rouge to fight against Vietnam's occupation; (2) seeking to maintain the Democratic Kampuchea (Khmer Rouge)'s membership in the United Nation while attempting to block the People's Democratic Kampuchea (the new Cambodian regime established by Vietnam after removing the Pol Pot regime in Cambodia) from the United Nations; and (3) intensifying economic isolation of Vietnam. All of these developments contributed to a chilled and hostile US-Vietnam relationship until the late 1980s and resulted in Vietnam's strong mentality against the United States.

First, in the aftermath of Vietnam's military intervention into Cambodia and the defeat of the Khmer Rouge, the United States firmly supported China in Beijing's efforts to rebuild the Pol Pot forces, which had been severely damaged by the Vietnamese attacks. During a trip to Thailand in early 1979, US National Security Adviser Brzezinski persuaded Thai leaders to cooperate with China to strengthen the Khmer Rouge as part of the effort to contain Vietnam: 
I encouraged the Chinese to support Pol Pot. I encouraged the Thai to help the DK. The question was how to help the Cambodian people. Pol Pot was an abomination. We could never support him but China could" (Becker 1986: 440).

Chinese aid to the Khmer Rouge via Thailand border was thereafter the main source of survival for the ousted Pol Pot soldiers to continue their guerilla warfare against Vietnamese army on Cambodian land.

As the atrocious conduct of the Khmer Rouge while in power became evident after the removal of Pol Pot, who was responsible for the deaths of approximately two million Cambodians between 1975 and 1978, it was a dilemma for the Carter's administration not to publicly criticize the ousted Khmer Rouge regime. However, US criticism on Khmer Rouge's genocidal policy and atrocity appeared to be a total hypocrisy when the US chose to stand beside China in Beijing's plot to nurture the Democratic Kampuchea. One of the most convincing evidence was the US refusal to grant political asylum for Cambodian Prince Norodom Sihanouk in early 1979 when he was trying to escape from the Khmer Rouge's control.

As a hostage of the Khmer Rouge, Prince Sihanouk became the symbolic head of state of the new régime while Pol Pot held power after the Khmer Republic fell to the Khmer Rouge in April 1975. During the Vietnamese invasion, in January 1979 Sihanouk was sent to New York to speak against Vietnam before the United Nations. Although Sihanouk opposed Vietnam's occupation of Cambodia, he was strongly against the Pol Pot regime that he was forced to represent. Being fully controlled by Khmer Rouge bodyguards during the trip, Sihanouk managed to escape to American intelligence agents 
and asked the US government for political asylum. However, the United States turned down the request as there was an immediate concern among American policymakers in giving asylum to Sihanouk about the chilling effect US asylum for Sihanouk could have on the newly established Sino-American ties, since "it was essentially through Chinese initiative and entirely at China's expense that Sihanouk had been plucked out of Phnom Penh before Vietnam entered and sent to New York to represent the discredited Pol Pot regime". In addition, as Chinese Vice Premier Deng Xiaoping was going to visit the United States (within 2 weeks), for the United States "to grant asylum to Sihanouk on the eve of Deng's visit could be seen by Peking as an affront" (Chanda 1986: 363-369).

Second, in addition to a support for China's course of rebuilding and strengthening the Khmer Rouge, the United States also supported the ASEAN and Chinese demand that Democratic Kampuchea retain its credentials in the United Nations. It also backed the creation of the Khmer resistance using the remnants of Pol Pot's forces as the nucleus. These decisions were viewed by the Carter administration as vital to supporting ASEAN's rejection of irreversibility ${ }^{13}$ (Brown 1989: 42). As a result, Vietnam's attempt to unseat Democratic Kampuchea from the world body was defeated in the General Assembly session in September 1979. By a vote of 6 (including the United States) to three, the UN Credential Committee allowed the DK to retain its seat. This was an ironic vote cast in favor of the regime President Carter had earlier denounced as the "greatest violator of human rights" in the world. Since voting against the Democratic Kampuchea

\footnotetext{
${ }^{13}$ Vietnam persisted in their contention that the situation in Cambodia was irreversible because without Vietnam's occupation, Cambodia would fall into the hand of the genocidal Pol Pot regime again.
} 
would mean opposing China and ASEAN and legitimizing the Vietnamese invasion, "that fateful vote linked US support to a murderous group with whom US officials were forbidden to shake hands" (Chanda: 377).

In explaining such credentials vote, US Secretary of State Cyrus Vance argued that "I had weighed the pros and cons of this issue for weeks. Days before the final vote, I had come to the conclusion that, unpleasant as it was to contemplate voting, even implicitly, for the Khmer Rouge, we could not afford the far-reaching consequences of a vote that would isolate us from ASEAN, Japan, China, our ANZUS treaty partners, and most of our European allies, and put us in a losing minority with Moscow, Hanoi and Havana”. In such argument, a US vote to unseat the DK would be against US interest, since it might appear to legitimize Vietnam's occupation of Cambodia (Brown 1989: 43).

Consequently, the battle waged at the United Nations by the United States to force Vietnam to withdraw from Cambodia and to allow self-determination for the Khmer people brought together a strange coalition of over a hundred nations in support of the very Khmer Rouge many of them had condemned and continued to denounce. The Pol Pot regime might have been reduced to a band of guerillas in the hills, but it was voted in as the only legitimate representative of the Cambodia people. Consequently, each year at the United Nations, ASEAN rounded up virtually unanimous Western and Third World support for keeping Cambodia's seat in the hands of Democratic Kampuchea, thus isolating the PRK diplomatically by preventing recognition outside the Soviet bloc, with the exception of India. The continued UN recognition of the defeated regime meant the diplomatic isolation of Vietnam and gave China a favorable climate in which to wage its 
campaign to punish the Vietnamese and attempt to reverse Hanoi's military victory (Chanda 1986: 378).

In the fall of 1980 the new US Secretary of State, Edmund Muskie, was keen to follow departing Secretary Vance's advice and abstain in the UN vote for Pol Pot's credentials. But eventually, under tremendous pressure from China, from American ambassadors in ASEAN capitals, and from Brzezinski, Muskie agreed to a US vote in favor of Democratic Kampuchea. Consequently, the Khmer Rouge retained their seat, and the lobbying by the US-Chinese-ASEAN bloc won 97 votes for its resolution calling for Vietnamese withdrawal.

At the same time, the United States was frequently perceived as being supporting the Chinese rather than the ASEAN view of the Khmer Rouge role (Brown 1989: 44). The most egregious example was at the July 1981 International Conference on Kampuchea when ASEAN, in the drafting of the final resolution, was obliged to drop its call for disarming the Khmer factions and for holding free elections under and interim administration in a future Cambodia settlement. China successfully fought off even implied criticism of the Khmer Rouge in the resolution. Beijing was supported by the United States against ASEAN in this effort. The implications were not lost upon ASEAN, and the memory lingers to this day among some of US best friends in Southeast Asia (Brown 1989: 44).

Such American blessings for the Khmer Rouge were perceived by Vietnam as US plot to sabotage Vietnam's revolutionary course and as an act of taking revenge on Vietnam for the defeat in the Vietnam War. Vietnam accused the United States of taking revenge on 
Vietnam by borrowing hands from China and the Khmer Rouge ${ }^{14}$ (CPV Political Report 1979).

In further attempt to fight against Vietnam's occupation of Cambodia, the Coalition Government of Democratic Kampuchea (CGDK) was formed in June 1982 by ASEAN and China with American blessings (Brown 1989: 41). The CGDK was a tripartite coalition of Pol Pot's Democratic Kampuchea, Prince Norodom Sihanouk's National United Front for an Independent, Peaceful, Neutral, and Cooperative Cambodia (FUNCIPEC - in French), and the Khmer People's National Liberation Front (KPNLF) under a former Cambodia prime minister Son Sann ${ }^{15}$. The FUNCIPEC and KPNLF formed a loose alliance to constitute the noncommunist resistance (NCR), as distinguished from the Khmer Rouge. The formation of CGDK therefore could provide the United States with more legitimacy in supporting the anti-Vietnam's occupation forces.

US financial and nonlethal material contributions to the noncommunist resistance factions of the CGDK were small during this period but politically significant. In 1982, the United States began a program of covert assistance worth $\$ 15$ million a year, channeled through ASEAN countries to the non-Communist partners of the coalition. US

\footnotetext{
${ }^{14}$ Some 30 years later, Vietnam scholars still brought up this issue at the Symposium: US-Vietnam Relations toward a brighter future in 2010 in the occasion of the 15 anniversary of US-Vietnam normalization. Such mentality was also well reflected in interviews with Vietnamese senior officials who were involved in the normalization process.

${ }^{15}$ Sihanouk was president, Son Sann was prime minister, and Khmer Rouge leader Khieu Samphan was vice president and foreign minister.
} 
Congress also authorized up to $\$ 5$ million in overt economic or military aid to the Cambodian resistance under the Solarz program ${ }^{16}$ (Chanda 1986: 402; Brown 1989: 45).

Third, in addition direct assistance to the non-communist resistance group in the CGDK against Vietnam's occupation, the United States also lobbied for an international embargo and blockage to put pressure on Vietnam to withdraw troops from Cambodia. Part of such attempt was the US support to China and ASEAN's diplomatic and economic isolation of Hanoi and the People's Republic of Kampuchea. In a conversation with visiting Chinese leader Deng Xiaoping in January 1979, President Carter affirmed to his Chinese counterpart that the Americans were doing all what they can to encourage other nations to reduce foreign aid to Vietnam as long as Vietnam remained in Cambodia, emphasizing that

We (Americans) will not pursue discussions regarding normalization (with Vietnam) under these circumstances. We are encouraging the ASEAN countries to stand united against Vietnam and we are increasing military aid to Thailand" (Memorandum of Conversation with Deng, Jan 29, 1979).

Meeting with Deng in Beijing in August 1979, US Vice President Mondale further confirmed US attempt to isolate Vietnam: "we had substantial success in preventing major loans to Vietnam from the World Bank, the Asian Development Bank, and other

\footnotetext{
${ }^{16}$ In 1985, US Congress under the leadership of Representative Stephen Solarz, chairman of the House Foreign Affairs Committee's Subcommittee on Asia and the Pacific, authorized the program.
} 
international institutions" (Memorandum of Conversation between Deng and Vice President Mondale in Beijing, August 28, 1979).

In fact, the US embargo on trade and investment was an essential element in maintaining ASEAN pressure on Vietnam (Brown 1989: 41). Japan, the European Community (EC), and other potential aid donors or investors were reluctant to break ranks as long as the United States held fast, and the denial of American maritime oil technology to Vietnam through third countries and prevention of major development loans from international financial institutions were critical (Brown 1989: 41).

The above-mentioned moves by the United States were perceived by Vietnam as "US collusion with China and ASEAN to harm Vietnam revolutionary course", instigating hostility and hatred inside Vietnamese government against the United States. The United States was "playing the China card" against Vietnam on one hand, and at the same time utilizing the Khmer Rouge to weaken Vietnam, on the other hand (Tap Chi Cong San 1979).

Even though the United States attempted, especially since the formation of the CGDK in 1982, to show that it had been disassociating itself from the Khmer Rouge and from the distasteful reality of the Khmer Rouge presence in the $\mathrm{CGDK}^{17}$, such American support for the DK resulted in strong mentality in Vietnam's perception about the United States. In a Party Central Committee's Resolution (Resolution 09 of the IV Congress), Vietnam bluntly labeled the United States as "the principle and permanent enemy", and this was

\footnotetext{
${ }^{17}$ US Secretary of State Vance argued that there was no other reasonable choice in 1979 for the United States but to vote for the DK's seat in the United Nation, no matter how morally offensive the vote was (Brown 1989: 44).
} 
even specifically written in the Foreword of the 1980 Constitution of the country (Vietnam 1980 Constitution) ${ }^{18}$.

Anti-American sentiment in Vietnam grew stronger as the situation in Cambodia became further unfavorable to Vietnam. The Vth CPV National Congress in 1982 asserted:

Our external activities have to become a proactive front in the struggle to foil the policy by Chinese expansionists and chauvinists, colluding with American aggressive forces, which is aimed at weakening and taking over our country; first and foremost to win their multifaceted war of sabotage, contain their plot to repeat the war of aggression, and restore peace in Indochina and Southeast Asia (CPV 1982: 143).

Such animosity and confrontation remained vivid in US-Vietnam relations until the Cambodia issue was settled in the late 1980s and resulted in the roughest and most hostile period in US-Vietnam postwar relations.

\section{Cambodia issue in US-Vietnam relations in the 1980s}

US-Vietnam relations in the aftermath of the Vietnamese occupation of Cambodia and Sino-Vietnamese border war continued to be antagonistic throughout the early 1980s.

\footnotetext{
${ }^{18}$ In the Foreword, China was perceived as "the direct and most dangerous enemy", whereas the United States was perceived as "the principal and permanent enemy" of Vietnam.
} 
Before assuming office, US President Ronald Reagan had publicly criticized the Carter Administration policy toward Vietnam and viewed Vietnam in the cold war prism. Reagan opposed any normalization with Vietnam until the POW/MIA issue was resolved and Vietnamese forces had totally withdrawn from Cambodia. This stance reflected not only the administration's view of Vietnam in the cold war context but also the clearly held view that Vietnam was still a danger regionally and that the Vietnam War had been lost at home by incremental policy decisions and mismanagement (Slabey 1989: 29).

In his first term after entering office, President Reagan directed that the POW/MIA issue be made "one of highest national priority", to overcome both the inertia of the past and to fulfill promises he made to the families of our missing men before assuming office that aggressive measures to resolve this issue were needed and would be undertaken (Department of Defense 1989: 2). As a result, policy positions and implementing actions were adopted, including:

- $\quad$ high-level public statements by the President and his Cabinet;

- $\quad$ the opening of serious policy-level negotiations with Vietnam and Laos;

- the development of a bipartisan approach to the issue and encouragement of a public awareness campaign,

- $\quad$ an upgrade of intelligence priorities;

- $\quad$ separating the issue as humanitarian in our negotiations;

Consequently, an aggressive public awareness campaign in coordination with the National League of POW/MIA Families raised domestic consciousness of this issue to 
the highest level since the end of the war, and media coverage increased dramatically. In addition, as a result of the campaign, Congressional support for the effort grew substantially, and interest spanned the entire political spectrum in both the House and the Senate (Department of Defense 1989: 3). In addition, intelligence assets and priority devoted to the POW/MIA issue were also at the highest level since the end of the war, and interagency intelligence coordination improved substantially (Interagency Report on POW/MIA issue January 1989).

As a result of President Reagan's initiative for solving POW/MIA issue, high-level negotiations with the Vietnamese and Lao governments were initiated in 1982 with highest priority directed at resolving the question of live prisoners. Negotiations with Vietnam therefore became more frequent and sustained over the following few years, most notably with the appointment of General John Vessey as the Presidential envoy in 1987 to visit Vietnam for further talks on POW/MIAs.

However, despite the generated momentum for negotiation on POW/MIA issue, the Cambodia issue remained the principal obstacle that blocked normalization from going further. The United States steadfastly maintained its position that normalization of relations with Vietnam could only take place in the context of an acceptable settlement in Cambodia which included a complete withdrawal of Vietnamese troops and that humanitarian issue should be addressed regardless of political differences between the two countries (Interagency Report on POW/MIA issue 1989: 4).

The Cambodia issue continued to remain a central obstacle to normalization of relations during Reagan's second term. Reagan policy vigorously opposed both the Vietnamese 
occupation of Cambodia and the return of the Khmer Rouge. This policy was strongly supported in the Congress, including initiatives for direct aid to the Cambodian resistance (Childress 1998: 97).

There was very limited cooperation on POW/MIAs, since US-Vietnam relations remained confrontational due to the unsettled Cambodian issue and the boat people issue. After a three year gap, in 1981 Vietnam resumed cooperation on POW/MIAs by returning the remains of three Americans that also showed evidence of storage. The United States resumed MIA discussion with Vietnam and expanded the dialogue to include communication about the emigration of Amerasian children, the Orderly Departure Program, and the legal exit of former inmates of Vietnamese reeducation camps (Brown 1989). However, the US continued to refuse to consider normalization as long as Vietnam occupied Cambodia and otherwise played a destabilizing role in the region (Stern 1995: 29).

As a result, Vietnam's ideas about the US remained negative: on one hand the United States maintained the strict embargo on Vietnam, on the other hand the United States unilaterally demanded Vietnam for cooperation on POW/MIA. In April 1980, the Vietnamese Department of Press and Information of the Foreign Ministry issued a "white paper" entitled "On the Question of Americans Missing in the Vietnam War" took the position that Washington had seriously politicized the issue and thereby hampered progress, especially by efforts to "play the China card" against Vietnam (Stern 1995: 26).

The White Paper also went further in criticizing the testimony by the mortician (who went before the Congress in 1980 fabricating that he saw remains stored by Vietnam in a 
warehouse), denouncing it as a primary example of "negative attitudes and action by the US side" (Stern 1995: 26), referring to this as a "story concocted for political ends with familiar political tricks and with fictional details which can confuse public opinion". The paper concluded by stating that the US had "distorted" Hanoi's sincerely humanitarian inclinations, warning that such act could only cause difficulties to the efforts to promote peace and friendship between the two peoples, and certainly could not contribute to creating favorable atmosphere in Vietnam for efforts to account for American MIAs, and by following such a course, the US could be taken in by the insidious maneuvers of the Beijing expansionists (Stern 1995: 27).

Through mid-1985 (although there have been meetings and talks on MIA issue between the two), the Vietnamese media continued to characterize Washington's position on the POW/MIA issue in strong, inflammatory terms. According to a 6 June article from the Military's Daily newspaper:

The US is trying to capitalize on the concern of many Americans about the MIA issue in order to incite anti-Vietnamese sentiment, in disregard of truth and reason. It is quite preposterous what while Mr. Reagan is imposing on Vietnam the responsibility of seeking American MIAs in Vietnam, that is, those who had come to Vietnam and committed crimes, he is washing his hands of all responsibility of the US for having caused suffering and death to millions of Vietnamese and its duty to help heal the wounds of war in Vietnam (Stern 1995: $33)$. 
The above-mentioned negative developments in US-Vietnam relations casted a long shadow on normalization process, leading to the roughest and most hostile period in USVietnam postwar relations. The relationship remained frozen until the late 80 s when the Cambodia issue came to final settlement after Vietnam shifted it ideas as a result of Doi Moi Reform .

\section{Conclusion}

Chapter 2 has illustrated that ideational factors and asymmetry offers profound explanation for the missed opportunity for normalization, and the hostile period afterward in US - Vietnam relations in the 1975-1986 period. While the vivid war mentality and old orthodoxies (ideas) in both sides' ideas created antagonism and hostility in the relationship, asymmetry of power exacerbated them in generating different perceptions and expectations from each side, leading to the outcomes of their interaction - the failure of normalization.

With a victory mind-set, Vietnam expected US aid, not as a reward for cooperation on the MIA issue, but as an act of moral obligation, and therefore stubbornly stuck to their reparations demand out of a sense of moral victory. Vietnamese mindset was, in Stalin's words, "dizzy with success". Having conquered the South and humbled a superpower, while suffering immense human and material losses in the process, the Vietnamese leaders seemed to ignore a central reality: Hanoi needed normalization far more than Washington. 
For the United States, being a more powerful (but defeated) country in this asymmetric relationship, keeping face was the major concern in normalization with Vietnam, and therefore the United States expected deference by Vietnam in settling the legacies of the war, since paying reparations was seen as the symbol of accepting the defeat and guilt in the war. This explains the overwhelming opposition in US Congress for any moves toward Vietnam that may indicate such sentiment, and the Administration's constant raising conditions for normalization (as pattern of behavior expected in an asymmetric relationship where the smaller country is expected to show deference).

It is also observed that the war mentality was vividly visible in the discourse by leaders of both sides as the empirical evidence has illustrated, and was institutionalized as in the case of Vietnam in which the sentiment was even written in the Constitution where the United States was perceived as Vietnam's "principal and permanent enemy". Once institutionalized, ideas have clear causal impact that cannot be reduced to strategic circumstances by realist logic, as the Chapter has demonstrated in the missed opportunity for normalization.

US collusion with China amidst open Sino-Vietnamese confrontation and American support for the Khmer Rouge regime against Vietnam's occupation of Cambodia were perceived by Vietnam as US resentment for the defeat in the war, all contributed to a strong anti-American sentiment in Vietnam. American antagonism therefore reinforced and contributed to the continuity of the old Marxist/Leninist orthodoxy of viewing the world via a two-camp lens in Vietnam's thinking, leading to Vietnamese distrust of capitalist America and leaning toward the socialist Soviet Union. 
In short, by examining the actual process of interaction between the two countries, Ideas and Asymmetry approach has demonstrated a convincing account for the most confrontational episode in the history of US-Vietnam postwar relations. 


\section{CONCLUSION FOR PART I}

Part I of the dissertation has sought to explain the period US-Vietnam relations since the end of the Vietnam War in 1975 until Doi Moi was initiated in Vietnam in 1986 that served as a pivot for change in Vietnam's policy toward the United States. Applying alternative theoretical approaches: Realism and Ideas and Power Asymmetry theory, Chapter 1 and Chapter 2 respectively seeks to answer the same question of central interest for this period: What explained the missed opportunity for normalization that led to a long period of fierce confrontation and hostility between the two countries?

By examining the evolving power situation and strategic contexts that governed foreign policies of Vietnam and the United States, Chapter 1 under a realist approach has offered a sound explanation for the frozen relationship. Under realist lens, it was the Cold War context in this particular period that hindered normalization from happening: US normalization with China when Vietnam was at war with China, and the invasion and occupation of Cambodia by Vietnam, together with the Vietnam's taking side with the Soviet Union, all of which put the United States and Vietnam at confrontation and resulted in the failure for normalization. US-Vietnam relations in this period therefore appeared to follow realist logic in most part, as Chapter 1 has demonstrated with relatively adequate empirical support.

However, there is a central puzzle that remains unanswered by Realism: why the United States and Vietnam failed to normalize relations in the short 1977-1978 episode when both countries strongly desired for it and the strategic environment at that time was favorable for normalization? 
Chapter 2 went beyond realist logic to explore the role of ideas and asymmetry in shaping US-Vietnam relations. Findings obtained from the test of hypotheses by Ideas and Asymmetry against empirical evidence indicates that ideas (the war mentality and old orthodoxy in thinking embedded in both sides) and the disparity of capacities between the United States and Vietnam, in which ironically the stronger side was not the winner in the war, have significant impact on US-Vietnam relationship. By examining the actual process of interaction between the two countries, the combination of ideas and asymmetry could unravel the rationale behind each country's stiff position that allowed no room for compromise in negotiation: the stronger side with resentment of defeat attempted to dictate the game by setting high and infeasible conditions as a way to keep face, whereas the weaker side embedded with a victory mindset stuck to its unswerving demands for war reparations as an acknowledgement of moral obligation. This explains for why both the United States and Vietnam stuck to their own terms for normalization, failing to seize the opportunity before further developments blew it away. The missed opportunity therefore proves to be an extreme case of process affected by ideas and asymmetry, an archetypal situation that brought their effects together in a particularly clear way.

In addition, since disparities in capacities generated systemic differences in interests and expectations (in this case, the United States was much more important to Vietnam than Vietnam was to the United States), power asymmetry could explain why Vietnam tended to be over-attentive to US behaviors, for which Vietnam's strong reaction to any US moves in supporting China and the Khmer Rouge could serve as vivid examples as the Chapter has convincingly demonstrated. 
It is noted that Chapter 2, while exploring the impact of US rapprochement to China and US assistance to the Khmer Rouge, does not attempt to explain why these developments occurred as they did (which seemed to belong to realist account), but to explore the negative impact of such US action on Vietnam's perception and mentality.

In short, the weight of empirical evidence of the 1975-1986 period strongly favors Ideas and Asymmetry theory in explaining this most hostile episode of US-Vietnam post-war relationship. Ideas and Asymmetry proves to have advantages over Realism by moving beyond the "big picture" of strategic circumstance - in which preferences are given and taken for granted - to explore the actually process of interaction between these preferences. Ideas and Asymmetry theory could answer the question that Realism found puzzling in this period: why normalization could not happen even when both sides desired for it and the environment was favorable. 


\section{PART II}

\section{US-Vietnam relations 1986 - 1995}

While the 1975-1986 period was the most hostile and confrontational episode in the history of US-Vietnam post-war relations as described in Part I, the 1986-1995 period witnessed significant change in the relationship: antagonism gradually transformed into cooperation, started by the Doi Moi (Reform) in Vietnam in 1986 that significantly reoriented Vietnamese foreign policy to the United States and ended in the successful establishment of bilateral diplomatic relations in 1995. However, initial success toward normalization did not come easy and cooperation was not without fierce struggle and skepticism.

US-Vietnam normalization process in this period was characterized by three major observations/developments:

1) A dramatic shift in Vietnamese US policy: from considering the United States "the principal and permanent enemy" to "a partner of significant importance to the success of Doi Moi”.

2) Vietnamese enthusiasm for normalization appeared to sharply contrast with US extreme sluggishness and incremental approach in the normalization process for the whole period.

3) US "moving the goalposts" in POW/MIA cooperation and the Cambodia issue was responded by Vietnam's over frustration and skepticism. 
This part of the dissertation, consisting of Chapter 3 and Chapter 4, seeks to explain the above-mentioned developments in US-Vietnam relations by applying the two competing theoretical approaches: Realism versus Ideas and Asymmetry, respectively. Hypotheses based on each approach will be tested against empirical evidence in the 1986-1995 period, and findings from the chapters will be evaluated as a test for each theory against their alternative. Part II will conclude with an overall evaluation on the validity of the two competing theories. 


\section{Chapter 3}

Realist approach to the incremental process of US-Vietnam normalization 19861995

This chapter aims to test the validity of the realist hypotheses that the developments in US-Vietnam normalization process in the 1986-1995 were the results of evolving power condition and strategic circumstances in this period that brought the two countries together on a rough and bumpy path toward establishment of diplomatic relations. Realism looks for evidence in the strategic interests and calculations by both sides to explain the sharp shift in Vietnam policy toward the United States and Vietnamese enthusiasm for normalization in contrast with American "politics of inattention" and moving the goalposts for normalization throughout the process, and the final decision to establish diplomatic relations in the last minutes by both sides.

Under a realist lens, it was the worsening economic situation internally in Vietnam, and the changing external environment (i.e. Sino-Soviet rapprochement and the end of the Cold War context) that induced Vietnam to seek to normalize relations with the United States. These motives were reflected in Vietnam's positive moves in the Cambodian issue as well as more fruitful cooperation on POW/MIA issues. For the United States, it was the strategic interests and changing power structure of Southeast Asia in the post-Cold War context that resulted in positive move toward normalization, and the slow progress and US lack of responsiveness was the result of American response to the changing strategic environment as the Cold War was heading to its end. 
The chapter will first examine the strategic constraints for Vietnam in the 1986-1995 period that led to the shift in policy orientation. It will then discuss the motives behind American incremental approach to normalization and the final decision to establish diplomatic relations with Vietnam, ending another wavy episode in the history of USVietnam postwar relations. The chapter will conclude with an overall evaluation of the validity of the realist assumptions under test.

\section{The effect of international political and economic changes on Vietnam's US policy:}

The changing power relations in the China-USSR-USA strategic triangle as the Cold War was winding to its end, which were disadvantageous to Vietnam, was one major factor that led to the adjustment of Vietnam's US policy. As a small state in the system, such change in major power relations had significant implications for Vietnam. Such external dynamics for interest change were apparently observed in the decline of the Soviet Union - the fundamental ally that Vietnam heavily relied on - that led to a major transformation of Soviet foreign policy in which rapprochement with both China and the United States took place. Being dependent on the Soviet Union, Vietnam was inevitably under pressure to make major adjustments to adapt to the newly arising situation. In addition, the worsening economic situation at home as a result of the heavy burden of maintaining troops in Cambodia and coping with a hostile neighboring China, as well as the severe consequences of the economic embargo and political blockage imposed by the United States, all put a huge pressure on Vietnam to make a change in its foreign policy orientation. 
First, it was the transformation of Soviet foreign policy in the mid-1980s that brought about significant pressure on Vietnam for change. It was commonly argued that, after the peak of its global influence in the late 1970s, Soviet power had been waning due to its economic stagnation and military overstretch. The Soviet Union was unable to catch up with American capabilities in the later stage of the Cold War and therefore had to adjust its policy and behavior. In the new Soviet policy, reassurance strategies were to replace force or threats of force to assert Soviet influence in the communist bloc and beyond. With regard to the Asia-Pacific, the change in Soviet policy was articulated in Gorbachev's Vladivostok Initiative in July $1986^{19}$. The USSR therein asserted its role as an Asian-Pacific power, but introduced a fresh approach to Asia-Pacific security which would be based on reassurance and diplomatic settlements of regional conflicts (Thakur and Thayer 1987).

The Vladivostok Initiative targeted China as a recognized major power in the AsiaPacific. This dramatically accelerated the rapprochement process between the USSR and China, which had been activated since 1982 with few improvements. China raised "three obstacles" in Sino-Soviet relations, in which Vietnam's occupation of Cambodia was eventually elevated to obstacle number one. The USSR initially refused to discuss "third countries" matters with China, but after Vladivostok, it made concessions to China by agreeing to include Cambodia in Sino-Soviet negotiations (Qian 2006). China demanded that the USSR pressure Vietnam into withdrawing from Cambodia and remove Soviet

\footnotetext{
${ }^{19}$ In a speech in Vladivostok on July 28, 1986, Soviet leader Mikhail Gorbachev signaled a new assertive foreign policy toward Asia and the Pacific. Recognizing the strategic importance of Southeast Asia, Soviet foreign policy makers seek to improve Soviet bilateral relations with the member nations of the ASEAN (Brunei, Indonesia, Malaysia, the Philippines, Singapore, and Thailand) in an effort to reverse a quarter century decline in Soviet regional influence.
} 
facilities from Cam Ranh Bay before Sino-Soviet relations could be normalized (later China delinked its demands on Cam Ranh Bay from Cambodia). When Deng-Gorbachev summit was convened in April 1989, the two leaders discussed the Cambodia issues in detail at their meeting in Beijing (Evens and Rowley 1990). Being keen on normalizing relations with China, the USSR pressed Vietnam on the issue of troop withdrawal from Cambodia. It also encouraged Vietnam to normalize relations with China and hinted at a Soviet mediating role. Especially, the USSR listed Cambodia among key issues to be managed according to a Soviet initiative of Helsinki style security system in the AsiaPacific (Thayer 1987: 171-200).

With the Sino-Soviet summit in May 1989, a principal pillar of support to the Vietnamese in their struggle with China was lost. Within a few months of Gorbachev's Beijing visit the Soviet Union withdrew most of its air contingent from Cam Ranh Bay, and planned to totally withdraw by the end of 1991 (Chanda 1991: 22). Not only did the Soviets shock Vietnam by their refusal to give even verbal support to Hanoi in March 1988 when the Chinese navy attacked the Vietnamese in the Spratlys but by 1990 Moscow and Beijing had begun talking about military cooperation. In October Soviet Deputy Premier Igor Belousov, who also heads the state military-industrial commission, visited Beijing and was told of the Chinese interest in buying the Sukhoi Su-27 Flanker, a supersonic fighterinterceptor and Soviet avionics and technology that would give the Chinese navy a bluewater capacity (US-Vietnam Dialogue Series 1991: 22). Despite the setback suffered as a result of the Tiananmen massacre, China, being Vietnam's principal opponent, had improved its diplomatic position by normalizing relations with many neighboring 
countries, including Singapore (in 1990), Indonesia (in 1990) and South Korea (in 1992) and thus deepened Vietnam's isolation.

Rapprochement was also achieved in Soviet-US relations as a result of Soviet charm offensive. The first in a series of Gorbachev-Reagan summits was held in November 1985, leading to the end of the Cold War in 1989. Soviet-US cooperation resulted in diplomatic settlements of regional conflicts such as Afghanistan, Angola, and Cambodia, in which more concessions were made on the Soviet side. With regard to Cambodia, in August 1990 the five permanent members of the UN Security Council reached a framework for a comprehensive settlement of the conflict (Amer 1996: 12-36). In 1991, the USSR plunged into crises and ceased to exist by the end of the year. The United States became the sole superpower in the system.

In face of the sea change in power conditions, as Realism predicts, Vietnam was compelled to make necessary adjustments. Specifically, the decline of Soviet support would force Vietnam into withdrawing from Cambodia as well as accommodating with China and the United States. Vietnam therefore had no choice but to accept the solution imposed by the United Nations on Cambodia. When the Soviet Union, being Vietnam's biggest ally, got bogged down with crises, Vietnam as a result had to rush to normalize its relations with ASEAN, China and the US to avoid finding itself isolated. Hence, necessary concessions had to be made to China and the United States, especially on Cambodia issue.

Furthermore, changes in the international situation, especially the upheaval in Eastern Europe and political and economic transformation of the Soviet Union have added a new 
urgency to Vietnam's need to break out of the isolation. Of all the changes marking the world in 1990, the most traumatic for Vietnam was the transformation of the Soviet bloc. The collapse of communism in Eastern Europe and the descent of Soviet perestroika into chaos meant a serious loss of material support and political backing.

The impact on the changes in the Soviet bloc was felt the hardest on the economic front. An average of one third of Vietnam's imports - mostly essentials such as fuel, fertilizer, industrial raw material - had traditionally come from COMECON. In addition, the Soviet bloc aid had been the principal external source of capital and technology for Vietnam. All this received a dramatic blow in January 1990 when a COMECON meeting held in Sofia decided that beginning January 1991 all the COMECON transactions, conducted so far in ruble, would be in hard currency. In practical terms this meant that the Vietnamese would have to pay a higher price for low quality Eastern bloc imports and receive a lower export price. The IMF has estimated that the change would cost Vietnam a terms-of-trade loss of \$250-300 million or 4-5 percent of GDP (IMF 1990 Report, in Chanda 1991: 23). The Soviet Union has also drastically cut back its aid and wanted Vietnam to repay its debt worth 9 billion rubles ( $\$ 4.5$ billion) in hard currency. In a report to the National Assembly in 1990, Prime Minister Do Muoi (who became General Secretary of CPV later) stated that:

1991 is the year that we will face unprecedented challenges when 3 million tons of fuel, 2.5 million tons of fertilizer and 400,000 tons of iron and steel that were previously provided by the Soviet Union at friendly prices in rubles, now we 
have to buy these materials at the world market price and payment is made in hard currency (CPV Political Report 1991).

The events of Eastern Europe and later the Gulf Crisis brought additional pressure on the Vietnamese economy. In 1990, there were 200,000 Vietnamese guest workers in Eastern Europe and Soviet Union. Many had begun returning to Vietnam, as did Vietnamese workers in Iraq. This along with the demobilization of 600,000 men from the Vietnamese army, resulting partly from Hanoi troops withdrawal from Cambodia, had sharply increased the number of unemployment in the country (Chanda 1991: 23).

However, even more serious than material loss has been the blow that Eastern Europe dealt to the Vietnamese government's ideological raison d'etre (Chanda 1991: 22). Initially Vietnam had welcomed Gorbachev's perestroika and the Vietnamese party itself had adopted a program of renovation called Doi moi. But as perestroika turned into a call for political pluralism and democracy "the Vietnamese recoiled in horror" (Chanda 1991: 22). Hanoi condemned the Polish solidarity as "counter-revolutionaries" and even organized protest demonstrations against changes in Poland. Soon however, it had to relegate its ideological concerns behind the pragmatic needs of maintaining economic ties with Poland and other former East bloc countries. General Secretary of CPV Nguyen Van Linh went to Berlin in October 1989 to attend the $40^{\text {th }}$ anniversary of the German Democratic Republic, as a gesture to confirm Vietnamese solidarity with Eric Honecker against the Moscow-inspired reform. But within months of his visit, Vietnamese leaders witnessed the collapse of East Germany and the rest of the communist regimes in Eastern Europe. 
Last but not least, the biggest challenges for Vietnam derived directly from the United States. In addition to the severe consequences of the blockage and embargo the US imposed on Vietnam, the end of the Cold War with the victory by the United States added more to the Vietnam's deep concerns. As the Tiananmen episode and the American reaction had already worried Vietnam's security apparatus, the collapse of communism in the Soviet Union and Eastern Europe even added more to Vietnam's concerns about the threat of subversion. Vietnam media carried repeated stories accusing the US of trying to subvert the communist system through "peaceful evolution" using democratic ideas. Vietnamese media started to warn against "the criminal all-out attempts by the imperialist forces and international reactionaries to take advantage of the difficulties facing the socialist countries by carrying out sabotage from within and without and using peaceful revolution to eliminate the socialist camp" (Nguyen Mai 1997). Vietnamese newspapers event went on further to warn the public that US intelligence services had deployed a "network of spies" around the country (Chanda 1991: 24).

However, despite Vietnam's concern about US intentions, this negative Vietnam perception of the United States was surpassed and modified by other developments, such as the Sino-Soviet and US-Soviet rapprochement as discussed above, together with the growing congressional concern about a return of the Khmer Rouge. Vietnamese policy makers therefore welcomed the policy change that these pressures had engendered.

In addition to the external dynamics that generated enormous pressure for change in Vietnam foreign policy, the domestic economic situation in Vietnam in the mid-1980s 
also added to such urge for change. The Vietnamese economy in 1986 was described as standing on the verge of collapse with a hyper-inflation rate of 774.7\% (Phuc 2006: 141). The command economy proved to be very inefficient and the economic crisis affected Vietnam severely. Having an economy in crisis, Vietnam found it hard to feed its own people, let alone to fund its missions in Laos and Cambodia. The dismal situation propelled the CPV to adopt new goals and measures to break out of its pariah status. As a result, economic restoration was given the top priority. A slash in defense expenditure and adoption of economic diplomacy were logical behaviors of a government seeking to redirect its resources to overcome a serious socio-economic crisis.

In addition, economic dimension of the regional distribution of power was also another important factor that induced Vietnam to reform. While Vietnam's economy was in trouble, China and ASEAN countries were undergoing economic prosperity with high growth rates. This power distribution came at a time when the economy became an increasingly important dimension of national power.

Normalization of relations with the United States therefore became vital for Vietnam. Certainly to the extent that the US blocked economic activity on trade, aid, and investment, not only by Americans but by others as well, including the International Financial Institutions (IFIs). This was a major consideration for Vietnam as it struggled with its renovation/reconstruction policy. Especially with the change in Soviet policies, related to but not entirely a function of the end of the Cold War, Vietnam's need for outside capital and technology was greater than ever. 
In addition, the United States would also seem to be of importance to Vietnam's relationships in the region and even beyond. For the most part, other states would make their own decisions without relying on the United States for their lead. However, for example, technology transfer issues could depend importantly on Washington's approach. If the United States and Vietnam remained at substantial odds, this would complicate the availability of certain technologies either directly or via others. The provision of aid may also be coordinated between some potential major donors and the US. Moreover, to the extent that serious consideration was given to Vietnam's joining ASEAN, ASEAN members could be expected to factor in American (and other) attitudes toward the effect this would have on the utility of the annual post-ministerial consultations.

Normalization with the United States would also bring about enormous economic benefits for Vietnam. It would not only provide a green light for multi-lateral economic relations and infrastructural improvements, but also, despite the embargo, the United States was Vietnam's preferred trading partner, because US resources were extensive but they were less likely than Japan to dominate the Vietnamese market (Womack 1993: 12).

Fundamentally, despite the official announcement of "normalized" relations between Vietnam and China during the course of the November 1991 summit meetings between state and party leaders in Beijing, one can discern the continuing mistrust between the two nations and the wariness with which they continued to deal with each other. Although at one level the China-Vietnam normalization represented a coming together of like-minded ideologues who both sought some buffering from the evil influence of 
Western thought (i.e., peaceful evolution), at another level one senses that, despite some key personnel changes, the involvement of the United States in Indochina was still seen by Hanoi as providing a certain guarantee against long-term Chinese (as well as Japanese) domination (Romberg 1992: 44). Normalization of relations with the United States would therefore also provide a political, economic and even cultural counterweight to China (Womack 1993: 12).

The above discussion indicates that the whole range of external developments as well as internal difficult situation made it imperative for Vietnam to seek to normalize relations with the United States. Its continued isolation would not only condemn it to stagnation but could lead to a serious economic crisis and explosion. Though some Vietnamese leaders were concerned about the impact of greater opening to the West on such restiveness of the population, the sheer economic compulsion of keeping the country afloat was likely to overcome such opposition. Ending isolation and the embargo imposed by the United States was therefore an urgent need for Vietnam, and normalization of relations was the ultimate solution.

As a result, Vietnam's enthusiasm in promoting relations with the United States was strongly felt as Doi Moi was initiated in Vietnam in 1986 that brought about total transformation of Vietnam policy orientation, in both domestic and external realms. Vietnam started to implement open-door foreign policy in which Vietnam sought to be friends with all nations, including the United States. Following this line, Vietnam sought to normalize relations with China in 1991, joined ASEAN and established relations with the European Union in 1995. Since POW/MIA and the Cambodia issue were the main 
hurdles in relations with the United States, Vietnam made significant attempts to improve cooperation on these issues (Bui Thanh Son 1999).

In short, the power condition and strategic context of the 1986-1995 period set a strong rationale for Vietnam to improve relations with the United States.

\section{Changing power condition and the US Vietnam policy:}

As discussed in Part I of the dissertation, from the fall of Saigon to the Ford Administration, US normalization policy was dominated by the desire to forget, bitterness, and low priority. After Carter, normalization became a third rank foreign policy issue and was dealt with mainly in the context of US relations with ASEAN and China. During Reagan's two terms in office, the United States refused to consider normalization with Vietnam while Vietnam occupied Cambodia (Brown 2010: 320). In fact, until 1995 the United States never enjoyed anything approaching "normal relations" with any government of Vietnam, either North or South, nor with the Vietnamese people themselves (Brown 2010: 318). The path to normal relations was strewn with obstacles that were emotional and psychological as well as political - the "Vietnam syndrome". Under realist lens, the argument that American psychological health required a formal end to hostilities that had in fact ended had little political appeal, and business interest in offshore oil prospects was not vigorously pursued and there were few to argue that the United States had anything important to gain from normalization, except for POW/MIA accounting and the solution to the Cambodia issue (Colbert 1992). 
In contrast with Vietnam's high interests in promoting relations with the United States since Doi Moi was initiated in 1986, the United States preserved a low priority in Southeast Asia in general, and in Vietnam in particular. The Reagan Administration devoted its economic attention to Europe-centered Cold War issues, and the succeeding Bush administration was preoccupied with the collapse of the Soviet Union and Europe's transition to post-communism. The Bush Administration's rationale for not proceeding at once to establish relations was the US economic and trade embargo under the Trading with the Enemy Act, the presence of which was considered "leverage" to force Vietnamese cooperation on Cambodia (Brown 1993: 30).

With the collapse of the Soviet Union, US policy-makers actually did not pay much attention to Vietnam, except for Cambodia and the POW/MIA issue. By April 1991 the United States held an enormous strategic advantage in normalizing negotiations with Vietnam (Brown 2010: 319). In 1991, Washington presented Hanoi a plan (which was commonly referred to as the "road map") for a four-stage process of mutual confidencebuilding measures that would give the Vietnamese political and economic benefits in return for cooperation on the United Nations-sponsored peace settlement in Cambodia. The roadmap unequivocally outlined what Vietnam had to accept as a practical basis for moving incrementally towards full diplomatic relations and modification or removal of sanctions (Appendix B for details outline of the road map). With the collapse of the Soviet Union and communism in East Europe that put Vietnam in enormous disadvantage, Vietnam saw that it had little choice but to follow the roadmap and agree to an internationalized compromise political settlement in Cambodia and to accommodate American requirements on POW/MIAs (Brown 2010: 319). 
Proponents of normalization with Vietnam in US policy making elite made the case for Vietnam that although the United States did not have central strategic interests in normalizing relations with Vietnam, promoting relations would bring about significant benefits, since normalization would result in improvement in Vietnam's cooperation in seeking for American POW/MIAs, and in a settlement for the Cambodia issue since Vietnam was the key player in the conflict (Colbert 1992; US-Vietnam Dialogue 1992). Furthermore, it was in the interest of the United States to engage with Vietnam to minimize the potential for a power vacuum in Southeast Asia since the Cold War ended, especially considering the recent US military withdrawal from the Philippines and the rising power of China in the region. Vietnam was therefore geo-strategically important to the United States by reasons of its size, location, attitude toward the "Greater Dragon" to its north, and also the potential of its vigorous people.

First of all, as proponents of normalization argued, the Socialist Republic of Vietnam was situated in an area of increasing strategic as well as commercial importance to the United States, and one that the US administrations would like to see "develop new mechanism to manage or prevent emerging concerns" without requiring the intervention of the United States (Goodman 1993: 44). ASEAN countries in particular wanted Vietnam to be part of any new multilateral security arrangement and they had already encouraged Hanoi both to play a constructive role in resolving the Cambodia civil war and to desist from creating any new border tensions with its neighbors. As the members of ASEAN moved to implement a common market, moreover, each looked for ways to reduce military spending - part of which has been predicated on anticipating a threat generated by the export of Vietnam's revolution. Including Vietnam as an active participant in the 
regional drive to create a zone of growing and complex interdependence was a critical step toward the goal of reducing military spending and conflict throughout the region, which was in the interest of the United States.

The United States also could reap promising economic benefits in normalizing ties with Vietnam. With a population of 65 million (Vietnamese data in early 1990s) and a rich natural resource base, Vietnam represented a good target for American investment and business activity, indeed one of the few remaining unsaturated markets. With the US embargo in place, American businessmen were shut out. Since Doi moi in 1986, Vietnam had been privatizing and moving towards free market economics. Its labor costs were low compared with other developing countries of Southeast Asia and even China, and its labor force was energetic and trainable. There was considerable scope for US business in oil, aviation, communications, information systems, agricultural equipment, and medical supplies. But US entrepreneurs were already well behind their competitors from the ASEAN countries, Japan, Taiwan, South Korea, Australia, France, and Canada, and every day that passes put the United States further behind. US oil companies were particularly exercised over their handicap and were the leaders in pressing the administration to move ahead (Brown 1993: 30).

In fact, Vietnam was rapidly becoming a land of beckoning opportunity, the reality that Japanese, Thai, overseas Chinese, and French leaders had clearly recognized and were cautiously exploiting (Goodman 1993: 45). However, while American businesses with interests in Asia were only acting as speculators, corporations and entrepreneurs from other nations forged ahead as active participants in a potentially lucrative market. They 
virtually ignored the US embargo by permitting business development and initiating direct trade. In fact, Vietnam was one of the places in Asia where American manufacturers could find both a warm welcome and the human resources for doing business competitively. As Citibank's chief Vietnam-watcher observed in the early 1990s, "Vietnam's culture emphasizing sacrifice, education, and hard work is similar to that of other economic success stories in East Asia. And unlike Taiwan, Hong Kong, Singapore, and South Korea, Vietnam will be a net exporter of foodstuffs and energy for the foreseeable future" (Goodman 1993: 45). World Bank officials were equally impressed. "The Vietnamese have done far more preparation for foreign investment than most transitional countries with which we deal, and they are very open to advice that will also lending to begin". Vietnam got similar high marks from the United Nations Development Program consultants who praised the leadership's "pragmatic policy of reform" in a 1990 baseline report and noted that "... what is gradually emerging is a new economic model which will allow Vietnam to benefit from international trading opportunities by using it comparative advantages in such sectors as aquaculture, agriculture, mining and labor intensive manufactures (Goodman 1993: 46).

Second, proponents of normalization with Vietnam in the US government also believed that there was a strong rationale for improving US-Vietnam relations: the rise of China as a threatening force to US interest in the region. The increasing power of China had important implications for both Vietnam and the United States.

Without a question, China played an important role in US-Vietnam relations (Womack 1993: 10). For Vietnam, China has always been the looming presence of Vietnamese 
foreign relations throughout the history of the country, being "as a model, a resource, and a threat" (Womack 1993: 10). The border war that China launched against Vietnam in 1979 to 'teach Vietnam a lesson”, Chinese support to the Khmer Rouge and diplomatic efforts to isolate Vietnam throughout the 1980s and the use of force in the incident over Spratlys islands in 1988 against Vietnam, all contributed to Vietnam's unswerving and overwhelming concerns about China's intention. Vietnam's disquiet about China therefore increased its interest in better relations with the US.

For the United State, the Vietnamese relationship with China played an important role in American policy toward Vietnam. The strategic purpose of American military involvement in Vietnam was the containment of communism and China was part of the picture. In addition, US Cambodia policy has depended much on China factor since all US policy decisions with regard to Cambodia, and Vietnam for that matter, since 1979 have been taken with "one nervous eye cocked to China's reaction" (Brown 1993: 90). Although the rise of China was not yet threatening to the United States in the period that immediately followed the end of the Cold War, since the United States came out of the Cold War as the single super power unmatched by other countries, the United States was concerned of an arm race between China and Japan as those powers were competing for position in East Asia, since this would be destabilizing to the region and therefore go against US interests. It was argued that a normalized relationship with Vietnam could contribute to a lessening of pressure for such conflict between the regional powers, and would serve as a balancing force in American efforts to stabilize the region (US-Vietnam Dialogue - Conference Report 1993: 5). 
In addition, there was a big shift in US policy toward China since the Tiananmen Square incident in June 1989. The United States strongly criticized China for mistreating its own people with violence and seriously violating human rights. As a result, a tougher policy was adopted by the United States against China in which the former called for international isolation of the later.

However, although US-Vietnam relationship proved to be one that had high profile, it was not strategically central (Elliot 1993: 46). This means that there were not great pressures of situational logic which would shape the relationship but it also meant that the Washington policy makers did not have as much of a free hand in determining the pace and direction of the relationship as they had done in the cases of countries that were either strategically critical (so the situational logic predominated over other factors) or strategically marginal but relatively obscure to the American public (so the foreign policy bureaucracy could do what it wanted) (Elliot 1993: 46). This explained the slow progress and an incremental approach toward normalization by the United States, despite the fact that both shared preferences for normalization. Conditions for normalization presented to Vietnam by the United States were American leverage to force Vietnamese cooperation on POW/MIAs and the settlement of the Cambodia issue.

As Vietnam completely withdrew its troops from Cambodia in 1989 and at the same time made tremendous efforts in searching for American MIAs, the United States eventually made positive steps toward improving bilateral relationship.

In July 1990, Secretary of States James Baker announced a significant shift in US policy by stating that the US would no longer support the anti-Phnom Penh coalition in the 
United Nations, preferring that the seat be left temporarily unfilled (Conference Report US-Vietnam Dialogue 1992). At the same time, Secretary Baker indicated that the US was prepared to enter into discussions with Hanoi. Late September 1990, Baker met with Vietnam's foreign minister Nguyen Co Thach to discuss further cooperation in resolving the MIA issue. Some further easing in the US position took place in October 1990 when Congress took the additional step of ending lethal aid to the Cambodian Non-Communist Resistance (NCR) and required that \$20 million in humanitarian aid, which used to be set for the NCR, be made available to all Cambodians, including those inside Cambodia, as should an additional \$5 million to children. The Paris Agreement in 1991 was another significant step in solving the Cambodia issue, one of the major obstacles in US-Vietnam normalization process.

As Vietnam committed to full cooperation on searching for American MIAs and the unfolding strategic context of South Asia in the early post-Cold War period, on July 2, 1993, the US ceased blocking efforts to settle Vietnam's arrears and gradually removed the embargo on Vietnam. On February 3, 1994 President Clinton announced the decision to remove the provisions of the Trading with the Enemy Act that prohibited American from doing business with Vietnam, and to expand the official US presence in Vietnam by establishing a liaison office, and in July 1995 official diplomatic relations were established between the United States and Vietnam. 


\section{Conclusion:}

The above discussion indicates that Realism provides a convincing explanation for the development of US-Vietnam relations in the 1986-1995 period and for why the United States and Vietnam eventually normalized relations with each other. Empirical evidence obtained in the period indicates that the United States and Vietnam's preferences in the normalization process were indeed defined and governed by the strategic contexts presiding both countries. In other words, their preferences were the responses to the evolving power structure and strategic situations that shaped their interests. For Vietnam, it was the urgent need to break through isolation in face of enormous challenges generated from both severe internal economic crisis and external security concerns caused by the evolving developments that led to the end of the Cold War. Under realist lens, Doi Moi was therefore the product of Vietnam's response and adaptation to the new environment. For the United States, it was the strategic calculations and geo-political and economic interests in Southeast Asia in general, and in Vietnam in particular, that led to the gradual shift in its Vietnam policy toward normalized relationship.

Realist logics therefore give a convincing explanation for how the preferences in US and Vietnam policies were shaped, and how the interaction of these preferences brought about the observed outcomes in the bilateral relationship: a slow and bumpy path toward normalization on which two passengers walked with different pace and manner: an enthusiastic but frustrated Vietnam in contrast with an ignorant and arrogant America.

However, there remain several central puzzles in US-Vietnam relations in the 1986-1995 period that realist account falls short to provide convincing answers. 
First of all, Realism failed to adequately explain the extreme sluggishness and irresponsiveness by the United States in the whole process: why was the United States so inattentive and sluggish in its Vietnam policy despite strategic interests to move forward to normalization? Realists have pointed to the fact that although normalization with Vietnam would bring about significant economic and political benefits, there was no urgent need for the United States to move fast in the process, since the United States enjoyed a huge advantage on normalization negotiation (in the strategic circumstances of the end of Cold War that were favorable to the United States but unfavorable to Vietnam) and used it as a leverage to induce cooperation from Vietnam on POW/MIA issue and the settlement of the Cambodia issue. In realist rationale, only after a satisfactory Cambodia settlement had been achieved, this leverage would no longer be required. However, Realism finds it puzzling in explaining American continued "moving the goalposts" and "politics of inattention" in adjusting to resolution of the Cambodia problem even after Vietnam had withdrawn all of its troops from Cambodia, the pre-condition that the United States had originally set for starting the normalization negotiation process, and fully cooperated in searching for POW/MIAs. In fact, among the countries that involved in negotiating for a peaceful settlement of Cambodia issue, the United States was the only country that did not have normal relations with Vietnam.

Moving the goalposts appeared to have gone beyond the point that they could serve as leverage and became counter-effective to American interests as the United States persistently continued to maintain the embargo and blockage on Vietnam even after it proved to be no longer valid, since many other countries, including US major allies, had already moved ahead of the United States in promoting business with Vietnam without 
American blessings, thus leaving American business groups behind with disadvantage in approaching the promising Vietnamese market.

Realist logics also finds hard to explain the "last minute decision" to normalize relations with Vietnam: when the United States eventually recognized the Socialist Republic of Vietnam in July 1995, it was at "the end of the diplomatic receiving line" (Womack 2008: 5). In fact, it was Vietnam's impending entry into ASEAN in the same month that provided the incentive for the United States to act.

In addition, Realism also find hard to explain why POW/MIA issue in Indochina has become more important and influential than POW/MIAs issues that the United States had in other wars, and why such issue has become the single greatest obstacle in the normalization of relations with Vietnam, despite Vietnam's full cooperation on the issue. Furthermore, realist logics are also unable to adequately explain the skepticism, caution and over-attentiveness that Vietnam dedicated to the United States in the process leading to normalization.

In short, if developments in US-Vietnam relations had rigidly followed realist logic, given the incentives and favorable environment for normalization, normalization would have happened earlier and more smoothly than it did, given the incentives for normalization by both sides. By only looking at the "big picture" and assuming states' preferences as given, Realism may find the actual process of interaction between the United States and Vietnam puzzling. 
The following chapter will explore how ideas and asymmetry of power explain USVietnam relations in the 1986-1995 period and whether Idea and Asymmetry can fill the gap in providing answers to the puzzles that remain inadequately explained by Realism, as discussed above. 


\section{CHAPTER 4}

\section{Ideas and Asymmetry}

This chapter seeks to test the impact of ideas and power asymmetry on the observed developments of US-Vietnam relations in the 1986-1995 period, including the sharp shift of Vietnamese policy to the United States; the US sluggishness and the incremental approach to normalization in contrast with Vietnam's enthusiasm in moving forward in the relationship; and the delayed and prolonged process that resulted from the interaction of such different approaches to normalization by both sides.

The Chapter aims to test the hypothesis that ideas (the integrationist foreign policy orientation that arose from the Reform of thinking Doi Moi in Vietnam and the war mentality vividly embedded in both countries) and the disparity of capacities between the United States and Vietnam that resulted in different interests and expectations from both sides were the key factors that contributed to the prolonged and bumpy path to normalization of US-Vietnam relations in the 1986-1995 period. In the lens of Ideas and Asymmetry approach, we will expect to observe:

c) Vietnamese new perception of the United States as a result of Doi Moi is the driving force behind Vietnam's positive approach toward normalization, whereas the war mentality and resentment mindset as (an old idea) have strong influence in the policy making process of the United States, leading to antagonism and 
unexpected consequences. These different ideas will generate different preferences for normalization in each country.

d) Given the disparity in power, behaviors by the United States and Vietnam will follow some certain pattern in which the stronger side tends to dictate the pace and scope of negotiation while the weaker side tend to be over-attentive to the other party's behaviors.

The influence of ideas and asymmetry of power will be tested against empirical evidence in three main areas: 1) Doi Moi and Vietnam's reorientation of foreign policy; 2) the settlement of the Cambodia issue; and 3) US - Vietnam cooperation in solving POW/MIA issue.

Findings will then be pooled together to make an evaluation of the validity of each theory.

The chapter will begin by identifying what explains ideas in each country. It will then explore how these ideas interact with each other given the structure generated by power asymmetry that exists between the two sides in the three main areas mentioned above. Each section is designed in the way that it can highlight the interaction of these ideas and preferences (action by one party is followed by response from the other).

It is also noted that the Chapter does not seek to explain where these ideas come from. It only seeks to explore the impact of such ideas on US-Vietnam relationship. 


\section{Doi Moi and the rise of new ideas in Vietnam}

In the ten years after 1975, orthodox communist thinking dominated the workings of the CPV and Vietnamese state, which manifested in the campaigns of "socialist transformation" and "socialist industrialization" waged in the entire country. Vietnamese leaders tended to view international relations through a Marxist-Leninist prism. From this "old thinking" perspective, Vietnam viewed the world as split into two irreconcilable camps, socialist and capitalist. Driven by the revolutionary tasks and confrontations of the two rival blocs, the priority in Vietnam's foreign policy was given to its bonds with the socialist countries of which its relations with the USSR was the cornerstone, and "socialist internationalism", which held that socialist parties and countries would align and support one another, was the guideline for external relations. Under this lens, Vietnam placed top priority in developing external relations within the socialist camp and isolated itself from the capitalist world. Its emphasis on socialist internationalism made it extremely dependent on Soviet aid and led to confrontation with the West.

However, the disastrous results that Vietnam suffered in the mid-1980s - a devastated economy at home and isolation abroad while being bogged down in Cambodia, confrontational with neighboring China and the United States - proved the orthodox thinking to be unrealistic. The Sixth Congress of the CPV in 1986 officially appealed for a "renovation in thinking" (Đổi mói tu duy) on socialism and the Vietnamese path to socialism, which were the ideational thrust of the overall course of Doi moi: 
We must have our thinking renovated. Thinking is about the ability to grasp objective laws, to the reasoning in compliance with these laws, and to the square application of the laws to the specific conditions in our country, to the creative process which generates new ideas, and to the search for effective methods for our action....This requires us to be opposed to superficial empiricism in cognition, to subjective, conservative and dogmatic ways of thinking, and to the separation of theory from reality (CPV 1987: 10).

Having translated into "Đổi mói tu duy" in foreign policy, the implications of this renovation-in-thinking process for Vietnam's socialist internationalism was immense. Two significant changes in Vietnamese thinking occurred in this period: First, the concept of "interdependence" replaced the struggle between socialism and capitalism as the official presentation of international relations (Porter 1990); and second, "peaceful coexistence" replaced the use of revolutionary violence as the preferred instrument to settle class disputes at the international stage. These changes made Vietnam's new concept of socialist internationalism a sharp contrast to the pre-Doi moi period.

\section{Interdependence concept as a replacement for two-camp orthodoxy}

The dramatic change in foreign policy orientation resulted from đổi mói tu duy began with Politburo Resolution 32 of July 1986, the spirit of which was carried on by the Political Report of the Sixth Congress. Although orthodox expressions were prevalent in these documents, the introduction of new concepts and ideas were notable, acknowledging the undergoing important changes in the international situation for 
Vietnam. The Sixth Congress of December 1986 formalized the ideas put forth in Resolution 32.

Resolution 32 highlighted that "in spite of many difficulties and complexities, there are evidences of new opportunities and possibilities that allow us to consolidate the peace and develop the economy" (CPV 1986). The Resolution therefore indicated a big shift in Vietnam's national preferences: peace and development were defined as the highest policy goals of the Vietnamese nation. Correspondingly, the new foreign policy tasks were set as follow:

To do our utmost to combine the strength of the nation with that of the times, striving to adhere to peace in Indochina and Southeast Asia, and actively contributing to the maintenance of peace in the world; to consolidate the special relations among the three Indochinese countries, strengthen our friendship and comprehensive cooperation with the Soviet Union and members of the socialist community, making the most of favorable international conditions for the implementation of two strategic tasks, namely building socialism and defending the homeland, at the same time actively contributing to the struggle by the world people for peace, national independence, democracy and socialism (IIR 1998).

Therefore, economic development was brought on an equal footing with security issues although national survival, defined in terms of peace, still ranked highest among Vietnam's preferences in the Resolution. The CPV came to realize that economic development should be given the status of a "life-and-death" goal beside national security. Moreover, Resolution 32 implied that the goal of national security could not be 
achieved by military measures but by peaceful ones: the resort to peaceful methods to obtain peaceful goals was another significant development in Vietnam's redefinition of national interest.

As a continuation of reform thinking since the Sixth Congress in 1986, Resolution 13 of May 1988 secretly acknowledged the interdependence between the two camps, which was the most radical concept ever in Vietnam's communist thinking:

In the context of the current scientific-technological revolution and high level of internationalization in the world economy, countries large or small are both independent and interdependent, and the security of each country must be founded upon a developed economy and scientific base. Moreover, the security of each country depends on the common security of every country (Resolution 13, in Ngoc 1999).

Resolution 13 of the Politburo in May 1988 on foreign policy was therefore an important specification and development of Doi Moi spirit. The resolution made explicit Vietnam's national interests through the direct use of the concept "lợ ích" (interest). This was the first time the CPV had ever referred to "national interest" in such an explicit manner. Previously Vietnam's national interest could only be inferred from its policy goals as the CPV had never printed "lợi ích dân tộc" (national interest) in its documents. Resolution 13 was thus a milestone in which the national interest formally made its way into Vietnam's political discourse: 
In implementing the Resolution of the Sixth Party Congress, we are resolved to carry out the strategic tasks of adherence to peace, making the best use of favorable external conditions and time to concentrate our efforts to the highest extent to stabilize and lay the foundation for the development of the economy in the next 20 to 25 years, building socialism and defending the independence of the Homeland, actively contributing to the common struggle for peace, national independence, democracy and socialism. These constitute the strategic goals and highest interests of our Party and entire people. All our policies, domestic or external, must serve these fundamental and long-term goals and interests (IIR 1999).

The resolution therefore showed an evolution in the CPV redefinition of these national goals: the relationship between security and development was defined as interrelated and the former being dependent on the latter. In this sense, Vietnam's national security was re-conceptualized as less dependent on military power, more dependent on economic strength and interdependent with the security of other states.

Most importantly, Resolution 13 called for the demilitarization of Vietnamese foreign policy and reallocation of national resources for development. The Resolution also made a case for diplomacy as a peaceful measure employed to address Vietnam's international situation, the use of which had not been attached adequate importance to previously.

We need to adopt specific measures to concentrate resources on national construction, including gradual reduction of troops and defense spending to a minimum necessary, so as to both gather up our strength for economic 
development as well as vigorously demonstrate to the world, first and foremost to Southeast Asian countries, our determination to adhere to peace and economic development.

In our external relations, we have to "make more friends, fewer enemies", strive our best to win the support of fraternal and friendly countries and broad public opinion in the world...” (Resolution 13).

In parallel with security and development, Resolution 13 also redefined Vietnam's concept of "international obligations", which refers to its support to revolutionary forces in the world, including Vietnam's military mission in Cambodia its commitments to Laos. Resolution 13 explicitly redefined the goal of "international obligations":

We are to fulfill our international obligations basing ourselves on our conditions and capacities, in accordance with our strategic goals of peace maintenance and economic development (Resolution 13)

This redefinition of security and national interests, which emphasized the supremacy of national security and development in comparison to other external goals, were reflected further in other important CPV documents in March 1990 (Resolution 8A), the Seventh Congress in June 1991, and the Third Plenum of the CPV Seventh Central Committee in June 1992. The new concept of interdependence and the redefinition of international obligations were therefore significant changes in Vietnam's thinking, setting the foundation for Vietnam's rapprochement to the West and a desire for a solution to the 
Cambodia issue, and opening new opportunity for Vietnam's relations with the United States.

\section{Peaceful coexistence:}

Together with the new concept of interdependence, the renovation of thinking also resulted in the new concept of "peaceful coexistence" which implied the need to cooperate instead of confronting capitalist countries. According to original Leninist principles of socialist diplomacy, which was rejuvenated in Đổi mới tu duy, "peaceful coexistence" was a form of struggle between socialism and imperialism in the period of transition to socialism, as this period did not happen simultaneously in all countries (Tuy 1989: 12-16). Together with the re-conception of the transitional period by the Sixth Congress, this principle was reintroduced on a par with that of proletariat internationalism to form the new principles of Vietnamese diplomacy. In fact, such a rethinking of Marxism-Leninism was the core of the ideational campaign against dogmatism in CPV theoretical base since Đổi mới tu duy.

Along this line, Resolution 32 viewed the situation as "offering new opportunities that allow us to actively move to a new stage of struggle under the form of peaceful coexistence between three Indochinese countries with China, ASEAN countries, Imperialist America, building Southeast Asia into a region of peace, stability and cooperation, creating favorable international conditions for building socialism and defending the Homeland (Resolution 32, 1986).

The policy line of peaceful existence was also confirmed by the VI Congress: 
Our party and State persists in the foreign policy of peace and friendship. We adopt and advocate the policy of peaceful coexistence among countries with different sociopolitical systems, ruling out wars of aggression and all forms of terrorism (CPV 1987: $105)$.

In the early 1990s, peaceful existence policy line took the form of "multi-lateralization and diversification" (đa phương hóa, đa dạng hóa). This new code was first introduced in the Strategy for Socio-economic Stabilization and Development toward 2000 by the VII Congress in 1991, and became a comprehensive external strategy since the $3^{\text {rd }}$ Plenum of the CPVCC (Sixth Tenure) of June 1992:

We adopt the policy of openness, multi-lateralization and diversification of external relations in all political, economic, cultural and scientific-technological fields; as well as in terms of the external activities by the Party, State and people's association, non-governmental organizations, on the basis of respect for independence, sovereignty, territorial integrity, non-intervention in internal affairs, equality and mutual benefits, economic safety and development, preservation and promotion of fine traditions and identities of the national culture (Muoi 2007: 65).

As a result, Vietnam now sought "to befriend with all countries". The Strategy for Socioeconomic Stabilization and Development toward 2000 declared that Vietnam would "diversify and multi-lateralize economic relations with all countries and economic organizations..." This new thinking has directly contributed to an open door foreign 
policy and an historic shift from dependency on the socialist states' system to full participation in the global economy.

The new thinking of integrationist therefore was the significant change in the way the country approach foreign policy as compared with its "old thinking" orthodoxy. As a result, Vietnam turned from a foreign policy model heavily structured by ideological considerations to a foreign policy model which placed greater emphasis on national interests, paving the way for a more positive approach to normalization of relations with the United States.

\section{New ideas and Vietnam's changing perception of the United States}

The significant shift in foreign policy approach of Vietnam led to a big change in its perception of relations with the United States. Instead of viewing the United States as the first enemy according to the old orthodoxy, Vietnam considered improving of relations with the super power as an important factor to carry out the reform process, first to remove the embargo posed by the United States which was isolating Vietnam from cooperation with many other important economies, and second to enhance Vietnam's position in the world community as good relations with the United States would facilitate Vietnamese cooperation with other nations and international organizations, given the important role of the United State in the international arena (Dao Huy Ngoc 1999). 
The pivot for change in policy toward the United States was the Resolution No.13 of the Politburo in May 1988 which stressed a "multi-directional foreign policy" orientation "to maintain peace, take advantage of favorable world conditions" in order to stabilize the domestic situation and set the base for economic development for the country over the next ten to fifteen years. The Resolution highlighted:

Improving and normalizing relations with all major powers and principal political and economic centers of the world has become an inevitable and urgent necessity of our foreign policy to develop simultaneously Vietnam's multi-faceted relations with a variety of potential partners, and thereby, to make best use of investments, technology, markets and advanced management experience (Resolution 13 1988).

The Resolution also emphasized that eliminating any unnecessary tension and confrontation with other countries, especially major powers, in order to have peace and stability for economic development was an urgent task for Vietnam. Although the resolution did not mention specifically relations with the United States, it served as the guideline and set a foundation for further positive moves toward the United States. It set in motion changes in Vietnamese national and foreign policies which contributed to a diplomatic settlement of the Cambodian conflict in October 1991 as an important step to improve relations with China, ASEAN countries and the United States who imposed the embargo on Vietnam because of its troop presence in Cambodia.

The Resolution, which opened a new approach to the United States, was further reinforced by the report of the Third Central Committee Meeting in June 1992 in which 
the need to seek better relations with the United States was highlighted when the Report acknowledged that "after the collapse of the Soviet Union, the world order has changed and the United States arises as the world super power", and thus "a good relationship with major powers will help create a stable and peaceful condition for Vietnam to implement Doi moi" (CPV Political Report 1992).

In addition to a new approach to the United States, these significant ideational changes help explain Vietnam's preferences in its foreign relations, particularly its relations with the United States. These led to positive moves by Vietnam in the efforts overcome the obstacles in the process of normalization of relations with the United States, most evidently including the Cambodia and POW/MIAs issues, which will be analyzed in the following sections of the chapter.

\section{American "moving the goalposts" and Vietnam's frustration}

As result of Doi Moi, Vietnam sharply changed its policy toward the United States. However, Vietnam's enthusiasm for normalization was contrasted with US sluggishness and politics of inattention in which the United States set high conditions for Vietnam's cooperation and at the same time moved the goalposts, adding more conditions for Vietnam to meet. The period of 1986-1995 observed such pattern in the relationship, characterized by incremental steps toward normalization and Vietnam's frustration at US sluggishness. 
On the one hand, the new ideas in Vietnam generated momentum for cooperation on the Vietnam side. On the other hand, the old idea (war mentality and resentment) embedded on the US side brought about sluggishness. The interaction of these different ideas and preferences, given the power structure of asymmetry, is expected to generate pattern of behaviors in which the stronger side sought to dominate the game and seek for deference whereas the weaker side strived for recognition of autonomy and attention to be met, generating outcomes that were less desirable than expected for both sides. Empirical evidence in US-Vietnam relations in the period of 1986 - 1995 in two main areas will be tested: the settlement of the Cambodia issue and cooperation on POW/MIAs issue, which were the two main hurdles for US-Vietnam relations throughout the period.

\subsection{The settlement of Cambodia issue}

Since 1979, Cambodia had been the principal political barrier to normalization of relations between the United States and Vietnam. With the Vietnamese occupation of Cambodia, postponement hardened into confrontation. Since 1986, as a result of major ideational changes under Doi Moi, Vietnam made significant efforts in settling the Cambodia issue in order to pave the way for normalization with the United States.

There were two major ideational changes in Vietnam's ideas under Doi Moi that

contributed to a more flexible approach to the settlement of the Cambodia issue: the redefinition of "international obligations" and the demilitarization of its foreign policy, as discussed in previous section of the chapter. Vietnam's determination to settle the 
Cambodia issue by peaceful means was affirmed in Resolution 32 in 1986 and Politburo Resolution 13 of the CPV, in which the settlement of the Cambodia issue was considered the most imperative task:

So long as the Cambodia issue is settled (and) our troops in Cambodia are withdrawn, on the condition that the Cambodian revolution keeps its foothold, can we soon shift our entire external relations towards peace maintenance and economic development (Resolution 13, in Dao Huy Ngoc 1999).

New ideas hastened Vietnam's determination to resolve the Cambodia conflict through non-military measures revealed the fact that it could accept a non-communist Cambodia, as Resolution 32 acknowledged that "Kampuchea's revolutionary cause should be determined by the Kampuchean people" (IIR 1998).

In addition, the decision of the VI Congress to "cooperate with all parties concerned to reach a sound political solution on Kampuchea (CPV 1987: 108) suggested Vietnamese acceptance of "national reconciliation" in Cambodia. From its resolve to exterminate the ultra-nationalist Khmer Rouge prior to Doi moi, Vietnam became tolerant of its erstwhile enemy and accepted it as part of a solution for Indochina. Vietnam's tolerance of the Khmer Rouge also resulted from the change in Vietnamese perception of Chinese socialist identity and socialism in general. That would explain the Vietnam's experiment of the "red solution" to the Cambodia conflict (around 1989-1991), in which the Khmer Rouge and the Vietnamese-backed Phnom Penh government should cooperate with each other as they shared a socialist identity (Tran Quang Co 2003: chapter 14) 
As a result, Vietnamese illusion of achieving "irreversibility" in Cambodia was finally abandoned. Vietnam accelerated the withdrawal of its troops from Cambodia, which had already begun in increments since 1982. After Resolution 13, this process was pushed up dramatically and completed in September 1989, paving the way for negotiations on a solution for the Cambodia conflict, leading to the signing of the Agreements on a Comprehensive Political Settlement of the Cambodia Conflict in Paris in October 1991. The end of the Cambodia saga relieved Vietnam of a burden it had been suffering for more than ten years, and allowed it to divert its resources from military missions and paved the way for further negotiation on normalization with the United States.

\section{Moving the goalposts and Vietnamese frustration}

Vietnam's efforts in settling the Cambodia issue, however, were not equally responded to by the United States. Instead, new conditions for normalization were added just as Vietnam fulfilled them.

Initially, Washington required that there would have to be a complete and verifiable withdrawal of all Vietnamese troops from Cambodia before normalization could take place. The United States has used all of its available tools to force the Vietnamese withdrawal, including both joining an entente led by China and ASEAN to isolate Vietnam politically, and imposing the embargo and blockage to put economic pressure on Vietnam, at the same time pouring aid to the Coalition Government of Democratic Kampuchea, an umbrella organization of resistance groups which included the Khmer Rouge and the non-communist resistance coalition in Cambodia. In 1986, the litany was

changed to a withdrawal "in the context of a satisfactory political settlement in 
Cambodia", with "satisfactory" meaning whatever the US wanted it to mean (Brown 1991: 29). At the same time, a kicker was added: the "pace and scope of normalization" would be affected by Vietnamese performance on humanitarian issues", which implied the POW/MIAs issue.

However, after the prerequisite conditions were met by Vietnam with a complete withdrawal of troops from Cambodia in 1989, the Bush Administration's condition was raised to a higher level: Vietnam must persuade its protégé regime in Phnom Penh (the State of Cambodia, or SOC, led by Hun Sen) to sign the proposed UN agreement crafted by the five permanent members of the Security Council which would, among other things, place a United Nations Transitional Authority (UNTAC) on the ground in Cambodia (Brown $1991: 29)$.

In early April 1991, Assistant Secretary Richard Solomon presented the Vietnamese permanent representative to the United Nations with a description of the four-phase process through which bilateral US-Vietnam relations would develop in the aftermath of Hanoi's signing the international agreement for a peaceful settlement of the Cambodia conflict and described how cooperation on the POW/MIA issue would influence the pace and scope of the normalization of relations. This set of conditions was famously known as the "roadmap" for Vietnam to follow.

Phase One of the roadmap was to begin with the signing of the Paris agreement, which took place on October 23. Phase Two was to begin with the establishment of the United Nation Transitional Authority in Cambodia (UNTAC) and the initial steps toward an UNsupervised election in Cambodia. Phase Three was to begin once Vietnam and the 
authorities in Phnom Penh had supported the implementation of the Paris Agreement on a free and democratic election in Cambodia for 6 months. Phase Four, the final phase, was to begin following a free and democratic election in Cambodia, the establishment of a new National Assembly, and the demobilization of the four Cambodian factions.

According to the Roadmap, Vietnam was expected to fulfill the following responsibilities:

- Vietnam must sign the Paris Agreement and fully support "the implementation of all parts" of the agreement;

- Vietnam must withdraw from Cambodia all military forces and advisers as internationally verified.

- Vietnam must convince the Phnom Penh authorities also to sign the Paris agreement and fully support the "implementation of all parts" of the agreement;

- A successful Cambodian settlement must be achieved, defined as including:

- The international verification of the removal of all Vietnamese military forces and advisers from Cambodia;

- The complete demobilization of all factional Cambodian military forces as agreed to in the Paris Agreement by the four Cambodian parties

- A free, democratic elections, as certified by the UN.

(Details of Roadmap are presented in Appendix B)

The April 1991 "road map" in which US policy was embedded therefore differed from previous policy statements in its specificity with respect both to what Vietnam was 
expected to do and what the US would do in return. In effect, the roadmap already moved the goalposts from Vietnamese military withdrawal from Cambodia (already accomplished) to much more stringent and protracted requirements. It also differed in outlining a phase by phase scenario that began with the signing of the Paris Agreement and would conclude with normalization itself. The demands on Vietnam were elaborated but continued to focus on cooperation in the Cambodian peace settlement process and in resolving POW/MIA issues (Evelyn 92: 8).

Together with moving the goalposts in settling the Cambodia issue, the United States continued to maintain financial and nonlethal material contributions to the noncommunist resistance factions of the CGDK in Cambodia to fight against Vietnam. While precise figures were not publicly available, covert assistance on the order of $\$ 10$ to $\$ 15$ million annually was reportedly provided to these groups since 1984 or earlier (Brown 1989: 45). The United States has overtly supported the non-communist resistant groups (NCRs) Sihanouk and Son Sann since fiscal year 1985 at an annual rate of about $\$ 3.5$ million through the Solarz program (medical supplies, malaria prevention, training, and commodities), and since fiscal year 1989 additionally through the McCollum program providing excess Department of Defense stocks (nonlethal) and administration requested $\$ 5$ million and \$ 0.5 million, respectively, for these programs. In March 1989, the Solarz program request was boosted to $\$ 7$ million, "in preparation for a settlement in Cambodia and to strengthen the noncommunist resistance to help prevent the return of the Khmer Rouge to power (Brown 1989: 80). 
In addition, after a lengthy debate, the US Senate on July 20, 1989 approved an amendment (by Senator Charles Robb, D- VA) to the State Department's authorization bill, which expressed the Senate's support for lethal aid to the NCR and gave the president this option. Similar legislation was passed in the House. The Senate's Democratic leadership, however, remained opposed to lethal aid, and the Robb amendment did not assure its future provision, either overtly or covertly (Brown 1989: $81)$.

The American active involvement in Cambodia and its moving the goalposts with higher conditions being raised to Vietnam highlighted a fundamental puzzle to Vietnamese leadership: Why was the fate of Cambodia so important to Americans? It was not because of historic ties between the United States and Cambodia because the latter was a French colony. In addition, Cambodia was no longer a frontier in a vast global confrontation with power, since the Cold War already ended with the collapse of communism in the Soviet Union. It was arguable that the United States had strategic interests in Cambodia during the Cold War because the war in Cambodia was once believed to be the proxy war between great powers (between the Soviet Union and China), but this argument line became less valid when the Cold War was winding to its end. It was also not because Vietnamese domination over Cambodia threatened stability of all South East Asia, since Vietnam had already withdraw troop from Cambodia (completed in 1989). To many observers, the only remaining rationale for American continued involvement in Cambodia was the belief that the resolution of Cambodian conflict would contribute to the peace and stability of all Southeast Asia, in which the United States had significant interests (Morely 1992: 17). However, the border between Cambodia and Thailand had 
been relatively stable since 1985, and first Indonesia and then Thailand had begun the process of transforming Indochina "from a battlefield into a market place", as Thai Prime Minister Gen. Chatichai Choonhavan asserted in his new foreign policy in May 1988.

The US involvement in Cambodia therefore inevitably resulted in Vietnam negative perception about US intention and was interpreted by Vietnam as part of American resentment against Vietnam resulting from the Vietnam War (Interview data). US "collusion" with China and ASEAN on the front against Vietnam's occupation of Cambodia, US embargo as punishment on Vietnam, and American consistent support, both politically and financially, for the Khmer Rouge as well as for the non-communist resistance groups in Cambodia, and the constant moving of goal posts for normalization, all had reinforced such Vietnamese perceptions.

Not surprisingly, Vietnam reacted strongly and negatively to the Road Map and accused Washington of moving the goal posts. From the start, Vietnam argued that the Roadmap was a unilateral document dictating a course of action, not a negotiating position, and was therefore an affront to their sovereignty. In Hanoi's view, the US government had set conditions that Vietnam would be unable to satisfy as a result of diminishing influence over the Phnom Penh government and trends beyond Vietnam's control (MOFA 1993).

Vietnamese Vice Foreign Minister Le Mai strongly criticized the roadmap:

The US "road map" of April 9, 1991, has brought with it many unacceptable and outdated aspects. The "roadmap" links US-Vietnam normalization to the signing and implementation of the Paris agreements on Cambodia as well as resolution of 
the MIA issue and release of re-education camp detainees in Vietnam. It is wellknown that the Cambodia problem has been internationalized. The resolution of the Cambodia issue through the agreements signed and their implementation depend on many parties: the Cambodia parties, the signatory nations to the agreements, and the US. Why it is that only Vietnam's responsibility is referred to in this regard? (Le Mai 1992: 13, cited in Stern 1995).

Vietnam's frustration and dissatisfaction was also explicitly expressed in its official public media. Voice of Vietnam in late May 1991 stated:

In life, goodwill must be manifested by action and absolutely not by empty words. Goodwill to successfully settle a problem or differing views must come from both sides and never from one. It has been publicly known that the US propaganda machinery has thus far held Vietnam responsible for the failure to settle the situation in Cambodia. It has forgotten or intended to forget Vietnam's most basic action in Cambodia which was the withdrawal of Vietnamese troops. On the contrary, it has distorted the event with ill intentions and has not satisfactorily helped settle the continued assistance of the Khmer Rouge and the prevention of war from reoccurring there.

Normalizing US-Vietnamese relations is a demand of the peoples of both countries and would benefit both sides. That the US side considers the Cambodian issue a condition for settling the normalization of relations demonstrates that it has not really wanted to normalize the relations as rapidly as large numbers of American people have desired (Stern 1995: 59) 
In Vietnam's view, the progress in the relations between Vietnam and the United States should not be held hostage to aspects of the Cambodia settlement, such as actions by the Khmer Rouge, which may be beyond Vietnam's control. Vietnam maintained that it was not appropriate to delay US normalization until after an election was held in Cambodia because that election would be subject to many factors that are not directly related to Vietnam. For example, Prince Sihanouk indicated that the election may have to be postponed for years. In addition, although Vietnam had influence over Phnom Penh in the past, Prince Sihanouk now has far greater influence: current ability to affect Phnom Penh's policy is vastly overrated in the "road map". Linking normalization with the full implementation of the Cambodian settlement therefore was criticized as imputing responsibility to Vietnam for a lack of progress more likely to result from the internecine warfare of the Cambodian factions than from action or inaction attributable to Hanoi. (Evelyn 92: 8)

Hanoi pressed the viewpoint that it had contributed to the resolution of the Cambodian conflict by withdrawing its troops and had participated in the efforts to formulate a peace plan. Hanoi had also committed itself to respect the decisions of Cambodia's Supreme National Council, accept international supervision and control of a ceasefire, and support an enhanced role for the United Nations in administering a free election in Cambodia. It was to Hanoi's conclusion that the United States had not done enough to respond to Vietnamese good will and efforts. Vietnamese media went on to make strong critics on US incremental moves: 
The US side has frequently imposed unilateral conditions considering that the normalization of relations will only benefit Vietnam. How can a unilateral solution promote rapidly and realistically the normalization of relations between the two countries?...in the relations with the US, the Vietnamese side has taken the first step in many issues. Particularly as regards the Cambodian issue - which the US considers main condition for settling normalization of relations - the Vietnamese side has withdrawn all its military force from Cambodia and created basically favorable conditions for a political settlement of the Cambodian issue. On that basis, the US government's position was weak and contradictory in the Vietnamese view. (Stern 1995: 58)

However, while strongly criticizing the Roadmap and openly expressing its frustration, Vietnam neither rejected nor accepted it. Vietnam continued to cooperate on searching for American MIAs, and on October 23, 1991, Vietnam signed the Paris international peace agreements on Cambodia.

In October, following the signing of the Paris Agreement in Cambodia, the United States announced the lifting of the embargo on Cambodia, the end to the 25-mile travel restrictions imposed on Vietnamese Foreign Ministry officials assigned to the UN headquarters, and termination of restrictions on group travel to Vietnam. However, such incremental development toward normalization by the United States was not satisfactory to the Vietnamese. In Vietnamese view, the amount of time it took the US government to implement the decision to lift the 25-mile travel limit and the restrictions on group travel 
was "one more signal that the US government was not really intent on moving forward and was not concerned about keeping promises to Vietnam” (Stern 1995: 64).

To further extend Vietnam's dissatisfaction about US sluggishness, in a meeting with Assistant Secretary Solomon in New York after the announcement was made, while Deputy Minister Le Mai made every indication that Hanoi planned to make its best effort to comply with US requirements regarding the accounting for missing American service personnel, he strongly criticized Washington's linking of the issue of normalization and the "very emotional issue of the MIA's and the implementation of the Cambodian peace agreement (Stern 1995: 65). Le Mai reasoned that Washington's insistence on linking implementation of the Paris Agreement on Cambodia with the MIA issue could derail the process. In Mai's words, Washington had made the normalization process "hostage to the activities of the Khmer Rouge" (Stern 1995: 76)

In the late 1991, Vietnam argued that the Roadmap was seriously out of date, given trends toward reconciliation in the region and progress in implementing the peace agreement in Cambodia. In Vietnamese view, after the Paris agreements were signed, the United States should have fully normalized its ties with Vietnam without raising further conditions (Interview data). However, the United States demanded that Vietnam contribute to the implementation of the agreements and holding of general election in Cambodia with a new government before US-Vietnam relations can be normalized. Such increased demand was interpreted by Vietnam that the United States again "held USVietnam relations hostage to the Cambodian question" (Interview data), since the resolution of the Cambodian question related to a third country, which must be solved by 
the Cambodians together with other signatories to the Agreements and the UN (Tran Minh Bac 1992: 25). The fact that the US continued to move the goalposts further therefore ignited Vietnam's deeper frustration and dissatisfaction.

In conclusion, the fact that the United States, being the only country who did not have diplomatic relations with Vietnam among the countries involved in the Cambodia peace talks, did not alter the connection it made between normalization and Vietnamese performance on Cambodia issue despite Vietnamese significant cooperation in the context of important global and regional changes in Southeast Asia and Indochina, indicates that the main issue between Vietnam and the US was not Cambodia but the psychological wounds from the war. In other words, it was the continuity of old idea (the war mentality) in American thinking that kept shaping US policy toward Vietnam, generating mistrust and skepticism. That old orthodoxy was further exacerbated by the asymmetric relationship that existed between the United States being the stronger (but defeated) power and Vietnam the victorious weaker side. This explains the US sluggishness in responding to Vietnam's concerns, pushing back the goalposts and adding more conditions and demands for Vietnam to meet; and Vietnam's over-attention and skepticism of US motives and intentions.

Such pattern of interaction is also expected to be observed in the handling of POW/MIAs issue between the two countries. The following section will test this hypothesis against evidence obtained from the process of interaction between the United States and Vietnam on POW/MIA cooperation. 


\subsection{POW/MIA issue}

The POW/MIA issue has a high profile in American politics and clearly represents the most important US policy concerning Indochina. It has been the main impediment to the US normalization of relations with Vietnam.

Following the termination of the Vietnam War, the POW/MIA issue gradually emerged as the main centerpiece of US-Vietnam relations, eventually overriding political and strategic issues such as Vietnam's relations with the Soviet Union and its neighbors. By the 1980s, the POW/MIA issue had become nearly the sole preoccupation of the United States in its dealings with Vietnam. Despite the initial official position that this was a "humanitarian" issue with no direct relationship to political and diplomatic questions such as normalization, the reality was that the POW/MIA issue became the dominant concern of the US government and ultimately the main demands on Hanoi were related to it. It had become the ultimate precondition for normalization for Vietnam to fulfill.

Of all of war's legacies, the POW/MIA story seemed to have the greatest staying power (Issacs 1997: 104). In a sense, it became the central legend of Vietnam, represented in POW-MIA flags flying over state capitols, in countless novels and movies, and apparently in the minds of a substantial majority of Americans. The issue aroused broad feeling of American public. In the Gallup poll in April 1990, 64 percent of the respondents expressed belief that American POWs were still held captive in Southeast Asia. A year later, a Wall Street Journal/NBC News poll found that percentage had increased by 5 points, reached to 69 percent (Turley 1992: 35). 
Such suspicion of possible POWs kept in Vietnam agitated important members of Congress of both parties. On October 26, 1990, the Minority (Republican) Staff of the Senate Committee on Foreign Relations distributed an Interim Report to the Senate, sponsored by Senators Jesse Helms (R-NC) and Chuck Grassley (R-IA), charging that the administration, a government of its own party, had "profoundly mishandled" the POW/MIA problem (Morely 1992: 20). After a year-long investigation in which for the first time Pentagon records also were examined by outsiders, the report contended that the US government had, contrary to its statement, abandoned "US citizens still in the custody of Vietnam, Laos and Cambodia, at the conclusion of US involvement in the Second Indochina War, and that the Defense Intelligence Agency (DIA) was guilty of "arbitrary rejection" of live sighting reports and "numerous misidentification of remains" (Morely 1992: 20). Consequently, POW/MIA issue did not diminish as the single greatest obstacle to strategic discussion of Vietnam-US relations

However, there remain puzzles to observers of US-Vietnam relations: Why did the POW/MIA issue become such an important and complicated problem that shaped the tone for the whole process of normalization of US-Vietnam relations, in which the United States moved the goalposts by pressing Vietnam hard on the issue? Why were the questions concerning American MIAs in other wars (78,794 US MIAs from World War II and 8,177 US MIAs from the Korean War) not a pressing or priority issue, but the 1,700 US MIAs from the Vietnam War became a national priority question for the United States? 
The fact that the issue, initially thought to have been resolved by the Montgomery mission in 1976 after visiting Vietnam, kept resurfacing and escalating suggests that it was not only the POW/MIA issue itself that was at stake, but some deeper current that propelled this issue along.

New ideas versus old ideas: an incremental path in POW/MIA cooperation:

Since Doi Moi and renovation in thinking was started in 1986, Vietnam sharply shifted its US policy. Instead of perceiving the United States as the "permanent enemy" in the 1975-1986 period, Vietnam viewed the United States as an important country with which to improve relations. This significant change in perception about the United States induced Vietnam's full cooperation in searching for American MIAs: the ideational change led to a decision by Vietnam to do what was necessary to satisfy the United States on POW/MIA issue.

As a result, American appointment in mid-1987 of General John Vessey, former chairman of the Joint Chiefs of Staff, as Special Presidential Emissary for Humanitarian Affairs was warmly welcomed by Vietnam, marking the beginning of a new phase on what was the most neuralgic bilateral humanitarian issue, Americans missing in Southeast Asia. Vietnamese leaders assured General Vessey that Vietnam would give unconditional cooperation (Morely 1992: 21) 
Since then, Vietnam became increasingly forthcoming on the issue. In an "unprecedented display of cooperation", Hanoi accepted a standing US offer to conduct joint, US-funded searches in provincial locations believed to have MIA remains (Brown 1989: 110). Using American jeeps, excavation machinery, computers, and a variety of specialized equipment, five joint search operations took place in North Vietnamese provinces since September 1988. As of July 31, 1989, 231 sets of remains had been recovered; 64 of these were positively identified as missing US servicemen. Vietnam showed full cooperation on the issue, providing in addition numerous bits of information relevant to the fate of MIAs. "Rice farmers have witnessed the strange spectacle of US vehicles and personnel roaming the North Vietnamese countryside with their government counterparts in a way that would have been considered unthinkable a few years ago" (Brown 1989: 110).

With Vietnamese full cooperation, the number of "discrepancies" was reduced to less than 200 by the early 1990s. In just over a year Vietnam had joined the US in ten major searches for information on the remains of American pilots reported missing during the war. The Vietnamese government created favorable conditions during the 10 searches in 24 provinces. The undertaking also involved investigations into some 100 registered cases of MIA and 6 rounds of identification conducted by the mixed team. Since the Vietnam war ended, Vietnam has handed over to the US side 404 sets of remains, among which 243 of them had been returned to the US side just within two years since the visit by General Vessey in 1987 (Stern 1995: 46).

However, Vietnam's enthusiasm in full cooperation on POW/MIA was not equally responded by the United States. Instead of rewarding Vietnam for its cooperation, the 
United States kept moving the goalposts for normalization by adding further conditions for Vietnam's compliance in searching for POW/MIA, and at the same time maintaining and expanding the embargo on Vietnam. US suppression as a result provoked strong Vietnamese sentiment, all contributed to the prolonged and bumpy path toward normalization.

In the course of negotiation with Vietnam throughout the process of POW/MIA cooperation, the United States moved the goalposts and added further conditions for Vietnam to meet for three times.

The first series of American increased demands for cooperation in return for easing the embargo and normalization were put forth specifically in the famous "roadmap" that was presented to Vietnam in April 1991. Besides demands for concrete Vietnam cooperation in the solution for the Cambodia issue, the United States set out specific conditions and requirements for Vietnam to meet in solving the POW/MIA issue. According to the Roadmap, Vietnam was expected to do:

- Vietnam must implement the agreed plan to resolve "live sighting reports"

- Vietnam must satisfy the United States that it has done all it can to help the United States secure the "fullest possible accounting" of the remaining "discrepancy" cases within the next 24 months, and that "significant results" have in fact been achieved; 
- Vietnam must repatriate rapidly all recovered and readily recoverable American remains;

- Vietnam must convince the Phnom Penh authorizes to cooperate fully with American POW/MIA requests during the period of transition.

The Roadmap with excessive conditions encountered strong reaction from Vietnam. Refusing to acknowledge the Roadmap as a legitimate negotiating position, Hanoi considered it simply Washington's own "stance" on the issue (Stern 1995: 67). Vietnam considered POW/MIA as a pure humanitarian issue, therefore the fact that the roadmap link POW/MIA with other political issues was not acceptable. Hanoi's position was that bilateral cooperation on the POW/MIA issue should proceed independently of progress toward normalization and that normalization should take place without preconditions. Vietnam therefore sought to proceed with MIA cooperation without making formal references to the Roadmap and indicated that Hanoi planned to make its best effort to comply with US requirements regarding the accounting for missing American service personnel (Le Mai 1991).

As a further indication of continued cooperation on POW/MIAs, in mid-November 1991 Vietnam repatriated 6 sets of remains to the United States. In Hanoi's account, this was the 36th repatriation of MIA remains and brought the total number of sets of remains returned to the US to 458 (MOFA 1992). Vietnam's goodwill in searching for MIAs was recognized by General John Vessey's report to the Senate Foreign Relations Committee after his trip to Vietnam in late 1991 that Vietnamese leaders had pledged "unconditional cooperation" for solving POW/MIA issue (Stern 1995: 65). 
However, Vietnamese cooperation was not always altogether satisfactory to the US government and Vietnamese concessions did not result in US positive moves toward normalization. Instead of rewarding Vietnam for accorded cooperation, the United States, for the second time, once again, added further requests to Vietnam in late 1991: the United States requested that US officials based in Hanoi be allowed immediate helicopter access anywhere in Vietnam to pursue live-sighting reports, including controlled areas and government and military achieves (MOFA 1992).

Such requests by the United States provoked strong reaction from Vietnam. In an article "The US should end its irrational attitude to the MIA issue" on People's Daily on December 7, 1991, the author argued that Vietnam had invested 600,000 workdays in unilateral and joint search efforts and repatriated 458 sets of remains, and that "it is necessary to say that Vietnam has unilaterally solved the MIA issue without demanding any conditions from the US side" and that Washington had taken an "irrational attitude toward the issue":

Right from the beginning the US side did not consider the MIA issue as humanitarian one. It has linked this issue with the normalization of USVietnamese relations, making it one of many other political conditions. It is indeed the US side that has caused setbacks in the settlement of this issue.

The article continued:

Some members of the US Congress demand that they be allowed to visit any prison in Vietnam at any time regardless of Vietnam's sovereignty. The US 
Secretary of Defense even likened the MIA search mechanism to the Gulf War operational command. This makes some people question whether the MIA issue is a humanitarian issue or an opportunity for the United States to undertake some dark schemes against Vietnam." (Nhan Dan, December 7, 1991, cited in Stern 1995).

Vietnamese stand became further hardened when Senator John Kerry presented further requests and conditions on Vietnam during his visit to Hanoi in mid-May 1993. Senator Kerry presented a letter by President Clinton to Vietnamese President Le Duc Anh expressing the desire that humanitarian cooperation be strengthened to create the conditions that would lead to normalization, asking Vietnam to allow US specialists greater access to wartime documents and to improve the program of interviewing witnesses regarding the details of loss incidents, and suggesting that Vietnam open an office in Hanoi to store all documents related to the POW/MIA issue. In addition to the letter from President Clinton, Senator Kerry also presented a letter from veteran group leaders which opposed granting access to loans from the international financial institutions to Vietnam unless there was convincing evidence that the Vietnamese had put a process in place that assured the US government of the ability to achieve the fullest possible accounting (Stern 1995: 105).

US further demands once again aroused critical reaction by Vietnamese leadership. Vietnamese General Secretary Do Muoi criticized US additional requests, indicating that this was not a helpful approach, and that Vietnam was prepared to stop looking for information if that approach persisted. The Vietnamese leader also stated that 
Washington should not believe that Vietnam feel compelled to respond to each and every US request as the result as a means of hastening the lifting of the embargo (MOFA 1992).

American moving the goalposts were not only present in the additional conditions set forth for Vietnam, but also in the delay and incremental approach to removing the embargo imposed on Vietnam.

Despite Vietnam's active cooperation and the achievements made in searching American MIAs that met the conditions set in Phase Two of the Roadmap which indicated that the embargo would be eased as achievements were made, the United States decided to extend the embargo in September 1992. The US explanation for the extension of the embargo was that although certain of actions by Vietnam fell into Phase Two of the four phases of the Roadmap, Washington made it clear that it would be wrong to say that Phase Two had begun because the US government still expected more cooperation from Hanoi on the issue of US remains and access to wartime archival information on missing Americans (Stern 1995: 81). Such incremental move by the United States was perceived by Vietnam as small steps in wrong direction (Interview data).

Vietnamese leaders were frustrated with the fact that the Americans had veered from the path defined by their own Roadmap. A senior Vietnamese politician recalled wondering why Phase Two did not begin with the signing of the Paris agreement on Cambodia, and why the Roadmap did not end with the UNTAC-supervised election in Cambodia - a condition that was clearly set in the Roadmap by the United States (Interview Data). 
Consequently, the renewal of the embargo in mid-September 1992 further fostered Vietnam's frustration with the United States. A commentary on the People's Daily on September 15, 1992 stated:

Vietnam's attitude is crystal-clear. We hope and are striving to normalize relations with the United States. But we will not tolerate any pressure. The US administration's decision to extend its trade embargo against Vietnam for another year shows a lack of goodwill and a move unsuitable to the present international situation (Nhan Dan September 15, 1992).

As a result, Vietnam decided to slow down efforts in searching for American MIAs with an explanation that Vietnam had already done all what it could and therefore American excessive demands could not be met (Interview Data). However, Hanoi continued to maintain some level of cooperation in searching for MIAs as a humanitarian action.

Not until July 2, 1993 did the United States, in another fragmented act to the embargo, announce the decision to refrain from opposing the efforts of other countries to settle Vietnam's arrears with the International Monetary Fund. However, such ease to the embargo did not come free and further demands were presented to Vietnam: the United States made it clear that no further steps would be taken toward normalization until the Vietnamese were responsive to US government requests for further action in four areas: the recovery and repatriation of remains; continued joint field investigations of the discrepancy cases and continued live-sighting investigations; trilateral cooperation on Lao border cases; and access to wartime information in Ministry of Defense archival 
holdings (Stern 1995: 107). Furthermore, adding to the already frustration by Vietnam, the United States once again renewed the embargo on September 13, 1993.

Responding to US's renewal of the embargo for another year, Hanoi criticized that US actions "did not match its words" when the decision to prolong the embargo veered from the course that the United set itself in the Roadmap. Vietnamese leaders made it clear that they were less and less likely to regard the "piecemeal approach to lifting the embargo as a serious commitment by Washington to moving toward a normal and proper relationship. In Hanoi's perception, the additional conditions that Washington had set for normalization and the president's decision to delay normalization aroused "indignation" in the US and the world (Stern 1995: 117).

No one fails to realize that the United States is the one who started the Vietnam War causing the Vietnamese people to suffer untold sacrifices and losses. After the war, the United States should have fulfilled its obligation to help Vietnam restore its wardevastated country. Far from doing so, Washington has imposed an embargo against us - its rival - over the past 18 years. During various contacts with Vietnamese, many responsible US officials have expressed the desire to close the past and open a new chapter. Therefore, the September $13^{\text {th }}$ decision to continue the embargo against Vietnam shows that the words of the United States do not really match its deeds (People's Daily September 14, cited in Stern 1995: 116-117).

The US incremental approach in moving along with the embargo, together with the sluggishness and inattentiveness to Vietnam's cooperation and concern generated Vietnam's frustration about the progress to normalization, and skepticism about US 
intentions. In fact, within the SRV government there remained serious disagreements over how to conduct relations with the US and how to respond to what they saw as infinitely escalating American demands for "cooperation" on the MIA issue. The fact that the United States was making successively more intrusive demands of the Vietnamese appeared to Vietnamese leaders as though the United States was asking Vietnam to act like a defeated country (Interview Data).

US sluggishness in moving normalization forward was reinforced further by a series of fake document incidents that hindered the process of removing the embargo and normalizing relations with Vietnam. In the summer of 1991, newspapers across the United States front-paged several photographs which purportedly depicted Americans in captivity in Indochina. The "Robertson-Lundy-Stevens" photo ignited a firestorm of American emotions, and intensified for Vietnam the problems involved in managing the sensitive live prisoners issues (Isaacs 1997: 105). Furthermore, in April 1993, just days before President Clinton was to review the Trade with the Enemy Act and considered easing the embargo on Vietnam, a second document from the Soviet military intelligence archives was revealed and again captured headlines in US papers in a manner that, to Hanoi, threatened to derail progress on the MIA issue The document stated that Vietnam held 735 US aviators as POWs in 1971 instead of the 368 whose names the Vietnamese had publicly released. However, both of the documents were later proved by the US government to be fake (Isaacs 1995: 107).

The incidents inevitably aroused Vietnam's strong reaction and frustration. What even frustrated Vietnamese leaders more was the fact that while accepting that there 
documents were proven by American experts to be without evidence, there was no authoritative pronouncement by the United States on this issue. Failure to say that in a public assessment therefore compounded the frustration in Hanoi (Interview data).

Consequently, the process of normalization was fragmented and delayed by the interaction of both sides with various incidents that ignited frustration that slow down cooperation. As a result, not until August 1994 did the United State announced the removal of the embargo on Vietnam, followed by the decision on January 28, 1995 to open liaison offices in Hanoi and Washington, and the official establishment of diplomatic relations on July 11, 1995. It is observed that the embargo was removed only after it appeared to have little effect since many other countries, including American major allies, had already broken through the barrier to have economic relations with Vietnam, and the United States was the last country in the diplomatic receiving line to normalize relations with Vietnam.

The above analysis describes the clear pattern of interaction between the United States and Vietnam in solving the POW/MIA issue during the 1986-1995 period in the process of normalization of relations. The US "moving the goalposts" and the cumulative/additional conditions and demands presented to Vietnam, at the same time being sluggish and inattentive in responding to Vietnam's efforts and concerns, all contributed to the prolonged and rough progress of normalization. US "politics of inattention" caused tremendous frustration to Vietnam. In Vietnamese view, it had done everything possible in cooperation to search for American MIAs, but the achievements gained had not been acknowledged adequately by the United States, not to mention 
further unreasonable questions and misinformation were brought up and laid out for Vietnam to solve.

As the transformation of ideas mingles with asymmetry of power in shaping US-Vietnam relationship, the POW/MIA issue had a number of important consequences for USVietnam relations, not merely in posing an obstacle to greater cooperation, but also in the way it has influenced how both sides think about the relationship. First, it kept the relationship mired in a bog of emotionally charged symbolism. This has made it very difficult to rationally determine what other interests the two countries may have shared, as well as to address other areas where their interests conflicted. It has locked USVietnam relations to a bilateral framework that overstated what each other can do for the other, and blinds both to the indirect ways in which they share mutual interests. The assumption has evidently been that "they need us more than we need them". The second direct consequence of this issue has been to make normalization only indirectly contingent on Vietnamese actions, as discussed in the above analysis.

In addition, the interaction of different ideas and asymmetry of power also generated different perceptions and expectation from both sides. For the United States, miscalculation can be seen in the conditions that were laid out for normalization with Vietnam after the complete settlement of the Cambodia issue. The Roadmap was crafted on the assumption that Vietnam was facing economic difficulties as a result of the sharp reduction of aid from the Soviet bloc and was confronted by both internal and external pressures to democratize. The United States therefore believed that the longer the economic embargo and political isolation against Vietnam prolonged, the worse the 
situation in Vietnam would be and therefore Vietnam would eventually have to accept US preconditions for normalization. However, while it was true that Vietnam was in tough situation, the economic reforms initiated in 1986 had diminished the impact of reduced Soviet aid while foreign investment started flowing in (Hoang Anh Tuan 2010: 346). The situation became less severe as Sino-Vietnamese relations improved in the late 1980s and early 1990 that led to normalization of relations between China and Vietnam.

For Vietnam, the acceptance of preconditions for normalization set by the United States would have been tantamount to surrender by Vietnam which had beaten the United States in the Vietnam War. In this context, the Vietnamese leadership viewed Washington's demand for the fullest accounting of MIAs as an unacceptable precondition for normalization, since Vietnam itself had more than 900,000 cases of MIAs. Consequently, as the above discussion reveals, Vietnamese leadership felt it had made a massive concession by accepting requests for full cooperation with the United States in searching for American MIAs. 


\section{CONCLUSION FOR PART II}

Part II of the dissertation has sought to explain the long and bumpy path toward normalization of US-Vietnam relations in the 1986-1995 period, characterized by a dramatic shift in Vietnam policy to the United States followed by the reform Doi Moi since 1986; the sluggishness and an incremental approach to normalization by the United States that was accompanied by Vietnam over-frustration throughout the process, and the delayed removal of US embargo and establishment of diplomatic relations with Vietnam in 1995. Similarly to Part I, the two alternative theoretical approaches, Realism and Theory of Ideas and Asymmetry, have been applied to explain the same set of events in US-Vietnam relations of the 1986-1995 period: the sharp shift in Vietnam's US policy and its enthusiasm for normalization in contrast with American indifference and "moving the goalposts" throughout the process. Empirical findings of each chapter have been compared to determine which theory has scored more of the weight of evidence in their explanation to confirm their relative validity.

Findings from Chapter 3 indicate that the Realist explanation provides a sound explanation for the developments of US-Vietnam relations throughout the period. For Vietnam, it was the urgent need to break through isolation in face of enormous challenges generated from both severe internal economic crisis and external security concerns caused by the evolving developments that led to the end of the Cold War. For the United States, it was the strategic calculations and geo-political and economic interests in Southeast Asia in general, and in Vietnam in particular, that led to the gradual shift in its Vietnam policy toward normalized relationship. 
However, empirical findings also reveal that realist logic falls short in explaining several main puzzles of the period: Moving the goalposts appeared to have gone beyond the point that they could serve as leverage and became counter-effective to American interests as the United States persistently continued to maintain the embargo and blockage on Vietnam even after it proved to be no longer valid, since many other countries, including US major allies, had already moved ahead of the United States in promoting business with Vietnam without American blessings, thus leaving American business groups behind with disadvantage in approaching the promising Vietnamese market.

Realist logic also finds hard to explain the "last minute decision" to normalize relations with Vietnam: when the United States eventually recognized the Socialist Republic of Vietnam in July 1995, it was at the end of the diplomatic receiving line.

On the other hand, in explaining the same set of events in the 1986-1995 period, Chapter 4 has indicated that the logic of Ideas and Asymmetry provides a more complete explanation for both the preferences and the actual interaction of US-Vietnam relations in this period. Empirical findings reveal that it was the interaction between different ideas (new ideas initiated by the reform by Vietnam versus the old idea of war mentality embedded in US thinking) and between the preferences that they form, given the power asymmetry between both sides, that appeared to have determined the pace and scope of normalization of US-Vietnam relations in the 1986-1995 period.

New ideas (the change in thinking by Doi Moi of Vietnam) explains the dramatic shift in Vietnam's preferences with regards to normalization of relations with the United States, whereas the persistence of old ideas (the war mentality) significantly determined US 
policy toward Vietnam. For the United States, the principle issue in relations with Vietnam was not economic, but coming to terms with the hurt- and for some- the guilt associated with the Vietnam War. The unfinished business of that war was manifest most directly for Americans in the enormous political importance of the POW/MIA issue that resulted in the cumulative demands and conditions that were raised on the path to normalization of relations with Vietnam.

Together with ideas in explaining the ups and downs in the normalization process, findings also reveal that asymmetry of power had a profound effect on the perspective of participants. Under Asymmetry logic, the weaker side is more exposed to the relationship than the stronger because of the difference in capacities. The stronger side by definition has proportionately less to gain or lose, and thus is less engaged in the relationship. If the stronger side must involve itself in a problem, it will tend to bully the smaller side, trying to push it into line with its preferences. In the case of US-Vietnam relations, the impact is even more noticeable since the stronger side was not the victorious one, and raising conditions was one way of keeping face. This explains for the United States moving the goalposts and setting the bar high for the weaker side Vietnam to fulfill. The significantly slow response of the United States to Vietnamese normalization overtures can therefore be best explained by the fact that the relationship simply was not important enough to the United States to merit the diplomatic rethinking and political reorientation that normalization would require (due to the asymmetric nature of the relationship). The fact that the US government remained unresponsive even to major steps taken by Vietnam, including the withdrawal of troop from Cambodia in 1989 and the implementation of the Paris agreement on a peaceful settlement of the Cambodia conflict, together with full 
cooperation on POW/MIA issue, and event went beyond the scope of its own Roadmap to add further conditions to extract concessions from Vietnam is a clear example of how asymmetry and ideas mingle in shaping the interaction of the relationship.

The discussion also indicates that asymmetry, intertwined with idea, generated different perceptions and expectation about normalization from each side. As a result, the two governments hold rather different views of normalization as a process relating to their broader interests: For Vietnam, the achievement of normalization represented the beginning of a process in which, as currently conceived, ending the embargo and USimposed barriers to assistance from IFIs (international financial institutions) will open a flow of Western resources enabling the Socialist Republic of Vietnam to reconstruct and develop its economy. In other words, normalization is valuable for its consequences. Whereas, for the United States, the achievement of normalization seems to represent the end of a process marking Vietnamese satisfaction of American requirements on the politically sensitive POW/MIA problem and on Cambodia. The "roadmap" epitomized this approach - maintaining previous demands while adding specificity to the steps required and the rewards for performance. Satisfaction of these demands, especially on POW/MIA - was accorded grave importance. However, the relationship with Vietnam thereafter was not seen as of truly major consequence to the United States.

The analysis also indicates that the basic problem that the United States had with Vietnam was associated in the public mind as "Vietnam" - the war, rather than Vietnam, the country. Such persistent "old idea" explains the problem of "pushing back the goalposts", why when some preconditions for better relations seem on the verge of 
fulfillment, others rise to take their place. This is clearly evident in the Roadmap that dominated the process of normalization of US -Vietnam relations in the 19861995period: after the Cambodia issue no longer served as a condition, the POW/MIA issue immediately rose up. In fact, as will be discussed in the next chapters of the dissertation, human rights and democratization have been the following incarnation of the POW/MIA, a symptom of an underlying refusal on the part of many Americans to accept the historical verdict of the Vietnam War. 


\section{PART III}

\section{US-Vietnam relations 1995 - 2006}

US - Vietnam relations were transformed from confrontation and hostility to dialogue and cooperation after the establishment of diplomatic relations in 1995. However, normalization did not automatically result in normalcy in the relationship. The relationship still remained neither cordial, nor close, nor hostile for the period of normalization despite the strategic interests they found in the relationship with the other, characterized by constant caution and skepticism about each other's intentions, and reluctance from both sides to move ahead for a more fruitful relationship.

Consequently, obstacles remained vivid in US-Vietnam relations after 1995 on various issue areas. In the realm of economic ties, even with diplomatic normalization Vietnam was not accorded "most favored nation" (MFN) status, renamed "permanent normal trade relations" (PNTR) in 1998, and the negotiation for the Bilateral Trade Agreement was the longest and most complicated process in the histories of both the United States and Vietnam. In addition, the approval of the PNTR status for Vietnam encountered significant opposition in US congress, and Hanoi's bilateral WTO accession agreement with Washington was the last - and according to most observers, the most difficult - of the twenty eight bilateral agreements Vietnam completed (Manyin and Cooper 2006: 1), although Vietnam's entry into the WTO did not establish any new obligations on the part of the United States. It was not until the end of December 2006 that PNTR was granted to Vietnam, serving as the official benchmark for normalcy. 
While economic ties gradually obtained a certain progress, security and defense relations between the two countries remained astonishingly modest and symbolic. Together with the remaining differences in perception about human rights and the remaining legacies of the war (the MIA and victims of chemical Agent Orange issues), all contributed to the abnormal and prolonged progress to normalcy.

Major developments of US - Vietnam relations in the period of 1995 - 2006 can be characterized as below:

1. A crippled and incremental progress toward normalcy with great variance in the degree of cooperation across issue areas: considerable progress was made in economic and humanitarian areas in contrast with symbolic and limited cooperation in defense realm.

2. A sharp reorientation of US foreign policy toward Southeast Asia in the aftermaths of September 11, 2001 events that brought about positive change to US-Vietnam relations.

3. Caution and suspicion remained vivid throughout the process.

The following Chapter 5 and Chapter 6 of the dissertation seek to explore the rationale behind the above-mentioned observations of US - Vietnam relations by testing the two competing theories, namely Realism and Ideas and Asymmetry theory, against empirical evidence obtained in the 1995 - 2006 period. Findings from each chapter will be compared and evaluated to measure the validity of each respective theory in the conclusion of the section. 


\section{Chapter 5}

\section{Geopolitical circumstances and the wavy path to normalcy}

Under a realist lens, this chapter examines the strategic constraints and power condition in shaping US-Vietnam relations since the establishment of diplomatic relations in 1995 until full normalcy was reached in 2006. Empirical evidence will be obtained from the normalization process in this period to test the following realist hypotheses for developments of US-Vietnam relationship: Changes in power conditions and national interests caused the transition in US - Vietnam relations, leading to full normalcy. The following assumptions are expected to be observed in the realist lens:

1. Evolving power influences, especially the rise of China, redefined Vietnamese/ US national interests (i.e. security or economic interests), which caused change in relationship, determining the pace and scope of normalization. Since Vietnamese/ and US strategic goals (preferences) in normalization are assumed (by Realism) to be shaped by structural constraints, developments in US-Vietnam relations were their responses to the situation, and the strategic means/instruments to achieve these goals in the normalization process would generally be in the form of balancing (e.g. USVietnam relations improve to balance against China).

2. Defense and economic relations are expected to be of top priority in the relationship and actively promoted. 
The chapter will first examine the evolving power structure, namely the rise of China, and its implication for US-Vietnam relations in security and economic realms. The chapter will then conclude with an overall evaluation of the validity of the realist assumptions under test.

\section{The China factor in US - Vietnam relations}

\section{Implication for the United States}

There were two major developments during the post-Cold War period have far-reaching implications for the future of Asia in general, and US - Vietnam relations in particular: the first was the emergence of the United States as the only superpower, and the second was the stunning surge of Chinese economic growth that has transformed the face of China and forced governments throughout the region to consider what sort of a neighbor a stronger and more prosperous China would be (Roy 2003: 18). The major power shift in favor of China after the end of the Cold War presented a whole set of economic and political challenges to regional countries, and to the United States since China was competing for US preeminent power position, and to Southeast Asia nations including Vietnam since these countries border this rising power.

First, the stunning surge of China's economic growth in the late 1990s and early 2000s was narrowing the disparity in economic power with the United States, and at the same 
time widening gap with regional countries. Chinese growth rates remained spectacularly high at 10 percent between 1980 and 2000 and at 8 to 9 percent after 2000 with its economic engine accounted for around 15 percent of global economic growth in 2004, with exports growing about 30 percent per year and imports growing even faster at about 40 percent per year (Chirathivat 2005: 39).

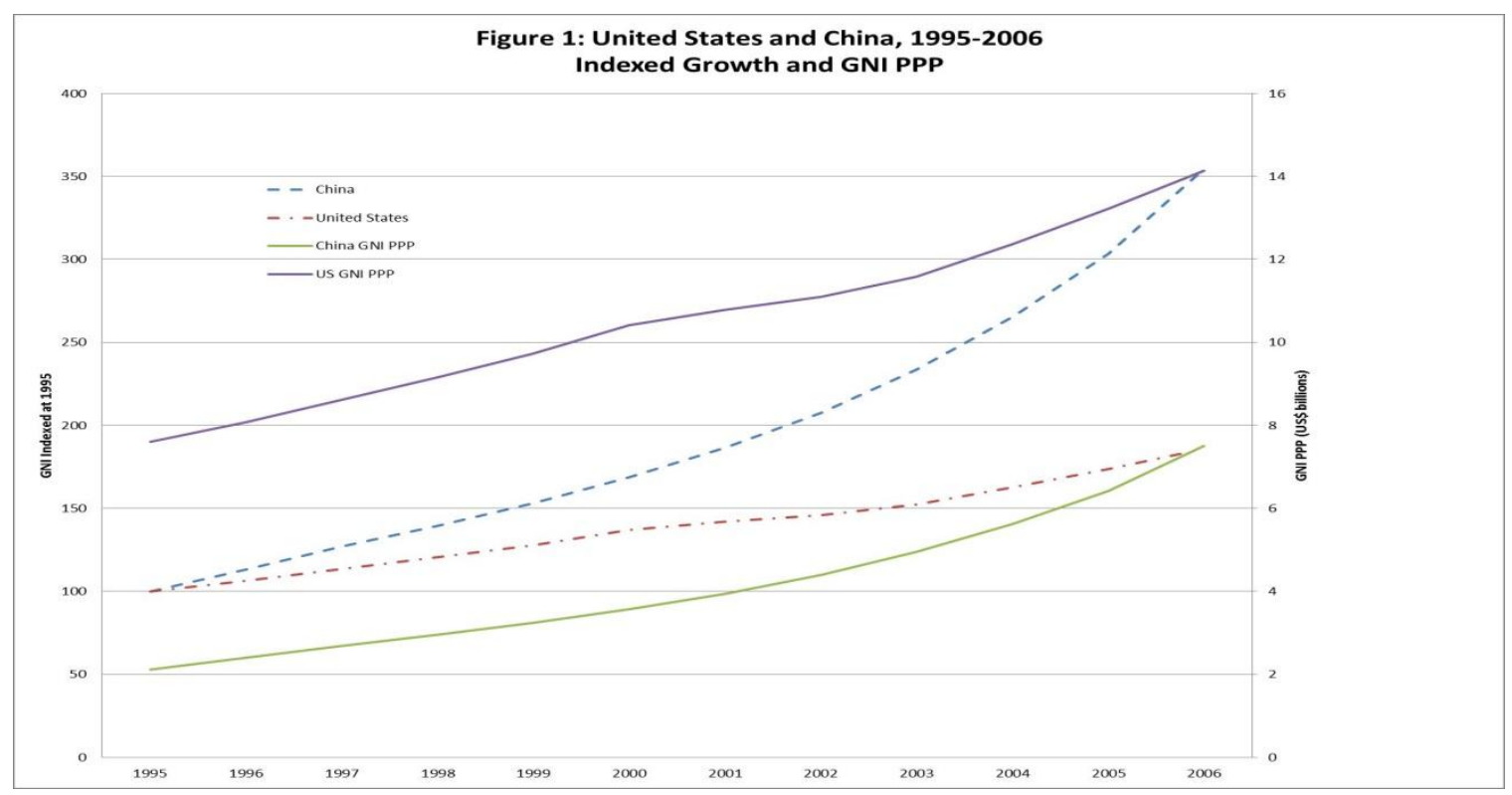

(Source: World Bank, World Development Indicators)

Figure 1 above indicates that China's indexed Gross National Income (GNI) per capita at purchasing power parity (PPP) was closely catching up with that of the United States, leading to its relative decline in comparison with China.

Second, China's growing military strength also caused great concern to the United States and regional countries, as China was perceived to be pursuing hegemony in the region (Mearsheimer 2005). As China's strategic ambition toward Southeast Asia and the South 
China Sea continued to developed, it would produce an inevitable encounter with the established American military presence in the region (Goldstein 2005: 45).

In an annual report on the "Military Power of the People's Republic of China" to the Congress in 2006, the Department of Defense concluded that China was a rapidly expanding military power and "China has the greatest potential to compete militarily with the United States and field disruptive military technologies that could over time offset traditional U.S. military advantages" (Department of Defense, Annual Report to Congress: Military Power of the People's Republic of China, 2006). In the near term, however, China's military build-up appeared focused on planning for Taiwan Strait contingencies, including the possibility of US intervention. The analysis went further to warn that China was acquiring capabilities that could apply to other regional contingencies, such as conflicts over resources or territory. Chinese military expenditure is presented in Figure 2 below. 
Figure 2 - Chinese Military Expenditure 1994 - 2007

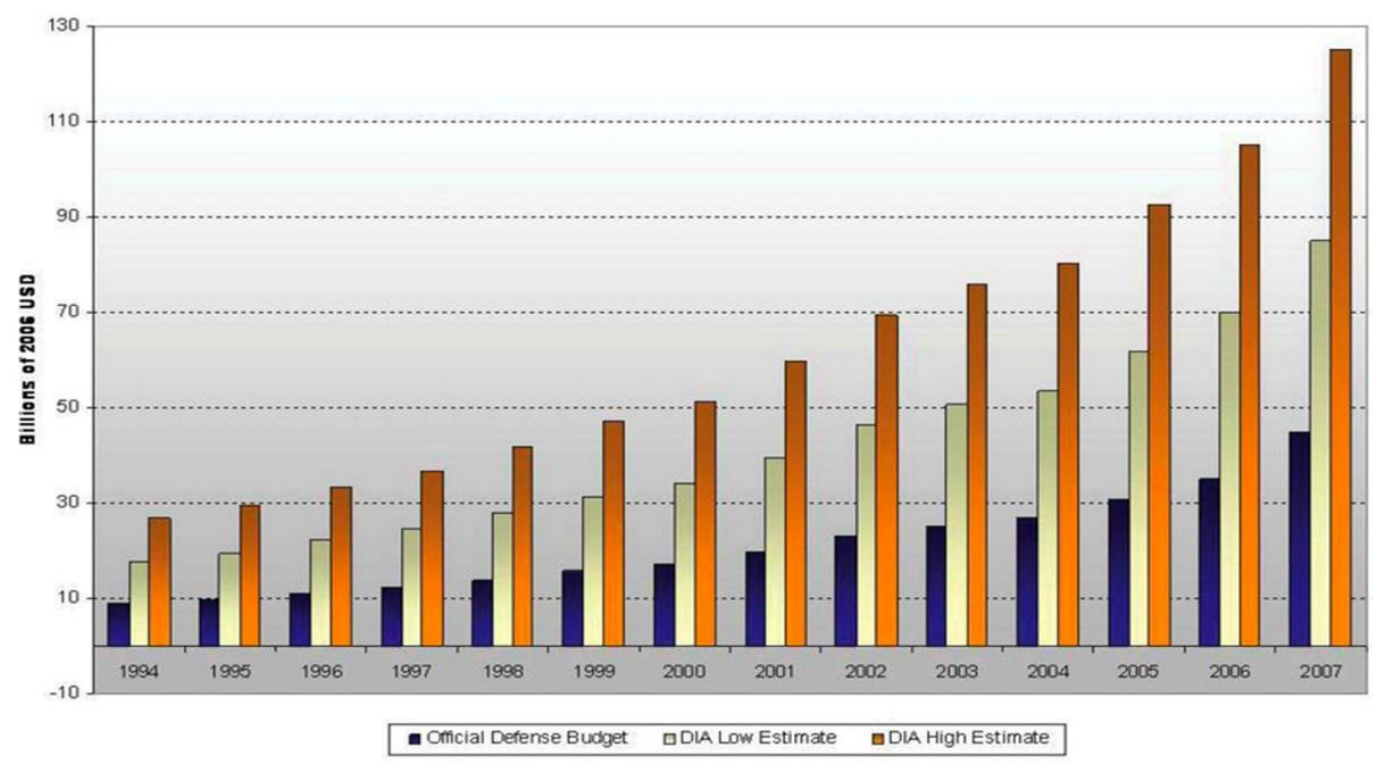

(Source: Department of Defense, Annual Report to Congress: Military Power of the People's Republic of China, 2007).

Lastly, it was the uncertainty of China's future intention that most concerned the United States and regional countries (Mearsheimer 2005), although Chinese leaders attempted to assure the world that the rise of China would be peaceful. From the mid-1990s, China adopted policies to reassure its neighbors with the decision not to devaluate its currency to help stabilize Southeast Asian in the 1997-1998 financial crisis, and embraced multilateralism via its participation in ASEAN post-ministerial meetings, the ARF, and ASEAN $+1 \&$ ASEAN + 3; formed its own security grouping focused on Central Asia the Shanghai Cooperation Organization, and became a central actor in the Six Party Talks dealing with North Korea's nuclear weapons. All of these activities were to demonstrate that China was a responsible nation, and the rise of China would be peaceful as Chinese 
leaders insisted that China "will never be a hegemon, never practice power politics, and never pose a threat to its neighbors or to world peace" (Goldstein 2005: 3). However, China's unprecedented economic growth and embrace of advanced military capabilities, accompanied by China's ambition for the South China Sea and increasing assertiveness in their sovereignty claims over disputed waters, inevitably invited concerns by the United States and other countries.

American concerns about Chinese assertive power were evident in the Taiwan Strait Crisis of 1996 when China deployed military power across the strait that was ready to counter US intervention, leading to serious tension between the two powers. China's placement of missiles opposite Taiwan heightened tension and suspicion, and its unwillingness to disclaim the use of force as a means for resolving its differences with Taiwan was being closely watched by its neighbors and the US as an element in how it would deal with other relationships in the region. In addition, in the wake of the EP-3 spy plane incident with China on April 1, 2001 ${ }^{20}$, the United States became even more concerned about China's muscle flexing. It was the geopolitical challenge that China was posing for the United States (Chanda 2012).

Further added to US concern, the return of Hong Kong and Macau to China by the year 2000 only augmented further Chinese capability to project its military power seaward and southward. Consequently, there was profound reason for the United States to worry about losing its decades-long privilege of access to one of the best and strategically located

\footnotetext{
${ }^{20}$ On April 1, 2001, a collision between the US EP-3 intelligence aircraft and the Chinese J-8 fighter caused the death of a PRC pilot, and the EP-3 was forced to make an emergency landing on Hainan Island. 24 American crew members were detained and interrogated by the Chinese authorities. The incident caused great tension between the United States and China.
} 
harbors in Asia (Pao-min 1999: 140). Taking into consideration of the combined weakness of Southeast Asian countries, Washington apparently calculated that lending a hand to Vietnam would serve both its own national interest and the purpose of regional security (Pao-min 1999: 140).

As a result, the 2001 RAND Corporation report on US strategy and force posture in Asia indicated that the United States should bolster its overall military presence in Asia in response to a rising Chinese power (Khalilzad 2001). The RAND report saw Washington's priorities in Asia as three-fold:

- To prevent the rise of a regional superpower that could undermine the US role in the Asia-Pacific and subsequently pose a global challenge to US predominance.

- To maintain stability and prevent the growth of rivalries and insecurities that could lead to war

- $\quad$ and the United States should manage events so that they would not spiral out of control, and also maintain policies that favor free trade and financial stability (Khalilzad 2001: 186).

In order to achieve these priorities, according to the Report, the United States must not only deepen its bilateral security treaties with South Korea, Japan, and Australia; it must also widen these pacts, possibly to include Singapore, the Philippines, and Thailand so that multilateral partnerships can create militaries that can respond to regional crises in the form of coalitions, and the United States should also consider promote relations with 
other potential partners in the region to enhance US leadership role in the region in face with China's increasing power.

Along this line, according to the Report, "there is an underlying logic to cooperation between the United States and Vietnam to prevent a Chinese bid for regional hegemony", since "Vietnam could provide additional access in Southeast Asia beyond that which Singapore and Thailand offer" (Khalilzad 2001: 186). With inherent concerns about China's increasing power and a new strategy to maintain US influence in the region, the United States therefore had important geopolitical incentive in promote relations with Vietnam.

US progress in developing relations with Vietnam and in the larger Asian regions followed its National Security Strategy issued in 2002, which emphasized the importance of maintaining regional stability through US long-standing alliances and emphasized that forward deployment of forces was a pillar of US policy. The US grand strategy also put priority in developing security dialogue and cooperation with potential new partners, such as Vietnam, and in working with institutions in Asia as ASEAN or APEC. As a result, the United States wanted Vietnam "to be a successful ASEAN member" (Burghardt 2003: 25). Along this line, it is arguable that "there is a strategic rationale that offers potential for a closer and more collaborative relation between the US and Vietnam, which is provided by the rising power of China" (Ott 2001: 34). All of these strategic calculations led to US swift response to Vietnam's peace initiatives in the 1990s after nearly twenty years of stalling and the quick acceptance of Vietnam by international community as a 
whole (Pao-min 1999: 140). It was therefore the geopolitical interest that resulted in American more positive move toward Vietnam.

In addition to the strategic interests in promoting relations with Vietnam, the United States also had economic benefits in moving the relationship forward. Although American economic interests in Vietnam were not as large as in many other regional countries, including China and other individual ASEAN countries, Vietnam was seen as the last potential market in Southeast Asia for its second most populous country in the region with an economy growing at 8.2 percent per annum in the late 1990s. US interests became more substantial since Vietnam was a member of ASEAN since US exports to the ASEAN countries exceeded those to any other region in the world except northeast Asia and western Europe (Bui Thanh Son 1999: 208). Thus, contrary to the Cold War period, the United States had a stake in seeing Vietnam succeed in its economic reforms and become a prosperous country. As US Secretary of Treasure remarked in his visit to Vietnam in April 1997, “the United States believes Vietnam's growth and prosperity, while certainly in Vietnam's interest, is also in our interest" (Bui Thanh Son 1999: 208).

\section{Implications for Vietnam}

The rise of China also had important implications for Vietnam and its policy toward the United States. There are geopolitical and economic reasons for Vietnam to be concerned about the rise of China.

First, it was the tyranny of geography that rendered the Vietnam and China strategic rivals. Geographic proximity and a long history of tension and conflict suggested that 
China remained the enduring centerpiece of Vietnam strategic calculations. Whenever China's economic and military capabilities grew enormously, Beijing's strategic ambition and outreach had expanded proportionately, much of that ambition was directed where it had been over millennia: toward the south (Percival 2007). Located on China's southern border, Vietnam had been a suzerain state of its neighbor for over a thousand years. From roughly $100 \mathrm{BC}$ through the early 15 century, Vietnam was subject to four periods of Chinese suzerainty spanning nearly 900 years. Chinese administrators replaced local nobility and attempted to impose Chinese culture, institutions, and systems on the Vietnamese populace. The legacy of this period was strongly imbued in Vietnamese thinking, as many of the country's historical figures earned their legendary status through their efforts to resist Chinese rule.

More recently, parts of northern Vietnam were briefly occupied by Nationalist Chinese forces under the United Nations mandate at the end of the World War II. Since the People's Republic of China was established in 1949, China had invaded Vietnam three times: China seized a Vietnamese-held island in the Paracels in 1974 by force, launched a massive border war against Vietnam in 1979, and attacked and occupied part of the Spratly Islands - the Johnson Reef - in 1988 which was claimed by Vietnam, killing 64 Vietnamese soldiers. In addition, the long contiguous border between the two countries also facilitated power projection by China into Vietnam. As China grew enormously, the Chinese enjoyed far superior or aggregate power compared to the Vietnamese armed forces, and the fact that Vietnam was traditionally part of a buffer zone for the great continental power resulted in Vietnamese perception that China "would never want a strong and independent Vietnam", all contributed to Vietnam strategic concerns about 
China. It was to the belief of Vietnamese leadership that Vietnam could be secure from China in only two conditions: one was when China was weak and internally divided. The other was when China was being threatened by "barbarians from the north" (referring to the Mongolian - interview data). Therefore, the current rise of Chinese power was perceived by Vietnam as a threat to its security.

Second, the history of conflicts with China consequently resulted in Vietnam's distrust of China's revisionist intention. Such distrust was further exacerbated by the fact that there remained territorial disputes between the two countries over both land and sea borders even after diplomatic relations were established in 1991, and the rival claims to the Paracel and Spratlys islands in the South China Sea (or the East Sea as it is called by Vietnam). Among Vietnam's physical concerns, the security of its land border occupied a special place as it has been the immediate source of major wars in Vietnamese history. This historical pattern was repeated in the Third Indochina Conflict when the existing disputes in Vietnams' northern and southwestern borders acted as catalysts for the wars with China and Cambodia.

In addition, the normalization of Vietnam's relations with China without a resolution to the territorial disputes did suggest that there is potential for tension in the relationship, although Vietnam was willing and determined to manage them through diplomatic channels (the $\mathrm{CPV}$ was determined to pursue dispute management with China by means of negotiations at the time of bilateral normalization in 1991).

Vietnam's diplomatic efforts to secure its border with China began almost immediately after 1991, even though this post-normalization period was plagued with tension 
generated by China's assertive moves in the South China Sea. The first manoeuver that signaled China's post-Cold War determination was the passage of the law on Chinese territorial waters and contiguous areas in February 1992, which incorporated the Paracels, Spratlys, and almost all South China Sea waters into its territory (MOFA 2002: 236). It was followed by a series of small-scale incidents initiated by China in the Spratlys and the sea areas that Vietnam claimed as its continental shelf. In May 1992, China struck a deal with the US petroleum company, the Crestone Energy Corporation, to conduct oil exploration in these disputed areas (MOFA 2002: 239). On the land border, China continued to occupy land areas controlled by Vietnam in the pre-war period. Vietnam found itself in a difficult situation as it shad to respond single-handed to China's assertiveness, almost right after the bilateral normalization it had been making a lot of efforts to bring about. It was not until 1999 that the two countries could come up with an agreement on the demarcation of land borders.

However, while land borders became stable after the 1999 agreement, territorial disputes over the South China Sea remained a complex, problematic and emotional issue between the two countries (Bellacqua 2012). The South China Sea is one of the world's most strategically significant waterways due to its convenience for ships traveling and its potential in natural resources, especially oil. Consequently, the competing territorial claims of China, Vietnam, and other nations in the region have made tensions over the South China Sea the greatest source of instability in Southeast Asia. As Table 2 below 
demonstrates, China and Vietnam are two of the six nations with overlapping territorial claims in the South China Sea ${ }^{21}$ :

Table 2 - Competing Claims over South China Sea

\begin{tabular}{|c|c|c|c|c|}
\hline Country & $\begin{array}{c}\text { Paracel Islands } \\
\text { Claimed }\end{array}$ & $\begin{array}{c}\text { Paracel Islands } \\
\text { Controlled }\end{array}$ & $\begin{array}{c}\text { Spratly Islands } \\
\text { Claimed }\end{array}$ & $\begin{array}{c}\text { Spratly Islands } \\
\text { Occupied }\end{array}$ \\
\hline Vietnam & All & None & All & 29 \\
\hline China & All & All & All & 7 \\
\hline Taiwan & All & None & All & 2 \\
\hline Philippines & None & None & 60 & 8 \\
\hline Malaysia & None & None & 12 & 4 \\
\hline Brunei & None & None & None & None \\
\hline
\end{tabular}

(Source: Adapted from James Bellacqua, "The China Factor in US - Vietnam Relations", CNA China Studies 2012: 14).

The progress on the South China Sea had been modest, often overshadowed by intertwined signs of tension and detent in bilateral relations. This uncertain situation was generated by China's creeping assertiveness, with an aim to altering the status quo in the sea without launching a major war. Vietnam's increasing concern over China's assertiveness was evident in policy debate within the Communist Party. Vietnamese Prime Minister Vo Van Kiet cited China's assertiveness in his report to the Politburo in an attempt to support his position of increased interactions with the United States and ASEAN:

\footnotetext{
${ }^{21}$ The PRC claims sovereignty over the entire South China Sea, including the Spratlys, Paracels, and Pratas Islands; the Macclesfield Bank; much of the Gulf of Tonkin; and the James Shoal off Malaysian Borneo. Vietnam also claims a sizable portion of the South China Sea, including the Paracel and Spratlys islands in their entirety. In addition to territorial claims, these countries also have overlapping disputes regarding EEZ rights and continental shelves as well as the range of permissible activities that can be carried out within these areas. Such disputed activities include the exploitation of natural resources, fishing rights, and military patrols and reconnaissance operations.
} 
News of Chinese presence on the aptly named Mischief Reef had just surfaced setting off alarm bells in many Southeast Asian capitals (CPV 1996).

The dispute became more intensive as China issued the 9-dash-line map that claimed almost all of the South China Sea, despite strong reaction by relevant parties, especially Vietnam and the Philippines. Such unresolved conflict continues to be a source of tension between Vietnam and China, and remains the hotspot for potential confrontation in the region.

Third, it was the economic competition with China that made Vietnam wary of the Chinese increasing power. The Vietnamese perception of the China threat in the late 1990s and early 2000s was bolstered by an increasingly important dimension: economic competition. Vietnam faced the greatest potential challenges from the growing Chinese economy since both countries shared the same comparative advantages on their low labor in the manufacturing sector, and both competed directly for similar sources of foreign direct investment. e.g., since China entered the WTO, Vietnam officials claimed that they lost significant amounts of FDI and suffered the relocation of foreign business to China (Goh 2005: 20). While Sino-Vietnamese trade increased significantly - it doubled from \$ 2.4 billion in 2000 to $\$ 5$ billion in 2004 - Vietnamese officials worried about the trade imbalance. The fact is that China is the top exporter to Vietnam - mainly machinery, agricultural and other production materials, and processed petroleum products - while importing mainly primary products from Vietnam (Goh 2005: 21). 
At the same time, Vietnam had fear of over dependence on China. Vietnamese officials became increasingly concerned that Vietnam's export-oriented economy had become overly dependent on Chinese suppliers for the materials needed in the production of exported commodities. According to Bui Huy Son, director of Asia Pacific trade Policies for Vietnam Ministry of Industry and Trade, 70 percent of Vietnam's imports from China consist of essential materials used in the production of exported goods, including materials and equipment, steel, chemicals, and petroleum as well as fabric, garment, and footwear materials (Pham Huyen 2011). Citing this dependence on Chinese exports, one Vietnamese paper observed that if the "giant who supplies these imports sneezes", it will affect both the domestic economy and Vietnam's exports to the rest of the world ("Overwhelming Trade Deficit with China" - VietnamNet Bridge 27 Dec 2010.

As Vietnam attempted to avoid over dependence on China's economy, it was in the interest of Vietnam to seek for alternative markets to diversify trade exchange, and the United States appeared to be a significantly promising and important one. For Vietnam, normalization and economic ties with the United States were crucial in achieving its most important national objective, which was to modernize and industrialize the economy, set by the Doi moi (Reform) process. The US removal of the embargo in 1994 and the establishment of diplomatic relations between the two countries in 1995 therefore opened a new chapter in US-Vietnam relations and paved the way for potential cooperation.

Given the economic objective of the Doi moi cause, Vietnam was undoubtedly conscious of the US's importance in terms of market, source of investment, capital and technology. The United States became an increasingly important market of Vietnamese exports. From 
2001, after the conclusion of the Vietnam-US bilateral trade agreement, the export value reached $\$ 1.05$ billion (overcoming Australia, Singapore and Taiwan) and in 2002 reached $\$ 2.394$ billion, in 2004 valued at $\$ 5.2$ billion which accounted for almost $20 \%$ of the total export turnover of Vietnam. Currently, Vietnam is one of the thirty largest exporters to the United States, and the United States is one of Vietnam's biggest importers in terms of footwear, textile and garments, seafood, crude oil, cashew nuts, wooden products, handicrafts, coffee and pepper, and in 2006 the US became the biggest trading partner of Vietnam (Vietnam Chamber of Commerce and Industry 2007).

These figures demonstrates that the United States plays a significant role in Vietnam's global integration when the country is opening up to the outside world and mobilizing sources for its cause of modernization and industrialization. Table 4 below reveals the increasing dependency of Vietnam's economy on trade with the United States:

Table 3- Vietnam Trade Relations with the United States

\begin{tabular}{|l|l|l|l|l|}
\hline & $\mathbf{1 9 9 6}$ & $\mathbf{2 0 0 1}$ & $\mathbf{2 0 0 4}$ & $\mathbf{2 0 0 6}$ \\
\hline $\begin{array}{l}\text { Percentage of Vietnam's total exports } \\
\text { going to the US }\end{array}$ & $3.6 \%$ & $7.2 \%$ & $18.8 \%$ & $23.9 \%$ \\
\hline $\begin{array}{l}\text { Vietnam's exports to the US } \\
\text { as a percentage of Vietnamese GDP }\end{array}$ & $1.3 \%$ & $3.3 \%$ & $9.7 \%$ & $11.2 \%$ \\
\hline
\end{tabular}

(Source: The CRS Report: Vietnam PNTR status and WTO accession: Issues and Implications for the United States, July 2006) 
Table 3 above shows that Vietnamese exports to the United States increased significantly in proportion out of its total exports, from 3.6 percent in 1996 rising up to 23.9 percent in 2006, increasingly occupying a relative high proportion of the total GDP of the country.

In addition, the US dominant role in the international economic and financial institutions such as the WTO, IMF, WB...etc..., made the United States loom even larger. The experience of the East Asian economies also evidenced the utmost importance of the US market, capital and technology for these countries' economic successes, creating incentives for Vietnam to promote economic relations with the United States (Bui Thanh Son 1999: 209).

Along this line, Vietnamese Foreign Minister Nguyen Dy Nien acknowledged that:

The growth miracles of the dragonets in East Asia could not have been possible without the cooperation with the United States...Vietnam is well aware of the role and the importance of the United States in regard to regional stability and Vietnam's own economic development and modernization strategy (Nguyen Dy Nien 2003)

The above analysis indicates that the rise of China had important implications for the improvement of US - Vietnam relations since both countries shared geopolitical and economic interests in improved ties. Encountering growing Chinese power and assertiveness in the South China Sea, US - Vietnam relations deepened. President Bill 
Clinton paid an official visit to Vietnam in 2000, being the first US president to visit the country, marking a new height in US-Vietnam relations. The high point in the warming ties came in June 2005 when Vietnamese Prime Minister Phan Van Khai became the first Vietnamese leader to visit Washington. In a joint statement, President Bush and Prime Minister Khai indicated that Vietnam and the United States "shared a vision of peace, prosperity, and security in the Southeast Asia and the Asia - Pacific region, and agreed to cooperate bilaterally and multilaterally to promote these goals" (Joint Statement, June 20, 2005). In a final step in the normalization process, the United States granted PNTR for Vietnam in 2006, serving as the benchmark for normalcy of the relationship.

\section{Normalization: a counter-balance effort against the rise of China?}

However, while the rise of China appeared to serve as the major driving force behind USVietnam cooperation that led to improved ties, it did not necessarily result in the "balance-of-power" efforts in conventional sense by the United States and Vietnam against China. It is observed that the preferred "balance of power" pursued by Southeast Asia countries in general, and by Vietnam in particular, was the preservation of regional equilibrium based on the predominance of the United States, rather than by the formation

of alliance between two or more powers of roughly equal capabilities balancing out one another's strengths (Goh 2005: 36). 
First of all, although the rise of China created great concerns to Vietnam and the United States, it is arguable that a prosperous, stable and cooperative China was to the interests of both countries, as well as regional nations (Lampton 2007: 115).

In terms of economics, the rise of China indeed offers tremendous opportunities for regional economies. Trade and investment links with China were very important for economic development in regional countries. In this regard, China was increasingly seen as "the new engine of growth for the region, replacing Japan" (Le Linh Lan 2005: 79). In fact, ASEAN was China's fifth largest trading partner (reaching 8.2\%) in 2001 and China was the sixth-largest trading partner of the predominantly export-oriented economies of ASEAN. China-ASEAN trade was valued at $\$ 55$ billion in 2002 . It was valued at $\$ 78$ billion in 2003 and reached $\$ 120$ billion in 2005 (Sutter 2003: 78). As a result, a booming trade relationship and expectations that China's economic growth would continue to contribute to the prosperity of regional countries have moderated resentment over competition for foreign direct investment and export markets in developed countries (Sutter 2003: 78). Being a part of ASEAN, especially in the current period of opening up to the outside world, Vietnam recognized the determining role that China played in regional development, stability, and security. As Vietnam required regional stability in order to facilitate crucial processes of reform and development, it therefore undoubtedly saw the benefits of China's steady growth.

In addition, Vietnam was constrained by reluctance to provoke or alienate Beijing because of the deep awareness of Vietnam's relative weakness. Vietnam needed to 
pursue friendship and cooperation with China because the same factors that contributed to the China threat also made stable Sino-Vietnamese relations critical for Hanoi.

For the United States, a stable and prosperous China also served American interests. As its fourth largest partner and the source of the largest US trade deficit (more than $\$ 100$ million in 2002, \$726 million in 2005), China's economy was important even for the United States. The fact is that U.S. importers were increasingly reliant on China, with almost 11 percent of US imports coming from China. In 2002, Chinese imports grew faster than overall US imports, at a growth rate of 22 percent. Furthermore, China was also a fast-growing US export market with exports of goods to China grew by 31.7 percent in 2006. US exports to China in 2006 were greater than US exports to India, Brazil and France combined (Department of Commerce, "Export Fact Sheet 02/13/07”).

In addition, China's emergence as a global economic power with increased economic, diplomatic and cultural influence in Southeast Asia did not necessarily signal the beginning of zero-sum competition between the United States and China in the region. In fact, China's increasing influence in the region and the Sino-centric order in Asia that China established appeared not to be marginalizing the United States, since regional countries continued to feel reluctant to "move under China's sway" due to their mistrust of China's future intentions and uncertain outlook and therefore sought to sustain contentious relations with the United States, being the "least distrusted power" in Southeast Asia with no territorial or other ambitions directly at odds with regional countries' interests (Sutter 2008: 91-106). 
Furthermore, given the American preoccupation with the war on terrorism, Iraq and the North Korean nuclear issue in the post 9/11 event, the United States had greater interests in consolidating relations and avoiding tension with China.

The United States and Vietnam therefore did not have strong incentive to "hard balance" against the rise of China. In fact, Vietnam, like most key states in the region, faced complex pressures with regard to China's growing role and did not perceive themselves as having the stark choices of either balancing against or bandwagoning with this powerful neighbor, but adopted a twin strategy of deep engagement with China on the one hand and "soft balancing" against potential Chinese aggression or disruption of the status quo on the other hand (Womack 2004: 167). This method is referred to as a "hedging" strategy in which the United States played a crucial role (Goh 2005) ${ }^{22}$.

According to Goh, hedging strategy by Vietnam comprised two elements: first was indirect or soft balancing, which mainly involved persuading other major powers, particularly the United States, to act as counterweights to Chinese regional influence. Second, Vietnamese hedging entailed complex engagement of China at the political, economic, and strategic levels with the hope that Chinese leaders may be persuaded or socialized into conduct that abides by international rules and norms. In this sense, engagement policy was interpreted as a constructive hedge against potentially aggressive Chinese domination (Goh 2005: 35). Along this line, the United States also found its interests compatible with this strategy by Vietnam and other Southeast Asian countries,

\footnotetext{
${ }^{22}$ Hedging, as defined by Goh, is a set of strategies aimed at avoiding (or planning for contingencies in) a situation in which states cannot decide upon more straightforward alternatives such as balancing, bandwagoning, or neutrality. Instead, they cultivate a middle position that forestalls or avoids having to choose one side at the obvious expense of another.
} 
since regional hedging helped maintain US influence and leadership role in the region, and at the same time created a constraint on the rise of China.

As a result, US - Vietnam, given the special importance of China in Vietnam's external relations, the burden of Chinese sensitivity was expected to put limit on the pace and scope of US-Vietnam relations: Hanoi could only develop relations with the US "at a pace consonant with relations with China" - meaning that it would tend to lag behind developments with China. Such concerns of provoking China by both the United States, and especially by Vietnam, resulted in the slow and reluctant progress in various issue areas, most noticeably military-to-military cooperation.

\section{Military ties and the incremental path to normalcy:}

Following the establishment of diplomatic relations with Vietnam in July 1995, American military officials saw a high level of strategic value in promoting defense relation with Vietnam (Khalilzad 2001: 186). US defense policy makers, area specialists and analysts were prepared to argue that Vietnam would see the value of a defense relationship with the US in terms of the potential security insurance such as link could offer Vietnam in its relationship with China. US strategic thinking about Vietnam was essentially confined to discussions of the China card (or Vietnam's “America Card” (Stern 2005: 241).

In US strategic calculation, cementing a military relationship with Vietnam was the most effective way to offset China's influence in the area and a policy decision to develop ties 
with the Vietnamese military would launch the United States in the direction of solving future access issues given the US government's continuing interests in regional stability, alliances with some ASEAN members, and Vietnam's new membership in ASEAN (Stern 2005: 241). As a result, the United States made initiatives for promoting military ties by exchange of working teams and high ranking military official visits, as well as ship visits and training.

However, US enthusiasm in promoting military relations was contrasted with Vietnam's reluctance to move forward for fear of provoking China. Vietnamese military leadership firmly believed that the most strategically consequential relationship for Vietnam was its links with China, and that the Sino-Vietnamese relationship should not be jeopardized by any suggestion that Hanoi was receptive to anything beyond symbolic steps toward normal military relations with the United States. Vietnamese foreign policy of having a balanced relations with both powers was stated consistently in many important documents of the Communist Party of Vietnam, emphasizing that "Vietnam should not conduct action that might be seen as leaning to one side against the other in our relations with the superpowers" (CPV 1996: 80). As a result of Vietnam's cautious step for not upsetting China, Vietnamese Ministry of National Defense (MND) went to great lengths to insure that Beijing understood Hanoi's views regarding the relationship with the United States, and that China was fully informed about all interactions between Vietnamese MND and the US Department of Defense (Stern 2005: 224).

The motivations behind the MND's reluctance to press ahead with US proposals for onthe-ground practical engagement in training, humanitarian cooperation, and high level 
visits were profound, in some instances emotional was the belief by Vietnam that moving ahead with the US in defense relations would be met with a negative reaction in Beijing (Jordan, Stern and Lohman 2012).

As a result, Vietnam refused US proposal for a ship visit in 1997 even when the event was configured in the most benign shape, revolving around a small vessel landing an extremely small number of visitors with a humanitarian mission. (Stern 2005: 128). It appeared that the Vietnamese was not nearly as enamored of the idea of a US naval vessel calling at a Vietnamese port and these was sufficient reason to believe the Vietnamese would see a ship visit as a one sided event which would leave the US with the bulk of the dividends and put Vietnam in the position of having to explain why US warships were steaming into Vietnamese territorial waters.

US-Vietnam military cooperation, as a result, seemed to cease. Not until 1999 did the relationship start to warm up with a mutual plan for US Secretary of Defense William Cohen to visit Vietnam as an attempt to promote bilateral defense relations. However, in the aftermath of the US bombing of Chinese embassy in Belgrade, Vietnam decided to postpone the visit for concern of being perceived by China that Vietnam was leaning to the United States amidst Sino-US tension (Nguyen Hoang Giap 2005: 35; Kenney 2002: 93, 121-23; Stern 2005: 199). As a result, the visit was rescheduled for 2000.

Vietnam's reticence in being seen as a US ally against China was further evident in March 2000 during the visit by Secretary of Defense William Cohen, being the first cabinet official to visit Vietnam, when Hanoi went out of its way to announce that there was no talk of strategic ties (Chanda 2012). 
In further efforts by the United States to enhance defense ties with Vietnam, the prospect of closer military ties between the United States and Vietnam, including a possible return to Cam Ranh Bay, was discussed in a 2001 RAND cooperation report on US strategy and force posture in Asia. The report pointed out that over the long term, "Vietnam could provide additional access in Southeast Asia beyond that which Singapore and Thailand offer" (Khalilzad 2001: 186). However, the US proposal to use the Cam Ranh Bay of Vietnam had always been strongly rejected and each time the United States expressed an interest in the Bay, the Vietnamese government downplayed the issue. Apart from the obvious political and historical sensitivities, Vietnam would risk provoking China's indignation if it ever came to an agreement with the United States over naval access to the facility since "such an agreement would simply reinforce China's fears that it was the target of a US-led containment strategy", and as a result, "Sino-Vietnamese relations would inevitably suffer" (Storey and Thayer 200: 467).

Between 2000 and 2004 the United States continued to make efforts to modestly expand the scope and pace of defense engagement with Vietnam (Jordan, Stern and Lohman 2012: 4), but it was not until 2003 that US-Vietnam military ties appeared to be warmer followed by the visit of Vietnamese Minister of Defense Pham Van Tra, being the first Vietnamese defense minister to visit the United States. Vietnam only decided to press forward on bilateral initiatives with the United States when there appeared to be no strategic consequences for doing so: it was the US-China significantly improved relations between the United States and China in the early 2000s, especially after the 9/11 event followed by US attempt to seek closer ties with China in the fight against terrorism. 
Despite success of the visit as a symbol of increased military cooperation, Vietnamese Ministry of Defense continued to make sure that its commitment to enhanced military engagement was not perceived as a tilt in overall foreign policy objectives toward a onesided reliance on a single friendship (Jordan, Stern and Lohman 2012: 5).

In summary, the extreme reluctance and caution to move forward in military-to-military cooperation with the United States by Vietnam was due to Vietnamese concern about provoking China and damaging Vietnamese - Sino relationship, which was deemed vital to Vietnam's security given its relative weakness and a long history of dealing with a troublesome neighbor. Vietnam therefore was forced to deal with its heritage as a Chinese vassal state in a way that was marked by deep pragmatism and the dark shadow of very asymmetrical power. Lewis Stern, a senior US military official of the Department of Defense who specialized in military ties with Vietnam, observed that:

It is fair to say that, though the Vietnamese were slow to make up their minds concerning what they wanted from a bilateral defense relationship with the US, they were quicker to acknowledge what they did not want: they did not want a full-blown partnership, and they did not want much in the way of direct practical cooperation. They wanted the minimum necessary to keep the US interested in interaction, without allowing the relationship to approach the point of strategic relevance (Stern 2005: 225).

For the United States, despite strategic incentives to promote defense relations with Vietnam, Washington shared some level of common concern of provoking China. The Pentagon understood that the China dimension would always be a variable in policy calculation regarding Vietnam, but felt that the US-Vietnam defense relationship should 
be pursued in a manner that explicitly ruled out efforts to develop military contacts with PAVN as a means of coping with Chinese behavior in the region. As a result, US Department of Defense believed it was critical that the US side refrain from depicting the military relationship as a hedge against the advantages that China might derive from a closer relationship with Vietnam.

The strategic interests and calculation by both Vietnam and the United States with regard to China therefore determined the pace and scope of US-Vietnam defense relations, led to the incremental path toward a more fruitful relationship.

\section{Conclusion}

The above analysis indicates that Realism provides a convincing explanation for USVietnam relations in the $1995-2006$ period when it appears that developments in the bilateral relations seem to rigidly follow realist logic: it was the strategic circumstances and evolving power structure of the Asia-Pacific region in post-Cold War era that brought about significant improvement in US-Vietnam relations that eventually led to normalcy. Empirical evidence obtained from this period does confirm that it was the geopolitical incentives by the United States and Vietnam in the face of a rising China that brought the two countries closer together: China's accelerated economic growth, increasing economic footprint, global search for natural resources, and rapid pace of military modernization created a wide range of new challenges for decision-makers in Hanoi and Washington and important implications for US-Vietnam relations. 
While the rise of China did not necessarily result in the formation of a counter-balancing alliance between the United States and Vietnam, it did serve as the glue that bound the two countries closer. For the United States, it was the geopolitical and economic challenge China was posing that induced American improved relations with Vietnam and other regional countries. For Vietnam, it was the security challenge the powerful neighbor created that invited Vietnam's moving forward to the United States.

The realist logic also provides a profound explanation for why US - Vietnam defense relations remained astonishingly modest and symbolic throughout the period and Vietnamese extreme reluctance and caution to enhance military ties with the United States because the same factors that contributed to the China threat made stable SinoVietnamese relations critical for Vietnam, and being aware of its relative weaknesses to China, Viet had to restrain from making any moves that might provoke China.

However, there are still puzzles in the process of normalization of US-Vietnam relations in the 1995-2006 period that remain inadequately answered by Realism. While bilateral defense relations somehow followed realist prediction, Realism found it hard to explain the extremely prolonged process for economic normalization despite the fact that both countries shared significant interests in promoting economic ties and the strategic circumstances were favorable: the overwhelmingly rough process of negotiation for Bilateral Trade Agreement and Normal Permanent Trade Relations for Vietnam was much longer and complicated than a realist logic could gauge; and the constant skepticism and caution by instigated by both sides in moving the relationship forward in all issue areas, not to mention security. 
The following section of the dissertation, Chapter 6, will test the validity of the alternative explanation for these puzzles by exploring the impact that ideas and power asymmetry cast on US-Vietnam relations in the 1995-2006 period. 


\section{Chapter 6}

\section{"Peaceful Evolution" and the war mentality: a final push to normalcy}

This chapter aims to test the validity of the following hypotheses by Ideas and Asymmetry Theory in explaining US-Vietnam final episode of the normalization process:

1) The change (and continuity) of ideas in US and Vietnam's thinking determined the making of their normalization policy and the interaction of these policy preferences led to the gradual progress to full normalcy in the relationship.

2) Such interaction might result in less desirable outcomes in the normalization process due to the different interest and expectations generated by the huge disparity of capacities between the two countries.

The chapter will start by identifying the ideas under test. It will then test the abovementioned hypotheses against empirical evidence obtained in two major areas of cooperation in US-Vietnam relations in the post-normalization period of $1995-2006$, namely security and economic relations. The chapter will conclude with an overall evaluation of the validity of the hypotheses on the role of ideas and asymmetry.

\section{Consolidation of new ideas and Vietnam's perception of the United States Ideas and Asymmetry and the threat of "Peaceful Evolution":}

As discussed in earlier chapters of the dissertation, under Doi Moi that was promoted since 1986, the Vietnamese government launched a comprehensive reform in ideas that led to the fundamental shift in its foreign policy orientation from separationist to 
integrationist. The new idea had directly contributed to an open door foreign policy and to a historic shift from dependency on the socialist states' system to full participation in the global economy. Such new integrationist ideas in Vietnam's thinking continued its momentum into the post - Cold War era and had important impact on Vietnam-US relations in the $1995-2006$ period.

With the prevalence of new reform ideas, Vietnam's identification of friends and enemies as a result shifted significantly. As Doi Moi proceeded, the orthodox classification of friends and enemies based on class struggles was replaced with a policy line of "befriending every country", as acknowledged by Vietnamese Deputy Foreign Minister Tran Quang Co:

States strive to expand their external relations, regardless of different sociopolitical systems and different objects, and work with anyone capable of cooperating efficiently (Tran Quang Co 1992: 12)

As a result, the specification of friends and enemies, as well as of forms and levels of relationships, became very flexible. Authoritatively, the $8^{\text {th }}$ Plenum of 2003 replaced the concepts of "friends" (bạn) and "enemies" (thù) with "partners" (đối tác) and "objects of struggle" (đối tượng), and a set of principles for identifying đối tác and đối tượng:

Those who respect the independence and sovereignty establish and expand the friendship and cooperation of equality and mutual benefits with Vietnam should all be our partners. Any forces plotting or carrying out hostile activities against our goals of construction and defense of the Fatherland should all be our object of 
struggle. However, given the rapidly evolving and complicated current situation, it is necessary to adopt a dialectical perspective: in each object of struggle there are aspects we still need to win the support and cooperation; in some partners, there could be some aspects that are different from and contradictory to our interests (Central Committee Ideological and Cultural Commission 2007:101).

The concept of Đối tác and Đối tượng explained the complex perception of opportunities and threats by the CPV after the Cold War. This could mean that no country was considered hostile to Vietnam (or at least to Vietnam's total security), especially with regard to China and the United States (CPV 1996: 119). The new identification also underlined the guideline of "befriending every country", which could mean the pursuit of "international obligations" not based on the "three revolutionary currents", but on the common values shared by "all nations in the world community, striving for peace, independence and development (CPV 1996: 120).

First, it was the new perception of opportunities that resulted in changes in Vietnamese foreign policy. Vietnamese leaders characterized the contemporary international relations in terms of the "five trends" that brought about new opportunities for the country:

- Peace, stability and cooperation for development are becoming an increasingly pressing need of the nations and countries of the world. All countries are giving priority to economic development, considering it of decisive significance for the increasing of their national aggregate strength.

- Nations, large or small, have taken part in growing numbers in the process of regional and international cooperation and integration in economy, trade and 
other fields of activities. Cooperation is intensifying, but competition is also no less sharp.

- Nations have heightened their sense of independence, sovereignty, selfreliance and self-resilience, struggling against any imposition and intervention from outside to prevent their national independence, sovereignty and culture.

- The socialist countries, the communist and worker's parties, and the revolutionary and progressive forces in the world are preserving in their struggle for peace, national independence, democracy and social progress.

- Countries with different socio-political systems interact through mutual cooperation and struggle in peaceful coexistence (CPV 1996: 77-78).

The characterization of contemporary international relations in terms of the "five trends" therefore radically replaced the "three revolutionary currents" that dominated Vietnam's Cold War thinking. According to the CPV, peace and cooperation were the salient trends of the world in post-Cold War era, which was the least hostile environment Vietnam had ever experienced in its long history, and therefore created precious opportunities for development. The struggles of the revolutionary forces against imperialism still continued to persist, but political adversaries could now cooperate and struggle in peaceful coexistence (CPV 1998). This was also the premise for the setting of Vietnam's strategic guideline of "cooperation and struggle" (hợp tác và đấu tranh) in its relations with every partner, especially with former enemies including China and the United States. Such guidelines were further validated in the $8^{\text {th }}$ Plenum (IX Tenure) of July 2003 as a major principle for diplomatic identification (CPV 2003: 54). 
Second, together with a new perception of opportunities as mentioned above, the evolution of Doi Moi also resulted in a change in Vietnam's perception of threats. In Vietnam's thinking, threat can be conceived as either the capability or intention of a state or agent in the environment to do hard to the realization of one's goals; the forms of threat could be numerous, ranging from military to economic to cultural ones; and the referent objects whose security is threatened can be a state's territory, its regime or society, etc... (CPV 2007: 192). Vietnam's perception of threat progressed into the 1990s with several modifications, consistent with its update of national goals. Vietnam's postCold War formal articulation of threats first appeared in the CPV's Midterm National Congress of January 1994, including four major threats:

1) the danger of our economy falling further behind many countries in the region and the world due to our low starting point;

2) the danger of derailment from socialism unless we overcome the incorrectness in supplying guidance to policy implementation;

3) corruption and other social vices;

4) and "peaceful evolution" plots and activities by hostile forces (CPV 1994: 192)

In short, the threats included: underdevelopment, deviation from socialism, corruption and "peaceful evolution" (CPV 1994: 192). Such threats were further confirmed in the CPV's VI Congress in 1996 (CPV 1997).

By definition, "peaceful evolution" is a term used to describe the strategy used by imperialism to undermine socialism in Eastern Europe and the Soviet Union (Thayer 
1999: 14). In Vietnam's interpretation, "Peaceful evolution" was a defined threat to its national security (or regime security) ${ }^{23}$, which had both internal and external dimensions of threat. As the nature of this imperialist strategy was conceptualized as "peaceful", counter-measures should also involve non-violent ones. Therefore, apart from other domestic measures, Vietnam designated diplomacy to cope with "peaceful evolution" issues in the international arena. Although the external dimension of "peaceful evolution" did not officially refer to any specific country, the CPV implicitly targeted the United States as the source of threat, or the "hostile forces". This threat perception stems not only from the US power superiority but also from the psychology of the American war and the collapse of European communism at the end of the Cold War. In the mind of the CPV, "peaceful evolution" was equated to a US threat to Vietnamese security (Thayer 1999: 14).

As a result, in Vietnam's new ideas, the United States presented both opportunity and threat to Vietnam, and consequently perceived both as a "partner" (đối tác) and an “object of struggle" (đối tượng) for policy making under the guideline of "cooperation and struggle” (hợp tác và đấu tranh). This explains why US-Vietnam relations were more fruitful in some certain issue areas (i.e. economics) but significantly limited in others (e.g. defense and security).

\footnotetext{
${ }^{23}$ The Vietnamese conception of "national security" was broadened to embrace regime security and ideologicalcultural safety. As defined by the 2004 Law on National Security, "national security" is "the stability and durable development of the socialist regime and the Socialist Republic of Vietnam. The inviolability of the independence, sovereignty, unity and territorial integrity of the Fatherland", and "national security infringement activities" are ones that harm "the political regime, economic regime, culture, security, defense, external relations, independence, sovereignty, unity and territorial integrity of the Socialist Republic of Vietnam (Thung 2005). This socialist conception of national security therefore explains why "peaceful evolution" was designated as a security threat.
} 
Being "partners" (đối tác) for cooperation since diplomatic relations were established in 1995, Vietnam and the United States made significant achievements in economic and humanitarian cooperation. In the 2000s, the United States became Vietnam's largest export market with an export turn-over of almost 6 billion USD in 2005 (Bui Thanh Son 1999: 209). Vietnam-US security cooperation was also expanding, albeit at a very modest speed. Interestingly, as Doi Moi proceeded, the CPV was willing to befriend an "object of struggle" that used to be its erstwhile enemy. While Vietnam-US cooperation seemed to be driven by shared material interests, it was therefore the evolution in Vietnam's socialist identity as a result of new thinking that made it possible.

On the other hand, Vietnam's perception of the United States as the source of "peaceful evolution" threat, and therefore the "object of struggle", had important implications for its America policy and US-Vietnam relations in the 1995-2006 period where the two countries struggled through hurdles to reach to normalcy. The following sections will explore the impact of such perception on the development of US-Vietnam relations across various issue areas.

\section{Peaceful Evolution and its impact on US-Vietnam relations}

Vietnamese concerns about the "peaceful evolution" campaign led by the United States resulted in great caution and skepticism in Vietnam's perception about the United States. The caution and skepticism became even more embedded in Vietnam's idea when US President Clinton, in his speech on the day of establishment of diplomatic relations on 
July $11^{\text {th }}$ in 1995 , made it explicit that there was an ulterior motive of the United States in normalizing relations with Vietnam as "normalization and increased contact between Americans and Vietnamese will advance the cause of freedom in Vietnam, just as it did in the Eastern Europe and the former Soviet Union"

In fact, the theme that Vietnam was threatened by "peaceful evolution" had been a constant refrain by Vietnam's ideological conservatives from the collapse of the Soviet Union to the present (Thayer 1999: 16). Many in Hanoi "see the collapse of the Soviet Union and the Warsaw Bloc as validating the lethality of the presumed American conspiracy against Vietnam". The skepticism, which was generated by the ideology factor, becomes even more embedded in Vietnam's foreign policy idea toward the United States due to the bloody war the two countries had experienced, and decades of hostility and confrontation in which the latter was considered the first enemy (Palmujoki 1999).

Consequently, soon after US-Vietnam normalized diplomatic relations in 1995, the Vietnamese conservatives in the CPV drafted a ten-page document entitled "American Strategies to transform Socialist Vietnam after normalization of US-Vietnam relations" to the Politburo. It argued that membership in ASEAN and normalization with the US, far from diplomatic victories, were part of the clever new US strategy of selective economic development to undermine Vietnam Communist Party rule by encouraging the development of diplomatic forces. The conservative memos argued:

\footnotetext{
${ }^{24}$ Speech by Bill Clinton, Normalization with Vietnam (Washington DC: White House, Office of the Press Secretary, 1995).
} 
America will push not only for economic freedom but also political freedom. America will urge Vietnam to discard communism...(which) will be replaced by foreign investors and capitalists businesses (Nguyen Hoang Giap 2005: 42).

The document also warned that US investment was designed to dominate the Vietnamese market and the United States would seek out and support reformist elements in the party. Consequently, "hardly any decision concerning relations with the United States can be made without great caution and sensitivity" (Brandon 2004: 10). Such Vietnamese caution and skepticism of the US intention was evident in developments of US-Vietnam relations throughout the period, contributed to the prolonged and rough process to normalcy.

\section{Military-to-military cooperation}

Following normalization, one of the US major interests in promoting defense relations with Vietnam was to continue to push for Vietnamese efforts in searching for American MIAs (Nguyen Hoang Giap 2005). As the United States continued to put pressure on Vietnam to cooperate in MIAs despite the fact that Vietnam had reiterated that it had done its best to satisfy the American demands during the process leading to normalization and there was not much that Vietnam could do since fullest possible accounting had been made, and at the same time the United States did not promote economic ties with Vietnam as expected, Vietnamese leaders were frustrated with American sluggishness. Vietnam's military had clearly grown uncomfortable with the manner in which the 
POW/MIA issue continued to be the featured, center-stage priority in the bilateral relationship with the US. Vietnamese military demonstrated that "it was prepared to urge a blunt, zero-sum approach to the question of US willingness to proceed with normalization in a measured way", and was convinced that insidious political reasons were the only credible explanation of why Washington was not moving with dispatch toward a completely normal and proper relationship (Stern 2005: 105).

In an open frustration, the Vietnamese military's daily newspaper published an article in March 1996 that was critical of the US POW/MIA excessive demands, alleging that Washington had used this effort to collect intelligence against Vietnamese targets, deploying the POW/MIA apparatus as a means of spying in Vietnam (Stern 2005: 107).

Embedded with deep skepticism of US intention, and the frustration that Vietnam had its own MIAs issue that remained unsolved, the Vietnamese Ministry of Foreign Affairs faced much criticism for Vietnam's failure to take its own MIA issue seriously, a view that had been spoken by members of the National Assembly, veterans groups, and military units with increasing regularity since 1995 . It was also hard to the Ministry to convince provincial officials, National Assembly delegates and party leaders that staying in the course would add up to real dividends in the bilateral relationship with the United States (Interview data) while at the same time it had to be responsive to the American requests for access to archives to archives, an increased operational tempo for field activities, and more direct contact with witnesses to serve the goal of improving bilateral relations, accelerating to access to international financial resources, and jump starting the process of negotiating a trade agreement. 
Being the key actor on behalf of Vietnam in promoting military-to-military ties with the United states, the Ministry of Defense embraced the argument that Washington was intent on destabilizing Hanoi, and that the US supported all manner of insidious schemes hatched by expatriate organizations to accomplish that goal. From the start of the normalization process, the Defense Ministry's thinking about relations with Washington remained focused on the POW/MIA issue. The MND's involvement in this issue was, by 1994, profound, and its memory of politically consequential aspects of the issue was acute. Senior military officers, while recognizing their government's commitment to be helpful to the US, considered this issue as one-sided, uncomfortable obligation that grated on their nerves, insulted their country, and neglected their own "humanitarian" problems stemming from the war. With such a negative view of US intentions that emerged from this sentiment, the Vietnamese military was not prepared to look at Washington as a potentially reliable friend or partner (Jordan, Stern and Lohman 2012; Stern 2005: 223)

In addition, Vietnam's caution and reluctance to move forward military ties with the United States was further consolidated by the observation that the United States was stressing human right issues and supported democratization in its policy toward Myanmar, a neighboring country in Southeast Asia who bears some similarity with Vietnam in the sense that it was under authoritarian regime, and thus worried about American peaceful evolution as well.

As a result, there was little evidence that Vietnam was eager in military cooperation in the first 12 months after diplomatic relations was established in 1995. Through mid-1996, the Vietnamese continued to hope that the process of normalization would somehow 
result in a more clear-cut end stage to the POW/MIA issue. In mid-1996, Vietnamese officials charged with working level responsibilities regarding the POW/MIA issue were actively posing questions about steps that might be taken jointly to reduce the expenditure of funds and energy involved in joint field work without diminishing the intensity of commitment to the fullest possible accounting (Stern 2005: 107).

It was not until late 1996 did Vietnam turn its attention to the possibility of a military relationship after the visit to Hanoi by Deputy Assistant Secretary of Defense Kurt Campbell. There were some meetings at low level between officials of the two defense institutions to discuss the prospect for defense cooperation, but they turned out to be unfruitful due to different approach to the issue by both sides and the suspicion that remained vivid. As Lewis Stern observed:

Hanoi would not gain security assurances from this link, and should not suggest that the Socialist Republic was at all invested in the possibility of security cooperation with the United States.

Consequently, recognition of basic similarities in regional security views, and shared defense concerns, could not be parleyed into a meaningful relationship. From the perspective of Vietnam, "such a relationship could not prosper as long as Washington wielded the cudgels that were America's major foreign policy tools - including human rights, labor standards, market access, intellectual property rights practices, and counterproliferation policies" (Stern 2012). 
Such mentality and different interests and expectations from both sides resulted in a very slow progress in military cooperation, especially at the beginning period of $1997-1998$. As a result, in 1997, Vietnam rejected US proposal for a ship visit despite the fact that the event were configured in the most benign shape, revolving around a small vessel landing an extremely small number of visitors with a humanitarian mission. While the rejection of US proposal for a ship visit in 1997 might be interpreted partially as Vietnam's concern about China's sensitivity over US-Vietnam potential military alliance, such extreme reluctance to move forward even in symbolic manner and the unnecessarily chilling attitude to Americans indicated a Vietnam's deep mistrust of the United States.

Vietnamese cautious manner in moving along with the United States in military relations was also evident in bilateral dialogues on regional and bilateral defense and security issues when "a somewhat lopsided exchange, with the American side providing detailed rundowns on current issues, and policies, and the Vietnamese side articulating predictable boilerplate, leaving little room for discussion" (Stern 2005: 198).

In addition, the majority of Vietnamese officers who came into contact with the US Defense Department officials in the context of efforts to develop military-to-military contacts were skeptical of the stated US intention to develop a modest relationship, suspicious of the agenda for working level meetings, and decidedly unfriendly in contacts with American officials: their demeanor indicated that they were less likely to believe that the shared wartime history would equip the two countries to cope with tensions and enable the two sides to agree on a practical approach to establishing normal defense relations. Officers with this back group were bitter, mistrustful, uncooperative and 
generally unhelpful (Stern 2005: 237). Some were intensely interested in extracting some indication of US regret for wartime "wrongdoings", and fixed their attention on manipulating humanitarian issues, such as the Vietnamese MIA problem or the consequences of the use of the Agent Orange during the war, to position the US for humiliation (Stern 2005: 237).

Vietnam's convenient postponement of the planned visit by US Secretary of Defense William Cohen in 1999 was another example demonstrating Vietnam's cautious manner in working with the United States in defense realm. It was not because Vietnam did not have strategic interests in promoting defense relations with the United States. It was, however, the mistrust of US intention due to historical factor and the idea that the United States was implementing "peaceful evolution" against Vietnam that hindered Vietnam from moving forward (Interview data).

It was not until 2000 was Secretary William Cohen welcome to visit Vietnam, and 2003 did Vietnamese Minister of Defense Pham Van Tra pay a visit to the United States, being the first Vietnam defense minister to visit America. The fact that the United States has still maintained an embargo on exporting lethal weapons to Vietnam indicate that both sides were not ready to completely put the past behind.

\section{Human rights issue}

In CPV discourse, "human rights" was the chief instrument employed by "hostile forces" in the implementation of "peaceful evolution" strategy toward Vietnam after the Cold War. As human rights should be conditioned by specific economic regimes and cultural 
traditions, undue emphasis on human rights may be detrimental to the rights of the nation-state. For the CPV, human rights must be subject to state sovereignty, and domestic or foreign criticisms of Vietnam's human rights were seen as attempts to undermine its state sovereignty. Hence, Vietnamese diplomacy was applied to defend the CPV regime against human rights pressure from these forces, first and foremost the United States.

In the post-Cold War period, Vietnamese diplomacy concerning human rights has evolved from a reactive to proactive posture. While Vietnam was puzzled by human rights attacks right after the Cold War, it was prepared to cope with this kind of challenge by the end of the century. It no longer just stays on the defensive about its human rights records, but utilizes human rights diplomacy to protect the regime in the international arena. As confirmed by the Xth Congress:

To proactively participate in the common struggle for human rights; To stand ready for dialogues with concerned countries, international and regional organizations on human rights issues; To be determined to foil all plots and attempts to distort and abuse "democracy", "human rights", "ethnicity", and “religion' issues expecting to intervene into the internal affairs, infringing Vietnam's independence, sovereignty, territorial integrity, security, and political stability (CPV 2006: 133).

Since human rights remained an important issue and one of the main obstacles in the process of normalization of relations between Vietnam and the United States, on one hand Vietnam criticized America of using human right issue as excuse to intervene into 
Vietnam's internal affairs, but on the other hand attempted to settle the issue to pave the way for normalization (Interview data). As a result, dialogue with the US concerning human rights started since 1993. Notably, these dialogues were started even before the lifting of US economic embargo in 1994 and establishment of diplomatic relations 1995 (CRS Report 2005). These dialogues were coordinated with Vietnam's lobbying within the US political system for a favorable US attitude toward its human rights profile. In its lobbying, Vietnam tended to emphasize common security and economic interests between the two countries, as against excessive focus on human rights. In other words, Vietnam tried to delink human rights from other issues and minimize the impact of human rights on the entire relationship (CRS Report 2005).

To Vietnam's further frustration, however, there remained sharp differences in each country's perception of human rights. The United States chose not to hold a human rights dialogue with Vietnam in 2003 and 2004, and in September 2004 designated Vietnam as a "country of particular concern" (CPC) in the State Department's International Religious Freedom Report (Manyin 2007: 15). Not until November 2006 did the State Department announce that because of "many positive steps" taken by the Vietnamese government since 2004 , the country was no longer a "severe violator of religious freedom" and therefore had been removed from the CPC list (Manyin 2007: 16). The human rights issue, associated with American plot of "peaceful evolution" in Vietnam's perception, therefore remained a hurdle that had negative impact on the bilateral relationship. 


\section{The war mentality -Continuity of old ideas and US Vietnam trade relations}

US-Vietnam relations have long been shadowed by the legacy of one of the bloodiest wards in the $20^{\text {th }}$ century. While it is undeniable that cooperation to solve the problems of the past, notably the MIA/POW issues and the US's cooperation with Vietnam to clear the remaining unexploded ordinances, has been a positive factor for bilateral relations, "the burden of the past still lingers US's policy making towards Vietnam in the period to come" (Le Linh Lan 2005: 79). The effect of this burden may even be reinforced by the US domestic politics. In fact, the American war in Vietnam remains not only "emotional", but also a "divisive" one in America (Manyin 2003: 28). Such American memories are expected to have significant impact on various issue areas of the relationship, even in trade relations given the huge disparity of economic capacities between the two countries.

\section{The Jackson-Vanik Amendment}

In Congress, with the annual review of the extension of the Jackson-Vanik waiver, one can still hear voices against normalization and improvement of relations with Vietnam (Cooper 2006: 7). The so-called "Jackson-Vanik Amendment" was a law passed by US Congress as part of the Trade Act of 1974 as US reaction to the severe restrictions the Soviet Union had placed in the late 1972 on the emigration of its citizens, but was expanded in its scope to apply to all so-called "non-market" economies (Pregelj 2005: 14). The Amendment barred non-market economies from receiving Permanent Normal Trade Relations (PNTR) status. Due to the Amendment, Vietnam had remained ineligible for any of the eight rounds of tariff cuts the US had made in the decades since World War 
II. By the 1990s, this led to a remarkable disadvantage. Vietnam's goods faced tariffs averaging about 40 percent, while most of the world faced a tariff of about 2.5 percent (Gresser 2003: 66).

The Jackson-Vanik law required two things in tern for a grant of PNTR: first, a certification by the US government of freedom of emigration rights - which requires a waiver that must be renewed periodically; and second, conclusion and congressional approval of a bilateral trade agreement. However, Vietnam appeared to be the last country in the list of those under such law to receive the waiver, and opposition in Congress for the waiver remained constantly high despite diplomatic recognition.

Table 4 below indicates that among 30 countries that are subject to the Jackson Vanik Amendment, Vietnam was the last one to receive the waiver in $19988^{25}$ (except Cuba and North Korea which has not been granted yet) and the waiver had to be reviewed every year for consideration of extension. It is noted that China received the waiver since 1979, and most other former communist countries received the waivers in the early 1990s.

Table 4 - Country Application of the Jackson-Vanik Amendment

\begin{tabular}{|c|l|}
\hline Year of Waiver & Countries \\
\hline 1975 & Romania \\
\hline 1978 & Hungary \\
\hline 1979 & China \\
\hline 1990 & Czechoslovakia, East Germany, Estonia, Latvia, Lithuania \\
\hline 1991 & Bulgaria, Mongolia \\
\hline 1992 & $\begin{array}{l}\text { Albania, Armenia, Azerbaijan, Belarus, Georgia, Kazakhstan, } \\
\text { Kyrgyzstan, Moldova, Russia, Tajikistan, Turkmenistan, Ukraine, } \\
\text { Uzbekistan. }\end{array}$ \\
\hline 1998 & Vietnam \\
\hline
\end{tabular}

${ }^{25}$ China was also a communist country but the waiver was considered right after normalization. The list excludes Cuba and North Korea because these countries do not have formal diplomatic relations with the United States, thus were not in the list of countries subject to the waiver. 
(Source: CRS Report for Congress, The Jackson-Vanik Amendment: A survey, August 2005)

In addition, the waiver for Vietnam seemed to be even more extremely delayed in comparison with Laos and Cambodia (who somehow shared with Vietnam a similar history of war with the United States, and who were subject to the 1951 suspension of the most-favored nation status and its restoration arguably could have been subject to the Jackson Vanik amendment) who had such status restored directly and unconditionally, without prior recourse to the Title VI procedure and with no reference to it in their implementing laws (Pregelj 2005: 14).

In fact, the Jackson-Vanik requirements had been viewed by many of the countries that were subject to them as an outdated legacy of the Cold War when US foreign policy was designed to limit Soviet influence, and trade policy was subservient to those foreign policy objectives. However, despite its outdated validity, the requirements were still applied to Vietnam by the US government.

In addition, Figure 4 below indicates that although the number of votes against the approval of the resolution tended to decrease as Vietnam-US relations were improving during the period, it is noticed that the against votes remained relatively consistent and high throughout the years. This indicates that negative attitude toward normalization and improvement of relations with Vietnam still vividly exists in American thinking. "Though this opposition group is not homogenous in nature, part of these opposing voices has to do with the burden of the past" (Nguyen Hoang Giap 2005: 43). 


\section{Figure 4- House Votes on Vietnam's Jackson-Vanik Waiver 1998-2002}

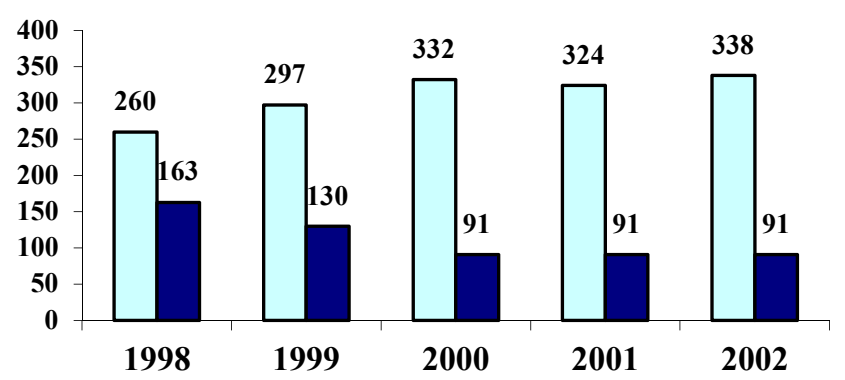

口Support Waiver (Votes vs. Disapproval Resolution)

-Oppose Waiver (Votes for Disapproval Resolution)

(Source: CRS Report for Congress: US-Vietnam relations: background and Issues for Congress, September 28, 2007). (It is noted that after 2002, as the Bilateral Trade Agreement with Vietnam went into effect, the US Congress did not continue to consider the issue).

\section{The rough road to Bilateral Trade Agreement (BTA) and the "Catfish" issue}

The negotiation for BTA, which was of strong interest for both the United States and Vietnam, turned out to be one of the toughest and longest process in history of trade relations of both countries, and the most complex of all the tasks involving in full normalization (Gresser 2003: 68). From the first negotiation mission in 1995 through the signature of July 2000 , the negotiation took nearly twice as long as those for North American Free Trade Agreements (NAFTA) (Nguyen Van Long 2003: 73). The negotiation process for BTA was deemed to be unusually longer than other bilateral trade agreements that the United States had with other countries because of three reasons: 
- First, the inclusion in the debate of the Vietnamese-American community association; military veterans of the Vietnam War and national veterans organizations such as the Veterans of Foreign Wars and American Legion, and family members of American MIAs in Vietnam and Laos. Such large set of participant was wider than earlier trade agreements that the United States had.

- Second, the Vietnam War had been a formative experience for many of the administration's senior political and foreign policy officials. For these people, normalization with Vietnam had an emotional significance that earlier trade agreement lacked.

- Third, for the White House political staff in the Clinton Administration, the president's opposition to the Vietnam War during the 1960s and early 1970s raised political concern about potential exploitation of the BTA by Republican Party (Gresser 2003: 67).

Such a broad scope of participants, whose mentality of the Vietnam War deemed vivid, led to lengthy debates on trade issues with Vietnam, inevitably with strong opposing voice. There were clearly domestic politics reasons for the inclusion of these Vietnam War -related groups, for BTA was considered an important step in war reconciliation. However, the fact that the negotiation process prolonged much more than that of other normal bilateral trades indicate that the war mentality was still embedded in American thinking.

However, the conclusion of BTA did not result in smooth normal trade relations between the two countries when a small trade dispute turned out to be big hurdle for bilateral 
relationship, among which the "catfish" issue was most notable one, generating irritants in US-Vietnam trade relations during the 1995-2006 period.

In July 2003, the US International Trade Commission (ITC) ruled in favor of the Catfish Farmers of America that the importation of Vietnamese catfish had caused losses to the US producers, and subsequently the US imposed higher tariffs on imported catfish of 37 to 64 percent (Brandon 2004: 10). Before this ruling, catfish import duties were just 5 percent. Consequently Vietnamese catfish exports to the US totaled just \$20 million in 2003, down from $\$ 55$ million in 2002 (Brandon 2004: 10), causing huge losses to Vietnamese farmers. Vietnam products were then forced to be labeled as "Tra" or "Basa" instead of the real name "Catfish" then subject to the rule of ITC for "dumping" the price that caused disadvantage for American farmers.

Such decision by the ITC, deemed unfair by Vietnam Ministry of Trade, provoked strong opposition by Vietnam. Vietnamese public media widely stated that the catfish decision, which followed "parochial interests", was not compatible with free trade or WTO spirit since Vietnamese catfish occupied only 10 percent of the US market. The unfair decision by ITC had hurt 400,000 people in the Vietnamese agricultural sector (Nhan Dan Daily September 2003). The media went on to criticize US intention behind such act:

Both countries must recognize the political aspects of economic change. The US habitually advises Vietnam to be pragmatic and to accept realities - but nothing will be resolved if the US administration "does not confront its own demons". Given the catfish "dumping" decision, how does Vietnam know that other 
products will not be treated similarly? If export-led investment is focused heavily on the US market, Vietnam's economy can be destabilized by such experience or other loop holes in American law.

According to Vietnamese policy makers, this was not only about trade, but it was about how the big economy trying to dominate the small one (Interview data). The "catfish" incident therefore was no longer a normal trade dispute (which is very common and inevitable in international bilateral relationships), but a political issue that halted the normalization progress (Nguyen Van Long 2005: 50).

\section{PNTR and Vietnam's accession to the WTO}

Ideas and perceptions therefore significantly matter in US-Vietnam relations, and the issues of Jackson-Vanik, BTA or "catfish" dipute were not the only examples of how negative attitudes hindered the relationship. The Congressional debate over the approval of the PNTR status for Vietnam proved to be another evidence of the impact of perception on US Vietnam policy.

PNTR status was very important for bilateral trade relations between Vietnam and the United States. It was considered the benchmark of economic normalization of the two countries. In fact, the United States had strong incentives in approving PNTR for Vietnam and promoting the latter's accession to WTO (Manyin 2007: 13). Although PNTR and WTO accession for Vietnam had much less significance for the United States than it did for Vietnam given the small share in US trade (0.3\%) that Vietnam occupied. 
However, the twin issues could be considered as steps in fulfilling broader US trade and foreign policy objectives.

First, in trade area, PNTR status for Vietnam was consistent with the policy of the US government to normalize trade relations with former adversaries (Cooper 2005). In addition, Vietnam's accession to the WTO could help the US manage its trading relationship with Vietnam in that Vietnam would be obligated to WTO rules thus providing some discipline in the relationship.

In addition to the strategic interests in promoting relations with Vietnam, the United States also had economic benefits in moving the relationship forward. Although American economic interests in Vietnam were not as large as in many other regional countries, including China and other individual ASEAN countries, Vietnam was seen as the last potential market in Southeast Asia for its second most populous country in the region with an economy growing at 8.2 percent per annum in the late 1990s. US interests became more substantial since Vietnam was a member of ASEAN since US exports to the ASEAN countries exceeded those to any other region in the world except northeast Asia and western Europe (Bui Thanh Son 1999: 208).

Furthermore, for the US to get full benefit of Vietnam's membership in WTO, the US Congress must vote in favor of granting Vietnam PNTR because "without Vietnam PNTR, US companies are put at a tremendous disadvantage" as all of Vietnam's WTO commitments will not be automatically extended to the US. The Congressional Budget Office estimates that Vietnam's PNTR would increase US revenues by \$18 million in 
2007, by 108 million over the 2007-2011 period, and by 253 million over the 2007-2016 period (Cooper 2006: 7).

Beside economic benefits, the United States also had political interests in granting PNTR and accession to WTO for Vietnam. The approval of PNTR for Vietnam and support for Vietnam's WTO accession were seen by US policy makers as tools to meet certain foreign policy objectives: They can serve important tools for the United States to expand cooperation with a country that has an ambivalent relationship with China, and WTO membership was believed to be an important means to promote increased pluralism, accountability, and adherence to the "rule of law" in Vietnam's political system. In addition, as President Bush was scheduled to attend the November 2006 Asia Pacific Economic Cooperation (APEC) summit in Hanoi, the administration would use this as meaningful gift to Vietnam (Manyin, Cooper and Gelb 2006: 16).

However, despite the significant benefits for the United States to approve PNTR for Vietnam, the process of approving the resolution encountered great obstacles in the Congress. On June 13, 2006, companion bills - S.3495 (Baucus) and H.R. 5602 (Ramstad) - authorizing permanent normal trade relations (PNTR) for Vietnam were introduced in the Senate and the House. On November 13, 2006, under suspension of the rules, the House voted 228-161 (Roll no.519) in favor of H.R.5602, short of the twothirds vote necessary for passage. Following the vote, House leaders reportedly had hoped to push for a vote - apparently under a rule limiting amendments - on November 15, but abandoned their efforts due to strong opposition to the move (Cooper 2006: 8). The opposition, as observed by Cooper, mainly came from those who maintained negative attitude toward improving relations with Vietnam. Only after President Bush's 
return from Hanoi was PNTR passed on the last day of the Congressional session in December 2006.

The failure to approve PNTR early despite the strategic interests that the United States would have obtained therefore serves as another example of how vividly the opposition to normalization remains in US policy making to Vietnam.

\section{Conclusion}

Findings of Chapter 6 have confirmed that ideas and asymmetry of power had a significant role in shaping the final episode of the normalization process of US-Vietnam relations. Empirical evidence obtained from various issue areas clearly indicate that Vietnam's perception of the United States as a threat of "peaceful evolution" led to the constant skepticism and reluctance in moving forward to normalcy of relations with the United States, whereas US old thinking of the war mentality proves to be the driving force behind American sluggishness and under-attentiveness to Vietnam's concerns in the relationship.

On the other hand, the fear of "peaceful evolution" loomed larger given the huge disparity of capacities that inherently existed between the two countries. This explained Vietnam's over-attentiveness and caution in developing relations with the United States. Accompanied by the war mentality embedded on both sides, it explained why military ties became such a sensitive issue and how a small dispute could cast huge impact on the 
pace of normalization since it was interpreted as a bullying action of the stronger side to the weaker. All of these contributed to the slow and incremental path to normalcy that the United States and Vietnam went through in the 1995-2006 period. 


\section{CONCLUSION FOR PART III}

Part III of the dissertation has explored the final episode in the process of normalization of US-Vietnam relations since the establishment of diplomatic relations in 1995 to the approval of the Permanent Normal Trade Relations for Vietnam that served as the benchmark for normalcy of the relationship. Using the logics of the two competing theories: Realism versus Ideas and Asymmetry, Part III has sought to answer an important research question for understanding US-Vietnam normalization process: why it took so long and bumpy for the two countries to come from initial normalization to normalcy during which cooperation in major areas remained astonishingly limited despite their strong interests to move faster.

Similar to Part I and Part II of the dissertation, the two competing logics have been utilized to explain the same set of events and developments in US-Vietnam relations of the 1995-2006 period: the extreme caution and reluctance from both sides to move forward to normalization in this asymmetric relationship in two main issue areas: defense and economic relations. Findings of each chapter have been compared to determine which theory scores more weight in their explanatory power.

By examining the strategic contexts and geopolitical constraints of the post-Cold War Asia-Pacific region, realism offers a very convincing account for why Vietnam and the United States came closer to each other as power transition occurred in favor of China, and why they moved slowly and cautiously in the path to a sensitive issue area: security cooperation. Under a realist lens, it was the sensitivity not to provoke China that restrained Vietnam from promoting closer military ties with the United States. Empirical 
evidence obtained in Chapter 5 appears to confirm realist prediction for US-Vietnam relations: although there was no obvious counter-balancing effort was made against the rise of China, the "smiling dragon" proved to be the key factor that brought Vietnam and the United States closer.

However, Realism appears to fall short in explaining why Vietnam was over-sensitive and cautious in moving toward the United States in military cooperation even when it was only at symbolic level. Realism also finds it puzzling in addressing the slow and incremental process of economic normalization between Vietnam and the United States leading to outcomes that were less desirable for both: the prolonged negotiation for BTA and approval of PNTR turned out to be going against each country's strategic interests.

On the other hand, findings from the tests in Chapter 6 have strongly confirmed the validity of Idea and Asymmetry theory in explaining the same events in US-Vietnam relations of the 1995-2006 period that Realism has attempted to do, but failed to offer adequate explanation as indicated in Chapter 5. Empirical evidence of US-Vietnam relations in the final stage of normalization does reveal that ideas (as perception of peaceful evolution threat and the war mentality) play a significant role in driving the normalization policy of each country. Furthermore, the impact of ideas was further exacerbated by the huge disparity of power between the two countries: "peaceful evolution" threat appeared to have loomed larger for the weaker side, whereas resentment seems to embed more permanently in the stronger side's mind, given the special history between the two. Such perception generated over caution and skepticism in such a sensitive realm as security relations that cannot be adequately accounted for by Realism. 
Power asymmetry also generated different interests and expectations from each side that led to circle of misperception when one action by one side could be wrongly interpreted by the other, as the "catfish" incident and the prolonged negotiation process for BTA, PNTR and Vietnam's accession to the WTO have confirmed.

It is also an interesting finding that the war mentality still appears to play an important role in US-Vietnam relations even at their final stage of normalization, thirty-six years after the end of the war. Although the US-Vietnam war has become far less an impediment to advancing bilateral ties with the passage of time, it still has the potential to play a role in bilateral relations, since there are still legacies of the war that remained unsolved, such as the issue of victims of the chemical Agent Orange, which will likely continue to affect US-Vietnam future relations. 


\section{CONCLUSION}

The dissertation has sought to explain the central puzzle in US-Vietnam post-war relations: why it took so long for Vietnam and the United States to normalize relations with each other. By applying congruence and process tracing methods, the dissertation has tested the validity of two competing theoretical approaches as alternative explanations for the normalization process: Realism versus Ideas and Asymmetry theory. Hypotheses based on these alternative theories were tested again empirical evidence obtained from US-Vietnam relations throughout the normalization process that consists of three different periods: 1975 - 1986, 1986 - 1995 and $1995-2006$.

Findings from six chapters of the dissertation analyzing the normalization process reveal that Realism has offered a relatively convincing explanation for the prolonged and rough path to normalization that Vietnam and the United States have gone through. By examining the evolving power situation and strategic constraints of the Cold War that governed foreign policies of Vietnam and the United States, realist approach could convincingly explain why there was no hope for normalization of relations in the late 1970s and 1980s: it was the US rapprochement with China in the context of open confrontation between Vietnam and China, and the invasion and occupation of Cambodia by Vietnam, together with Vietnam's taking side with the Soviet Union, all of which put the United States and Vietnam at confrontation line.

Realism could also provide sound explanation for the developments of US-Vietnam relations in the changing of strategic context after the Cold War ended and for why the United States and Vietnam eventually normalized relations with each other: it was the 
urgent need for Vietnam to break through isolation in face of enormous challenges generated from both severe internal economic crisis and external security concerns caused by the evolving developments that led to the end of the Cold War that led to its adaptation of foreign policy that favored normalization with the United States; and it was the strategic calculations and geo-political and economic interests of the United States in Southeast Asia in general, and in Vietnam in particular, that led to the gradual shift in its Vietnam policy toward normalized relationship. By examining the geopolitical context of East Asia in post - Cold War era, given the rise of China and the changing power structure in the region, realist approach also offers a sound explanation for why the United States and Vietnam eventually reached to normalcy in their relationship after traveling a long path.

However, findings of the dissertation also reveal that by only looking at the "big picture" and assuming state's preferences as their responses to strategic environment, Realism has failed to explain major puzzles in the normalization process. Empirical evidence proves that there were events that did not follow the "logic of consequences" that Realist predicts and anomalies that remained inadequately explained by a realist logic.

First of all, realism falls short in explaining the failed attempt for normalization in a short period of 1977 - 1978 when both Vietnam and the United States were proved to have strong preference for normalization and a window of opportunity was open to them when the strategic contexts were indeed favorable for normalization, as indicated in first chapters of the dissertation. Realism also find it puzzling in observing the United States and Vietnam stubbornly stuck to their own terms up to the point that eventually spoiled 
the possibility of establishing diplomatic relations. US sluggishness and moving the goalposts by veering out of its own roadmap that was designed by itself as conditions for Vietnam to meet, and the maintenance of the embargo against Vietnam even when it proved to be counter-productive, all appear to be contradicting with realist assumptions. Realism finds itself even more puzzling amidst evidence obtained in US-Vietnam relations after diplomatic relations were established: the path to normalcy was painfully slow and rough despite the strategic interests the two countries found in promoting bilateral ties: negotiation for Bilateral Trade Agreement (BTA) and Permanent Normal Trade Relations were the longest and most complicated one in the history of each country, and small trade disputes (i.e. the catfish issue), which are deemed common in any other normal trade relationships in international relations, appeared to be astonishingly severe in US-Vietnam relations that went against mutual interests for both, and there appeared to be a greater variance in degree of cooperation across issue areas than one would expect in a normal relationship when defense relations remained symbolic.

In short, analysis of empirical evidence throughout the chapters appear to indicate that if events in US-Vietnam relations had rigidly followed realist logic, normalization should have happened earlier and the path to normalcy would have been smoother than the actual outcomes observed in the relationship. By only examining the constraints that the two countries faced and taking their preferences for granted, Realism as a result has not offered a complete explanation for US-Vietnam relations. 
On the other hand, findings of the dissertation appear to confirm hypotheses of Ideas and Asymmetry theory by revealing the impact that the change (and continuity) of ideas and the constraints of the structure generated by power disparity had on development of USVietnam normalization process. Ideas and Asymmetry theory attempted to go beyond realist logic to explore how preferences of the two parties were formed under the impact of ideas - being the beliefs about effective means for achieving interests and the war mentality that still vividly exists on both sides - and the actual process of interaction between these preferences under the constraints generated by the disparity of capacities between the two countries. The combination of ideas and power asymmetry appear to adequately explain the anomalies in the normalization process that remained unanswered by Realism.

First, empirical evidence indicates that the continuity of "old idea" - the war mentality that vividly exists in the minds of both countries, given the fact that the stronger side in this asymmetric relationship was ironically not the winner in the war, had important impact on the normalization process that cannot be reduced to strategic circumstances. Evidence of US-Vietnam relations in the 1975-1986 period reveals the rationale behind the stubborn insistence by both sides to stick to their terms for normalization: while denying moral responsibility for the war, the United States did not share Vietnam's long range perspective and Vietnam, on its part, underestimated America's deep psychological war wounds as Vietnam was too proud to a victor to forgo the spoils of war reconstruction aids promised by the US in the Paris peace accord of 1973. As a result, the attempt for an early normalization ultimately failed due to the sharp difference in perception and expectation from both side despite their preferences for normalization and 
the favorable context of 1977-1978 that opened a window of opportunity for them. The idea that "Vietnam is a war, not a country", or "the United States is the principal and permanent enemy of Vietnam", that was even written in the 1980 Constitution of Vietnam, appeared to be embedded in both American and Vietnamese thinking in their interaction, leading to the most hostile and confrontational period in the history of USVietnam post-war relations. Once institutionalized, ideas produced clearer causal impact since they played a role in generalizing rules and guidance for the policy making process (Goldstein \& Keohane 1993: 20-23)

The impact of ideas and power asymmetry also prove to be evident in the process leading to normalization in the 1986-1995 period: the normalization talks with the United States were bogged down by unending American demands for accounting of their POW/MIAs. The conservatives in the administration and the military, who never forgave Vietnam for America's national humiliation, sought to restore the country's honor by bringing home the remains of fallen soldiers and maintaining a crippling trade embargo imposed since 1975, and to dictate the rules of the normalization game with Vietnam in which moving the goalposts and politics of inattention was evident of American sluggishness. As the empirical chapters have demonstrated, American moving the goalposts for normalization appeared to have gone beyond the point that they could serve as leverage to press for Vietnam cooperation on POW/MIAs issue and became counter-effective to American interests as the United States persistently continued to maintain the embargo and blockage on Vietnam even after it proved to be no longer valid, since many other countries, including US major allies, had already moved ahead of the United States in promoting business with Vietnam without American blessings. 
As Chapter 4 indicates, from the Vietnamese perspective, American sluggishness in moving forward and at the same time raising conditions and pressing for Vietnamese cooperation in searching for MIAs was perceived as US intention to weaken Vietnamese revolutionary cause. The mentality was exacerbated further by the fact the Vietnam had its own MIAs issue too that had not been solved, and American requests made Vietnamese leadership feel they were the defeated in the war if they were to accept the US commands, all resulted in a deeper suspicion on US plot for "peaceful evolution" to transform Vietnam. American incremental approach in negotiation for BTA and PNTR and a vividly strong opposition to normalization in US congress further fostered Vietnam's suspicion of US intention and this explains the over-sensitiveness and frustration by Vietnam about US action, and the skepticism that occupied Vietnamese perception of the United States, as presented in Chapter 6 of the dissertation. The significantly slow response of the United States to Vietnamese normalization overtures is also explained by the fact that the relationship simply was not important enough to the United States to merit the diplomatic rethinking and political reorientation that normalization would require due to the asymmetric nature of the relationship. Ideas and power asymmetry therefore provide a convincing account for the incremental path to normalization that the two countries took.

On the other hand, while the embedded old thinking in American and Vietnamese mind contributed to the slow pace of normalization, the dramatic shift in foreign policy orientation as a result of Doi Moi in Vietnam in which Vietnam changed its perception of the United States, and the sharp change in American foreign policy ideas in the aftermaths of the events of September 11, 2001, all prove to have contributed to the 
maintenance of momentum for the normalization process. It was the interaction of the old ideas and new ideas and the preferences that they formed that attributed to the ups and downs in the normalization process, as the six empirical chapters of the dissertation have demonstrated. New ideas resulted in Vietnamese shift in perception of the United States from "the principal and permanent enemy" to "a partner" of cooperation, and new American thinking indicated that "Vietnam was no longer a war, but a country", as illustrated in Part III of the dissertation. Such new ideas resulted in the gradual, but positive, steps toward normalization of US-Vietnam relations.

In short, findings of the dissertation have positively confirmed the role of ideas and asymmetry in shaping the process of normalization of relations between Vietnam and the United States. In testing the hypotheses of Ideas and Asymmetry theory against evidence, the impact of ideas and power asymmetry were confirmed when there is the existence of empirical anomalies that can be resolved only when these factors are taken into account. While ideas help explain the formation of preferences by each party, the asymmetric nature of the relationship determines how these preferences interact with each other to bring about the observed outcomes in the relationship: the prolonged and bumpy process toward normalcy in US-Vietnam relations. This is, however, not to refute that Realism does not have any account in explaining US-Vietnam relations. As indicated throughout the empirical chapters, to some extents, events in the normalization process did follow the realist logic as the strategic context and geopolitical circumstances proved to be important driving force behind the process. It is, however, the lack of attention to the actual process of interaction of preferences that has hindered Realism from providing a 
complete picture for US-Vietnam relations, for which Ideas and Asymmetry theory do a better job.

\section{Limitations and suggestions for further research:}

The most noticeable limitation of this study, as acknowledged in the introduction of the dissertation, is the fact that the dissertation restricts itself in only exploring the impact of ideas (continuity and change) on the dependent variable of the research question: the slow pace (speed) of the normalization process. The dissertation could not go further in comprehensively identifying the source of these ideas in both Vietnam and the United States, which is important in understanding how ideas, in its own transformation, have their influence on foreign policies of the two countries. Instead, the study only concentrates on exploring how the evolution of ideas as a product of their interaction affects the bilateral relationship. With a large scope of research that covers three different periods in the normalization process, it might be too ambitious for the dissertation to explore the source of these ideas. However, the lack of description on where these ideas come from does present a limitation of the dissertation. The sources of these ideas will therefore be a potential land for further future research.

Secondly, like many other research that seeks to study the role of ideas, the dissertation has to cope with a methodological issue of how it can measure such inherently elusive variables as dominant ideas, expectations and perceptions, since they are difficult to assess and seemingly more flexible and subject to change than other material factors. Being aware of the danger to assume a causal connection between ideas held by policy- 
makers and policy choices, the dissertation has developed a framework of analysis that allows testing hypotheses on the role of ideas and asymmetry against both empirical evidence and alternative explanation to find out the anomalies that can be explained only when ideas and asymmetry are taken into consideration. However, since it is methodologically challenging to identify the delineation between the existence of particular beliefs and the establishment of their effects on policy, there might have been intervening variables that affect both ideas and outcomes that have not been clearly identified by the dissertation.

Third, although Ideas and Asymmetry Theory has great application and potential in explaining international relations as dyadic asymmetric relationships are undoubtedly common, the conclusion of the dissertation may have some limitation in its generalization, since the particular case being tested is somehow unique, given the special history between the United States and Vietnam. However, this does not affect the overall validity of the dissertation, since its main purpose is to explain US-Vietnam relations in particular.

\section{Implications for US-Vietnam relations}

Given the special characteristics of the US-Vietnam relations, and based on the findings of the research, several implications for future bilateral relations can be made:

Firstly, it is important that greater efforts must be directed toward reducing mutual distrust and enhancing mutual confidence between the two countries. This is particularly important given the historical baggage in the US-Vietnam relationship. Concrete steps 
such as more frequent high level visits, people to people contacts, education exchange should be done to promote understanding between the two countries. In addition, it is necessary to achieve a level of confidence through increased transparency in each country's policy-making process as it relates to bilateral agreement to minimize misperception. In other words, each side needs to understand the other better and be confident enough in their ability to appraise the situation and make decisions that mesh with the interests of the other side. Since there remain sharp differences in ideology and perception of human rights, it is important that confidence building is promoted and respect for each country's sovereignty needs to be maintained.

Secondly, it is essential that both countries understand the basis for the bilateral relationship. Since disparity of capacities between the two countries it large, it generates different interests and expectations in which the relationship means different things to each side: for Vietnam it is economic interests that dominates the normalization process, whereas for the United States it is more of political incentives. Asymmetric bilateral relations therefore can only be placed on a stable and sustainable footing if they are configured to serve the national interests of both Vietnam and the United States. The current geopolitical context of the South China Sea in which China is increasingly flexing its muscle with sovereignty claims over disputed waters with regional countries has brought about new potential for a closer relationship between Vietnam and the United States. In such context, in order to have a more fruitful and realistic relationship, an understanding of the basis for mutual interests is vital. 
Third, if the positive trajectory of Vietnam-US relations is to be maintained, bilateral ties must be widened and deepened. Currently, US-Vietnam relations cover a wide range of issues, from trade and investment, to education and security. It is undeniable that strategic issues are one of the main drives for the current improvement of relations. However, the two countries can only maintain a stable relationship if they are able to concentrate on the non-security aspects, such as education, economics, trade, investment etc. Along this line, economic cooperation should be given first priority in the overall relationship in the years ahead. The approval of the PNTR and Vietnam's membership to WTO, and the fact that the two countries have been "comprehensive partner" 26 of each other now, all have laid the groundwork for closer bilateral relationship and a good momentum for the on-going negotiation for the Trans-Pacific Partnership agreement, which will be a benchmark for a higher level of bilateral cooperation. The United States should also be more active in helping Vietnamese victims of Agent Orange as a way of closing the past and moving toward to the future, an area of cooperation that will certainly help promote relations with Vietnam. In other words, US-Vietnam relations should not be seen as a single-lane road on which one small accident may block the whole flow of traffic, but should be a multiple lane highway so that relations will move forward even though there inevitably remain obstacles.

While it is undeniable that Vietnam and the United States have gone a long way in their relationship, it still can be argued that relations are still colored by the shadow of the past. It will take more time and especially more strenuous efforts by the two countries to move beyond the past and to start a wholly new era in the bilateral relationship: an era of

\footnotetext{
${ }^{26}$ The United States and Vietnam have become comprehensive partners since 2013.
} 
cooperative partnership. Convergent interests will provide the solid foundation for bilateral cooperation to forge ahead despite the sources of tensions. By focusing on areas that have the most potential for successful cooperation and avoiding issues that may afflict the bilateral relations, the two countries will eventually enhance mutual independence and understanding which in turn will improve the overall political climate conductive to cultivating cooperative and mutually beneficial relations for the two nations. A new and cooperative relationship between Vietnam and the US is not only in the interests of the two nations but also contributes to peace, security and development of the region and the world as a whole. 


\section{APPENDIXES}

\section{APPENDEX A \\ SOME PROVISIONS OF THE AGREEMENT ON ENDING THE WAR AND RESTORING PEACE IN VIETNAM 1973}

\section{ARTICLE 8}

a) The return of captured military personnel and foreign civilians of the parties shall be carried out simultaneously with and completed not later than the same day as the troop withdrawal mentioned in Article 5. The parties shall exchange complete lists of the above-mentioned captured military personnel and foreign civilians on the day of the signing of this Agreement.

b) The parties shall help each other to get information about those military personnel and foreign civilians of the parties missing in action, to determine the location and take care of the graves of the dead so as to facilitate the exhumation and repatriation of the remains, and to take any such other measures as may be required to get information about those still considered missing in action.

\section{ARTICLE 21}

The United States anticipates that this Agreement will usher in an era of reconciliation with the Democratic Republic of Vietnam as with all the peoples of Indochina. In pursuance of its traditional policy, the United States will contribute to the healing of the wounds of war and to postwar reconstruction of the Democratic Republic of Vietnam and throughout Indochina. 


\section{ARTICLE 22}

The ending of the war, the restoration of peace in Vietnam, and the strict implementation of this Agreement will create conditions for establishing a new, equal, and mutually beneficial relationship between the Democratic Republic of Vietnam and the United States on the basis of respect for each other's independence and sovereignty, and non-interference in each other's internal affairs. At the same time this will ensure stable peace in Vietnam and contribute to the preservation of lasting peace in Indochina and Southeast Asia. 


\section{APPENDIX B}

\section{The US Reported "Road Map” Proposal for Normalization with Vietnam}

\begin{tabular}{|c|c|}
\hline \multicolumn{2}{|c|}{$\begin{array}{c}\text { PHASE I } \\
\text { Began with October } 1991 \text { signing of peace agreement on Cambodia }\end{array}$} \\
\hline Vietnam is to: & U.S. is to: \\
\hline $\begin{array}{l}\text { Sign the Cambodian peace accord } \\
\text { and help to persuade the Phnom } \\
\text { Penh regime to sign }\end{array}$ & $\begin{array}{l}\text { Lift 25-mile travel ban on } \\
\text { Vietnamese diplomats in New } \\
\text { York. }\end{array}$ \\
\hline $\begin{array}{l}\text { Take needed steps to resolve } \\
\text { quickly "last known alive" POW } \\
\text { discrepancy cases, live sighting } \\
\text { reports, and return Americans }\end{array}$ & $\begin{array}{l}\text { Begin bilateral talks on normalizing } \\
\text { diplomatic relations. }\end{array}$ \\
\hline $\begin{array}{l}\text { remains with an eye toward settling } \\
\text { the POW/MIA cases in Indochina } \\
\text { in } 2 \text { years }\end{array}$ & $\begin{array}{l}\text { - Permit US organized travel to } \\
\text { Vietnam }\end{array}$ \\
\hline & $\begin{array}{l}\text { - Liberalize US economic relations } \\
\text { with Cambodia }\end{array}$ \\
\hline $\begin{array}{l}\text { Allow those Vietnamese detainees } \\
\text { previously affiliated with the US to } \\
\text { exit by means of the Orderly } \\
\text { Departure Program (ODP) }\end{array}$ & $\begin{array}{l}\text { State publicity US official concerns } \\
\text { regarding genocide in Cambodia }\end{array}$ \\
\hline
\end{tabular}

\section{PHASE II}

Began after Phase I and once UN peacemakers are well established in Cambodia Vietnam is to: U.S. is to:

- Continue to support Paris agreement and help persuade Phnom Penh to continue to support it

- Continue progress on POW/MIA issues begun in Phase I
- Send high-level delegations to Hanoi for talks on normalization of relations

- Allow US telecommunication links with Vietnam

- Allow signing of US commercial transactions meeting basic human needs in Vietnam

- Work with others to help Vietnam eliminate arrears to international financial institutions (IFI) 
- Allow US firms to open commercial offices in Vietnam

- Lift all restrictions on US nongovernmental organization projects in Vietnam.

\section{PHASE III}

Begins once UN procedures and Cambodian settlement process are well in place (i.e., cantonment of competing factional forces is complete and demobilization has begun).

$$
\text { Vietnam is to: }
$$

- Continue its support and encourage Phnom Penh's support of Cambodia peace agreement

- Withdraw all Vietnamese forces/military advisers from Cambodia

- Resolve last known alive discrepancy cases and repatriate US remains readily available to Vietnam.

\section{U.S. is to:}

- Open diplomatic liaison office in Hanoi and invite Vietnam to establish one in Washington

- Fully lift trade embargo

- Support IFI aid meeting basic human needs in Vietnam.

\section{PHASE IV}

Begins once UN-certified free election takes place in Cambodia; a Cambodian National Assembly is formed and is writing a new constitution; demobalization of factional forces specified in the 1991 accord has occurred; and the objectives of the US-Vietnam 2-year effort to resolve POW/MIA issues have been achieved.

Vietnam is to:

(No additional requirements at this stage)

U.S. is to:

- Establish ambassadorial-level diplomatic relations with Vietnam

- Consider granting most-favorednation status to Vietnamese trade

- Favorably consider IFI assistance for non-basic human needs projects in Vietnam. 


\section{APPENDIX C \\ Chronology of key events in US-Vietnam relations 1975-2006}

\begin{tabular}{|c|c|}
\hline 1975 & $\begin{array}{l}+ \text { April } 30-\text { North Vietnamese forces take over the southern part of Vietnam, } \\
\text { ending the war. Washington extends an embargo to all of Vietnam and } \\
\text { breaks diplomatic relations }\end{array}$ \\
\hline 1978 & + Talks between Hanoi and Washington on normalization break down \\
\hline 1988 & $\begin{array}{l}+ \text { Under Reagan Administration, Vietnam begins cooperation with the United } \\
\text { States to resolve the fate of American servicemen missing inn action (MIA) }\end{array}$ \\
\hline 1991 & 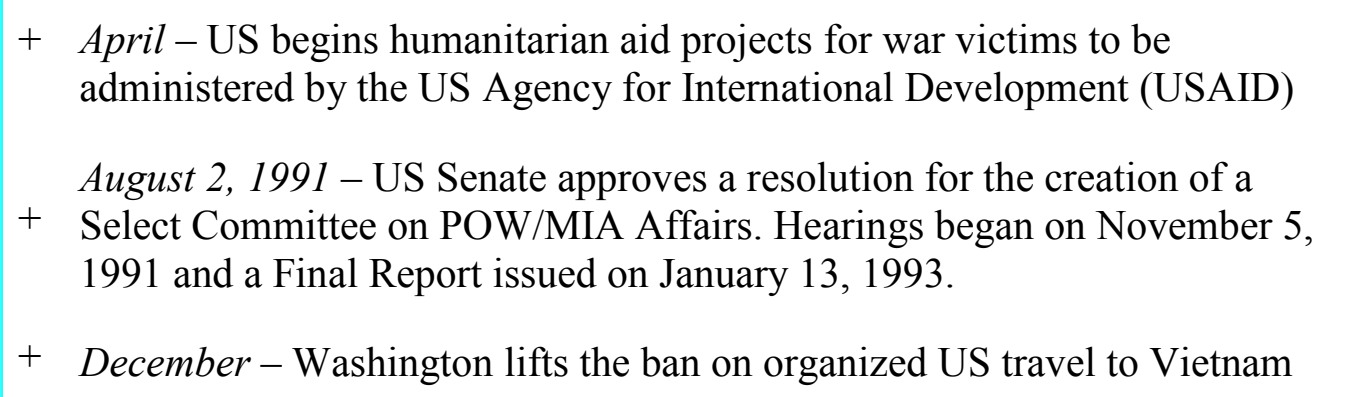 \\
\hline 1992 & $\begin{array}{l}+ \text { January - The Joint Task Force }- \text { Full Accounting was established with the } \\
\text { goal of achieving the fullest possible account of Americans missing from } \\
\text { the Vietnam War, including Laos, Cambodia and Vietnam. At the time the } \\
\text { Joint Task Force was formed, the number stood at 2,267 }\end{array}$ \\
\hline 1993 & $\begin{array}{l}+ \text { January } 13-\text { Submission of a Final Report by the Select Committee on } \\
+ \text { POW/MIA affairs } \\
\text { July } 2-\text { The Clinton administration clears the way for resumption of } \\
\text { international lending including IMF and World Bank to Vietnam }\end{array}$ \\
\hline 1994 & + February 3 - President Clinton lifts the trade embargo \\
\hline 1995 & 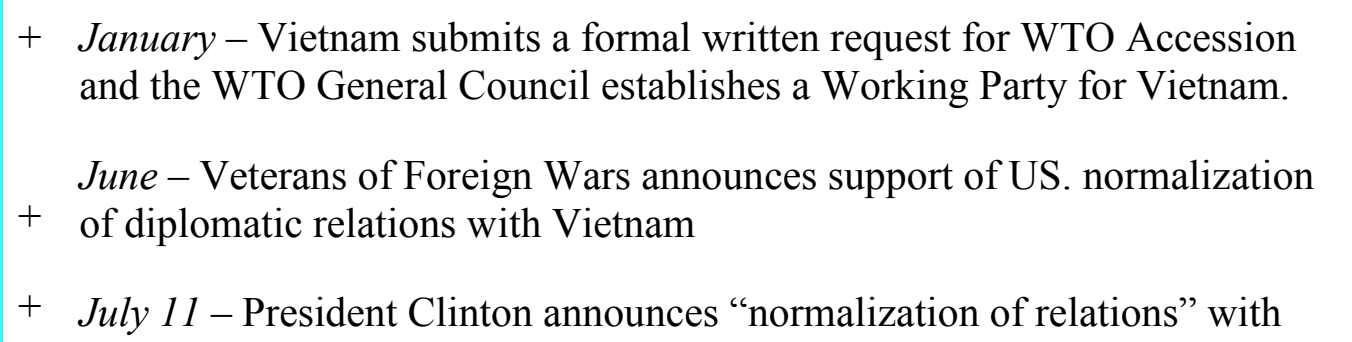 \\
\hline
\end{tabular}




\begin{tabular}{|c|c|}
\hline & $\begin{array}{l}\text { Vietnam } \\
\text { August } 6 \text { - Secretary of State Warren Christopher visits Hanoi and officially } \\
\text { opens US embassy. Vietnam opens embassy in Washington }\end{array}$ \\
\hline 1996 & + May-US presents Vietnam with trade agreement blueprint \\
\hline 1997 & $\begin{array}{l}+ \text { April } 7 \text { - US Treasury Secretary Robert Rubin and Finance Minister } \\
\text { Nguyen Sinh Hung sign accord in Hanoi for Vietnam to repay debts of } \$ 145 \\
\text { million, from the former government of South Vietnam } \\
+ \text { May } 9 \text { - Douglas "Pete" Peterson, Vietnam War veteran and former } \\
\text { prisoner of war, takes up post as US Ambassador in Hanoi, Le Van Bang } \\
\text { becomes Vietnam Ambassador in Washington, DC. }\end{array}$ \\
\hline 1998 & $\begin{array}{l}\text { March } 11-\text { President Clinton issues waiver of Jackon-Vanik Amendment } \\
\text { for Vietnam, paving the way for OPIC, Ex-Im, TDA, USDA and MARAD. } \\
\text { The US House of Representatives renews the Jackon-Vanik waiver for } \\
\text { Vietnam by a } 260-163 \text { vote. }\end{array}$ \\
\hline 1999 & $\begin{array}{l}\text { June to August } 3 \text { - President Clinton re-extends the Jackson Vanik waiver } \\
\text { for Vietnam. The Jackson-Vanik waiver passes the House by a vote of } 297- \\
130\end{array}$ \\
\hline 2000 & 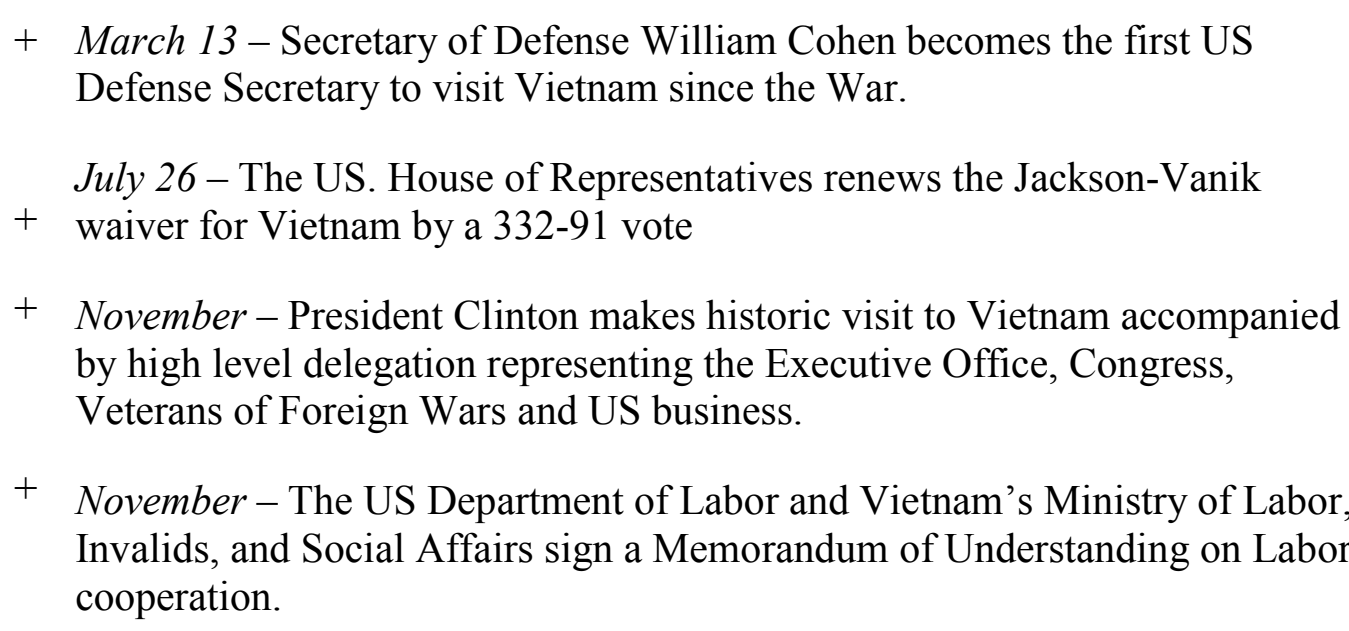 \\
\hline 2001 & $\begin{array}{l}+ \text { June to July } 26-\text { President Bush renews the Jackson - Vanik waiver for } \\
\text { Vietnam. The US House of Representatives renews the waiver for Vietnam } \\
\text { by a } 321-91 \text { vote. } \\
+ \text { October } 10-\text { Ambassador Nguyen Tam Chien presents Letter of Credence }\end{array}$ \\
\hline
\end{tabular}




\begin{tabular}{|c|c|}
\hline & $\begin{array}{l}+ \text { to President George W. Bush at the White House. } \\
+\quad \text { December } 3 \text { - Ambassador Raymond Burghardt sworn in as US } \\
\text { Ambassador to Vietnam. } \\
\text { December } 10 \text { - US-Vietnam Bilateral Trade Agreement signed into force at } \\
\text { a Blair House ceremony with Deputy Prime Minister Dung, Trade Minister } \\
\text { Vu Khoan and USTR Ambassador Robert Zoellick. Conference and banquet } \\
\text { hosted by US - VTC }\end{array}$ \\
\hline 2002 & 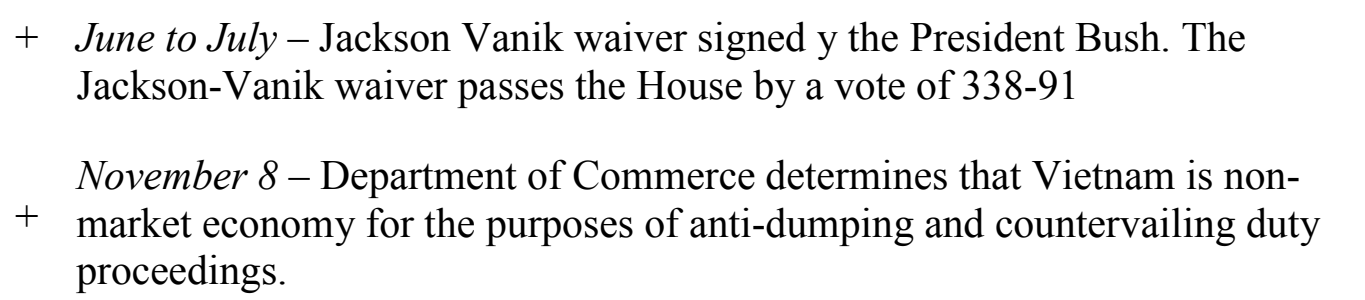 \\
\hline 2003 & 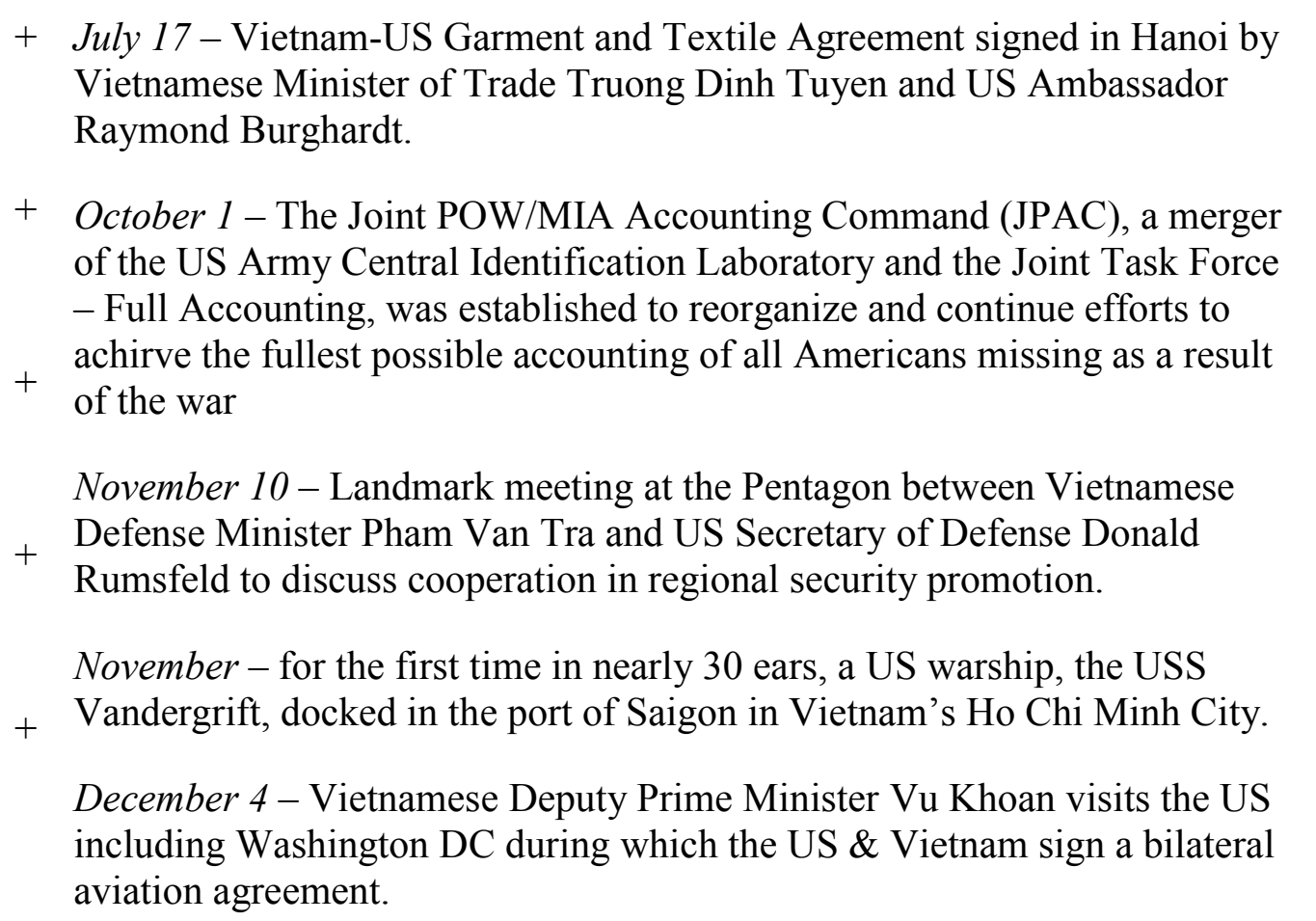 \\
\hline 2004 & $\begin{array}{l}+ \text { April } 2-\text { Formation of the US Vietnam Caucus in the US Congress, which } \\
\text { seeks to monitor and support normalized relations between the US and } \\
\text { Vietnam } \\
+ \text { May } 6-\text { Senate confirms Michael W. Marien, career Senior Foreign Service } \\
+ \text { Officer, as the } 3^{\text {rd }} \text { US Ambassador to Vietnam in the post war period. } \\
\text { June } 3 \text { - President Bush signed and sent to Congress the annual extension of }\end{array}$ \\
\hline
\end{tabular}




\begin{tabular}{|c|c|}
\hline & 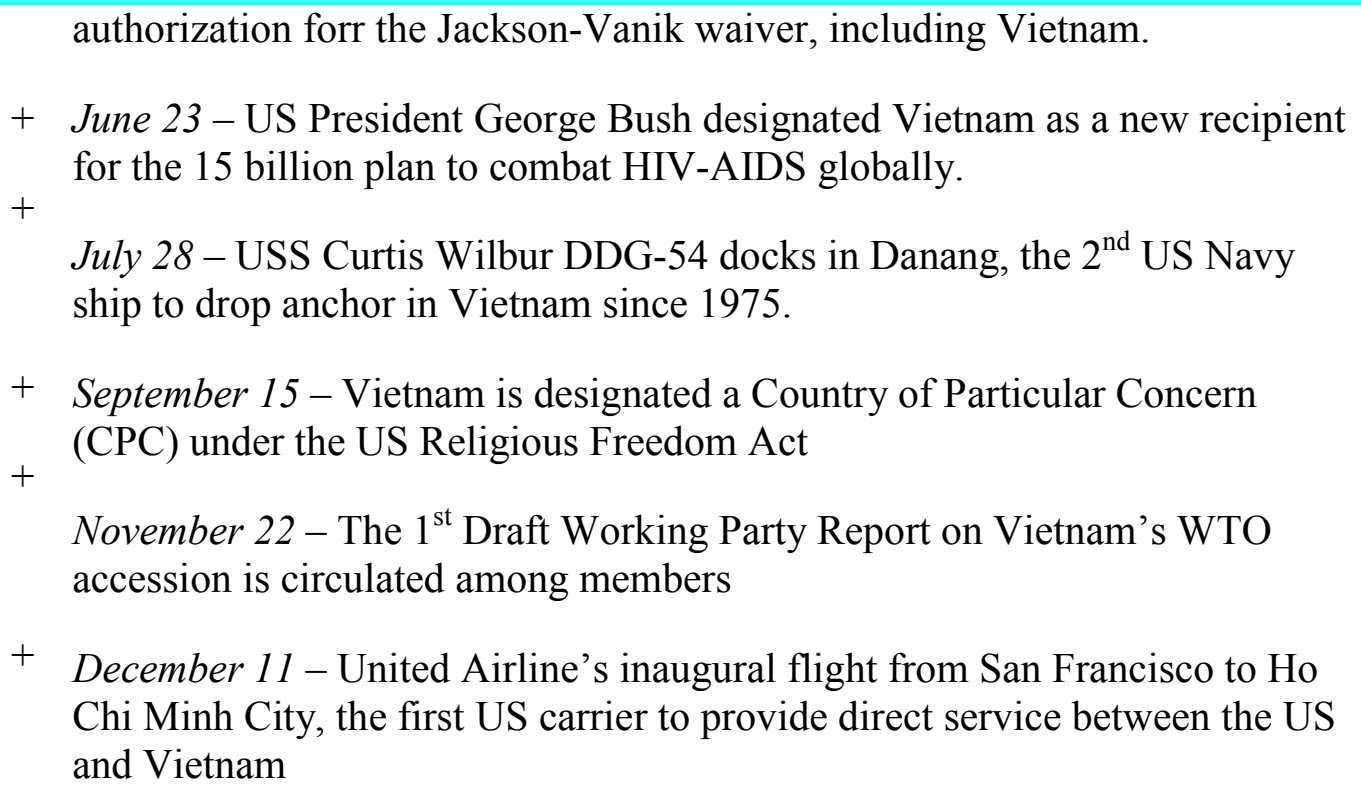 \\
\hline 2005 & 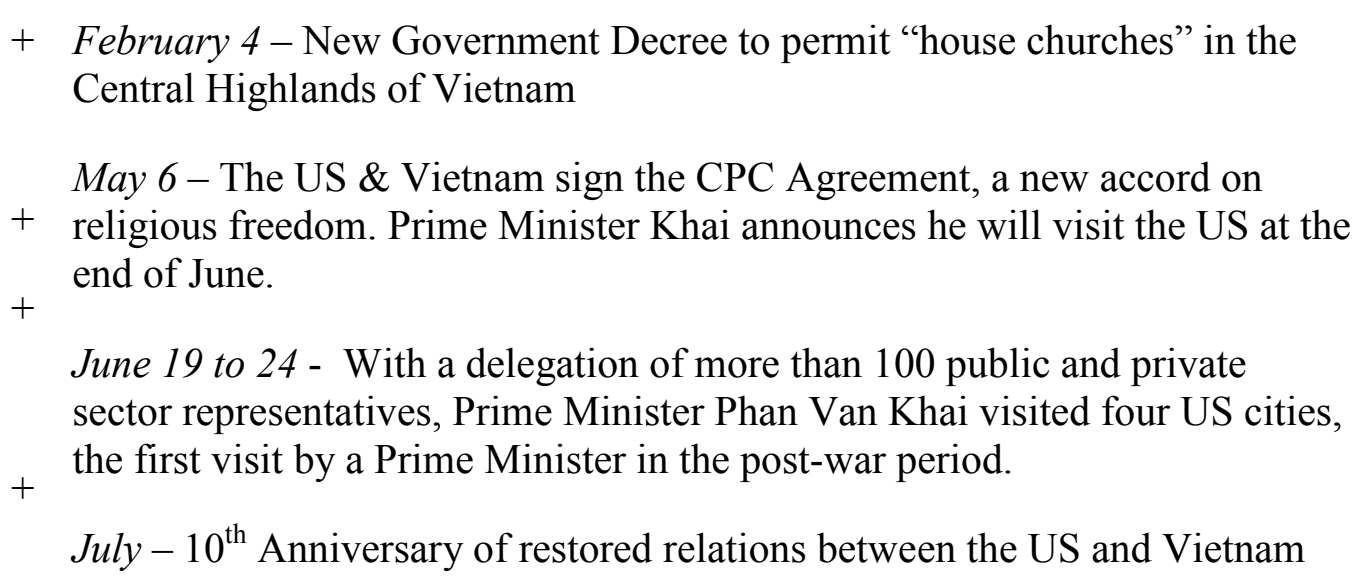 \\
\hline 2006 & 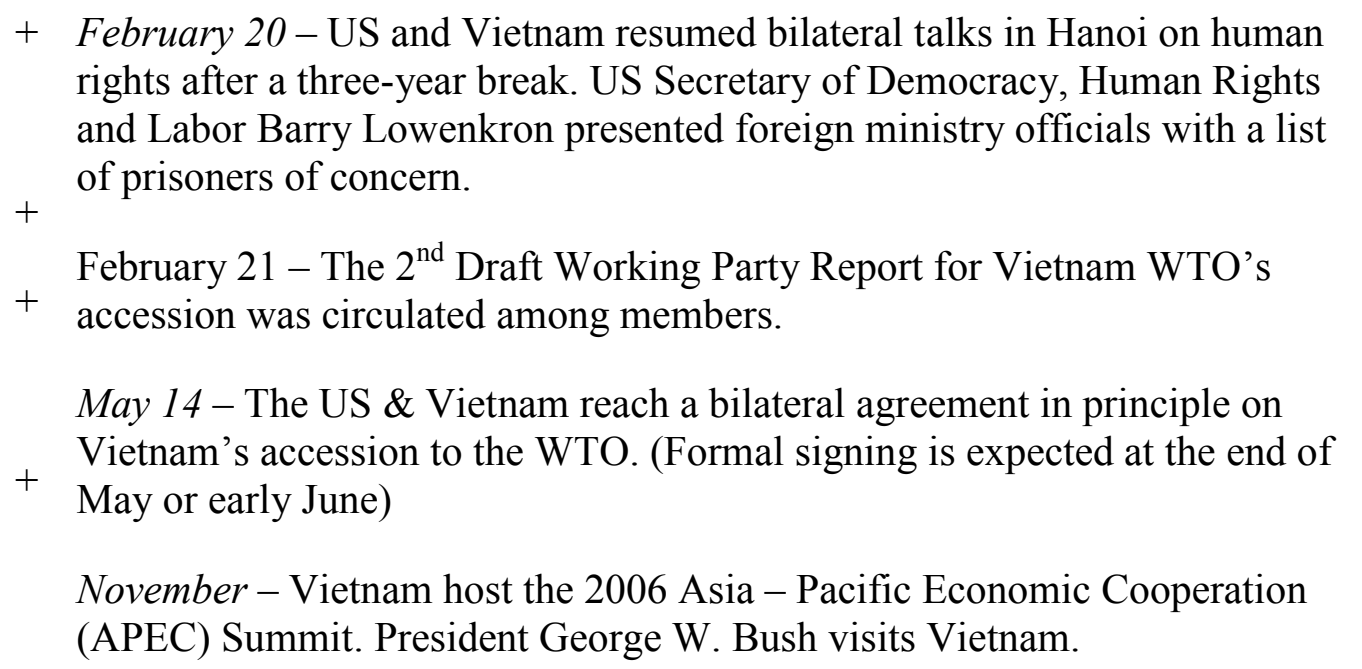 \\
\hline
\end{tabular}




\section{BIBLIOGRAPHY}

Amer, Ramses. "Sino-Vietnamese Relations: Past Present and Future." In Vietnamese Foreign Policy in Transition, edited by Carlyle A. Thayer and Ramses Amer, 68- 129. New York: St. Martin's Press, 1999.

Amer, Ramses. "Sino-Vietnamese Normalization in the Light of the Crisis of the Late 1970s”, Pacific Affairs, Vol. 67, No. 3 (Autumn, 1994): 357-383.

Arnold, Gordon. The afterlife of America's War in Vietnam: changing visions in politics and on screen. North Carolina: McFarland \& Company, Inc., Publisher, 2006).

Barta, Patrick. "U.S., Vietnam in Exercises Amid Tensions With China," Wall Street Journal (Online) [New York, N.Y] 16 July 2011.

Bellacqua, James. "The China Factor in U.S.-Vietnam Relations." CNA China Studies, DRM-2012-U-000184-Final, March, 2012.

Bijian, Zheng. "China's 'Peaceful Rise' to Great-Power Status." Foreign Affairs, Vol. 84, No. 5 (Sep.-Oct., 2005),18-24.

Brandon, John. "Global and Regional Influences on US-Vietnam relations", in Dialogue on US-Vietnam relations: Global and regional influences, edited by Jonathan R. Stromseth, 10-28. Washington DC: The Asia Foundation, 2004.

Brown, Frederick Z. "Rapprochement Between Vietnam and the United States." Contemporary Southeast Asia Vol. 32, No. 3 (2010), 317-42.

Brzezinski, Zbigniew. Power and Principle: Memoirs of the National Security Adviser, 1977-1981. New York: Farrar Straus \& Giroux, 1983.

Bui, Thanh Son. "Vietnam-US relations and Vietnam's foreign policy in the 1990s", in Vietnamese Foreign Policy in Transition, edited by Thayer, Carlyle and Ramses Amer, 202-214. Singapore: Institute of Southeast Asia Studies, 1999.

Burghardt, Raymond. "US foreign policy in a new international era", in Dialogue on USVietnam Relations: Global and Regional influences, ed. Jonathan Stromseth. Washington DC: The Asia Foundation 2003.

Catley, Bob and Makmur Keliat. Spratlys: The Dispute in the South China Sea. Vermont: Ashgate Publishing Company, 1997. 
Chanda, Nayan. Brother Enemy: the war after the war: a history of Indochina since the Fall of Saigon. Orlando: Harcourt, 1986.

Chanda, Nayan. "The slow rapprochement". American Review, 2012 http://americanreviewmag.com/stories/The-slow-rapprochement

Cheng, Joseph Y.S. "Sino-Vietnamese Relations in the Early Twenty-First Century." Asian Survey, Vol. 51, No. 2 (March/April 2011), 379-405.

Chirathivat, Suthiphand. "China's rise and its effect on ASEAN-China trade relations", in China, the United States, and Southeast Asia: contending perspectives on politics, security, and economics, edited by Evelyn Goh and Sheldon Simon. New York: Routledge, 2008.

Clark, Dick. Recommendations for the new administration on US policy toward Indochina. Washington DC: Indochina Policy Forum, 1988.

Clark, Dick. The American - Vietnamese Dialogue: Conference Report February 11-14, 1991. Washington DC: The Aspen Institute, 1991.

Clark, Dick. The American - Vietnamese Dialogue: Conference Report February 11-14, 1992. Washington DC: The Aspen Institute, 1992.

Clark, Dick. The American - Vietnamese Dialogue: Conference Report February 8-11, 1993. Washington DC: The Aspen Institute, 1993.

Clark, Dick. The Challenge of Indochina: an examination of the US role: Conference Report May 8-10, 1992. Washington DC: The Aspen Institute, Vol.7, No.3, 1992.

Clark, Dick. The Challenge of Indochina: an examination of the US role: Conference Report April 30 - May 2, 1993. Washington DC: The Aspen Institute, Vol.8, No.4, 1993.

Communist Party of Vietnam. Political Report of the $6^{\text {th }}$ National Congress of the Communist Party of Vietnam: Documents. Hanoi: Foreign Language Publishing House, 1986.

Communist Party of Vietnam. Political Report of the $7^{\text {th }}$ National Congress of the Communist Party of Vietnam: Documents. Hanoi: Foreign Language Publishing House, 1991. 
Communist Party of Vietnam. Political Report of the $8^{\text {th }}$ National Congress of the Communist Party of Vietnam: Documents. Hanoi: Foreign Language Publishing House, 1996.

Communist Party of Vietnam. Political Report of the $9^{\text {th }}$ National Congress of the Communist Party of Vietnam: Documents. Hanoi: Foreign Language Publishing House, 2001.

Cordesman, Anthony H. "The Military Balance in Asia: 1990-2011 A Quantitative Analysis." Center for Strategic \& International Studies, May 16, 2011.

Clinton, Bill. Normalization with Vietnam. Washington DC: White House, Office of the Press Secretary, 1995.

Cooper, William. Vietnam PNTR status and WTO accession: Issues and Implications for the United States. Washington DC: CRS Report for Congress, 2006.

Copeland, Dale. "Economic Interdependence and War: A Theory of Trade Expectations," International Security, Vol. 20, no.4 (1996):43-86.

Dao, Ngoc Huy. Overview of 50 years of Vietnamese diplomatic activities (unpublished manuscript), 1999.

Department of State. Foreign Relations of the United States 1977-1980, Volume XIII: China. ed. by David P. Nickles, Washington DC: 2013.

Destler, I.M. "The Rise of Foreign Economic Policy in the United States and the Role of Organized Business" in Dialogue on US-Vietnam relations: Domestic Dimension, edited by Jonathan R. Stromseth, 57 -66. Washington DC: The Asia Foundation, 2003.

Dixit, Avinash K. and Barry J. Nalebuff. Thinking Strategically: The Competitive Edge in Business, Politics, and Everyday Life. New York: Norton \& Company, 1991.

Dosch, Jorn and Manfred Mols. International relations in the Asia-Pacific: new patterns of power, interest, and cooperation. New York: St. Martin's Press, 2000.

Emmers, Ralf. "Regional Hegemonies and the Exercise of Power in Southeast Asia: A Study of Indonesia and Vietnam." Asian Survey, Vol. 45, No. 4 (July/August 2005), 645-665. 
FitzGerald, D. M. The Vietnam People's Army: Regularization of Command 1975-1988, Canberra Papers on Strategy and Defence No. 48, Australian National University 1989.

Friedberg, Aaron L. "The Future of U.S.-China Relations: Is Conflict Inevitable?" International Security, Vol. 30, No. 2 (Autumn, 2005), 7-45.

Gilpin, Robert. War and Change in World Politics. New York: Cambridge University Press, 1981.

Gresser, Edward. "The Bilateral Trade Agreement with Vietnam in Fin-de-Siecle US Trade Policy" in Dialogue on US-Vietnam relations: Domestic Dimension, edited by Jonathan R. Stromseth, 66-73. Washington DC: The Asia Foundation, 2003.

Goh, Evelyn and Amintave Acharya. "The ASEAN Regional Forum: Comparing Chinese and American positions" in Advancing East Asian Regionalism, edited by Melissa Curley and Nick Thomas, 134-198. London: Routledge, 2005.

Goh, Evelyn. "Meeting the China challenge: The United States in Southeast Asian Regional Security Strategies”, Contemporary Southeast Asia 26, no.1 (2005): 12-36.

Goldstein, Avery. Rising to the challenge. Stanford: Stanford University Press, 2005.

Goto, Junichi. Economic Interdependence and Cooperation with reference to Asia. Tokyo: Kope University, 1999.

Guo, Sujuan. China's "Peaceful Rise" in the $21^{\text {st }}$ Century: Domestic and international conditions. USA: Ashgate Publishing Company, 2006.

Hai Son. "Vietnam and the United States: toward a long-lasting stable relationship", Nghien Cuu Quoc Te. No.17 (2005):15-28.

Halbwachs, Maurice. On collective memory. Chicago: University of Chicago Press, 1992.

Hearden, Patrick. The tragedy of Vietnam. New York: Pearson Longman, 2005).

Henning, Charles. POWS and MIAs: Status and Accounting Issues. Washington DC: CRS Report for Congress, 2006. 
Hernandez, Caroline. "ASEAN responses to an emerging China: a Philippine Perspective", in The security environment in Asia Pacific, edited by Hung-mao-Tien and Tun-jen Cheng, 85-109. New York: Armonk, 2000.

Hoang, Tuan Anh, Conceptualization of Security Challenges in Southeast Asia after 9/11, Nghien Cuu Quoc Te, no.14 (2004):65-87.

Hoang, Tuan Anh. "Rapprochement Between Vietnam and the United States: A Response." Contemporary Southeast Asia Vol. 32, No. 3 (2010), 343-49.

Jamieson, Neil L. Understanding Vietnam. University Of California Press, Berkeley and Los Angeles, California, 1995.

Horn, Robert. "Soviet-Vietnamese Relations and the Future of Southeast Asia", Pacific Affairs, Vol. 51, No. 4 (Winter, 1978-1979): 585-605.

Intelligence Assessment Prepared in the National Foreign Assessment Center, CIA: Washington, June 1978, in Foreign Relations of the United States 1977-1980, Volume XIII: China. ed. by David P. Nickles, Washington DC: Department of State, 2013.

Intelligence Memorandum Prepared in the Central Intelligence Agency: March 1977, in Foreign Relations of the United States 1977-1980, Volume XIII: China. ed. by David P. Nickles, Washington DC: Department of State, 2013.

Interagency Intelligence Memorandum: November 14, 1978, Foreign Relations of the United States 1977-1980, Volume XIII: China. ed. by David P. Nickles, Washington DC: Department of State, 2013.

Isaacs, Arnold. Vietnam Shadows: the war, its ghosts and its legacy. Baltimore: John Hopkins University Press, 1997.

Jervis, Robert. "Realism, Game Theory, and Cooperation." World Politics, Vol. 40, No. 3 (Apr., 1988), 317-349.

Kan, Shirley A. "U.S.-China Military Contacts: Issues for Congress." Congressional Research Service, www.crs.gov, RL32494, July 26, 2011.

Kang, David C. "Why China's Rise will be Peaceful: Hierarchy and Stability in the East Asian

Region.’http://www.ou.edu/uschina/SASD/SASD2005/2005readings/Kangprediction. pdf (accessed May 4, 2013). 
Kang, Tong Hum. Vietnam and the Spratly Islands Dispute Since 1992. Monterey: Naval Postgraduate School, 2000.

Karnow, Stanley. Vietnam: A History. $2^{\text {nd }}$ ed. New York: Penguin Books, 1997.

Kelly, James. "The future of relations between Vietnam and the United States", in Conference Report 2003, edited by Institute for International Relations of Vietnam. Washington DC: The Ford Foundation, 2003.

Klare, Michael T. Resource Wars: The New Landscape of Global Conflict. New York: A Metropolitan/Owl Book, Henry Holt and Company, 2001.

Lamb, David. Vietnam, Now: A Reporter Returns. Washington DC: Public Affairs, 2002.

Lampton, David. “The Faces of Chinese Power”, Foreign Affairs, no.1 (2007): 115-127.

Lampton, David. "The U.S. Cannot Rely on ASEAN in the South China Sea."

WebMemo, Published by The Heritage Foundation, No. 3335, August 5, 2011.

Lampton, David. "China's rise in Asia need not be at America's expense", in Power Shift, edited by David Shambaugh. Berkeley, CA: University of California Press, 2005.

Lego, Jeffrey. Rethinking the world: great power strategies and international order. Ithaca: Cornell University Press, 2005.

Legro, Jeffrey. "What China will want: the future intentions of a rising power", Perspectives on Politics, Vol.5, no.3 (2007): 515-534.

Le, Dinh Tinh. "US-Southeast Asian security relationship revisited", Nghien Cuи Quоc Te, no.16 (2005): 93-99.

Le, Linh Lan. "The changing role of the US and China in Southeast Asia: perceptions, expectations and responses", Nghien Cuu Quоc Te No.16, (2005): 75-92.

Lohman, Walter. "Sorting American Priorities in the South China Sea." WebMemo, Published by The Heritage Foundation, No. 3297, June 20, 2011.

Lucius, Casey. Vietnam's Political Process: How education shapes political decision making. New York: Routledge, 2009.

Manyin, Mark. US-Vietnam relations: background and Issues for Congress. Washington DC: CRS Report for Congress, 2007. 
Manyin, Mark. "The Role of Congress in US foreign policy and US-Vietnam Relations", in Dialogue on US-Vietnam relations: Domestic Dimension, edited by Jonathan R. Stromseth, 24-30. Washington DC: The Asia Foundation, 2003.

Mayin, Mark. The Vietnam-US normalization process, CRS Issue Brief for Congress. Washington DC: CRS Report for Congress, 2004.

Manyin, Cooper and Gelb. Vietnam PNTR Status and WTO accession: Issues and implications for the United States. Washington DC: CRS Report to Congress, 2006.

Martin, Michael F. "U.S.-Vietnam Economic and Trade Relations: Issues for the 112th Congress." Congressional Research Service. April 5, 2011.

Mearsheimer, John J. "The Gathering Storm: China's Challenge to US Power in Asia." The Chinese Journal of International Politics, Vol. 3, 2010.

Mearsheimer, John J. "China's Unpeaceful Rise," Current History, Vol. 105, No. 690 (April 2006), 160-162.

Mearsheimer, John J. "The Rise of China will Not Be Peaceful at All," The Australian, November 18, 2005.

Mearsheimer, John. The Tragedy of Great Power Politics. New York: Norton, 2001.

Memorandum of talks between Vietnamese President Nguyen Minh Triet and US President George W. Bush, June 22, 2007 at the White House: People's Daily June 22, 2007.

Memorandum from Director of CIA to President's Assistant for National Security Affairs (Brzezinski) November 21, 1978, in Foreign Relations of the United States 1977-1980, Volume XIII: China. ed. by David P. Nickles, Washington DC: Department of State, 2013.

Memorandum From the President's Assistant for National Security Affair (Brzezinski) to President Carter January 26, 1979, in Foreign Relations of the United States 1977-1980, Volume XIII: China. ed. by David P. Nickles, Washington DC: Department of State, 2013.

Memorandum from the President's Assistant for National Security Affairs (Brzezinski) to President Carter: October 11, 1978, in Foreign Relations of the United States 1977-1980, 
Volume XIII: China. ed. by David P. Nickles, Washington DC: Department of State, 2013.

Memorandum from the President's Assistant for National Security Affairs (Brzezinksi) to Secretary of Defense Brown: Washington DC, December 12, 1980, in Foreign Relations of the United States 1977-1980, Volume XIII: China. ed. by David P. Nickles, Washington DC: Department of State, 2013.

Memorandum of Conversation between Brzezinski and Foreign Minister Huang Hua: Beijing May 21, 1978, in Foreign Relations of the United States 1977-1980, Volume XIII: China. ed. by David P. Nickles, Washington DC: Department of State, 2013.

Memorandum of conversation between President Carter and Vice Premier Deng: Washington DC, January 30, 1979, in Foreign Relations of the United States 1977-1980, Volume XIII: China. ed. by David P. Nickles, Washington DC: Department of State, 2013.

Memorandum of conversation between President Carter and Vice Premier Deng: Washington DC, January 29, 1979, in Foreign Relations of the United States 1977-1980, Volume XIII: China. ed. by David P. Nickles, Washington DC: Department of State, 2013.

Miller, Robert H. Vietnam and beyond: A diplomat's cold war education. Texas: Texas Tech University Press, 2002.

Ministry of Foreign Affairs. On the question of Americans missing in the Vietnam War. Hanoi, 1980.

Ministry of National Defense, Institute of Military History. Ho Chi Minh Thought on the Military. Hanoi: The Gioi Publishers, 2006.

Ministry of National Defense, The Socialist Republic of Vietnam. Vietnam's National Defense in the Early Years of the 21st Century. Ha Noi, 2004.

Minutes of a Special Coordination Committee Meeting: Washington DC, February 17, 1979, in Foreign Relations of the United States 1977-1980, Volume XIII: China. ed. by David P. Nickles, Washington DC: Department of State, 2013.

Morrison, Wayne M. “China-U.S. Trade Issues.” Congressional Research Service, www.crs.gov, RL33536, June 2, 2011. 
Mydans, Seth. "U.S. and Vietnam Build Ties With an Eye on China: [Foreign Desk]" New York Times [New York, N.Y] 13 Oct 2010.

Nash, John F. "Equilibrium Points in n-Person Games." Proceedings of the National Academy of Sciences of the United States of America 36, no. 1 (Jan. 15, 1950): 48-49.

Neher, Clark D. South East Asia in the new international era. USA: Westview Press, 2002.

Nguyen, Hoang Giap. "Relations with great powers in our Party and State's foreign policy under Doimoi”, Nghien Cuи Quоc Te, No.17, (2005): 34-42.

Nguyen, Manh Hung. "Vietnam-US Relations: Past, Present, and Future." Asia Pacific Bulletin, No. 69 (2010).

Nguyen, Nam Khanh. "US policy toward Southeast Asia after 9/11 events: opportunities and Challenges", Nghien Cuи Quос Te, no.14 (2004): 15-39.

Nguyen, Van Long. "The Bilateral Trade Agreement: Negotiations, Commitments, and Implementation Issues", in Dialogue on US-Vietnam relations: Domestic Dimension, ed. Jonathan R. Stromseth, Washington DC: The Asia Foundation, 2003.

Nguyen, Vu Tung. "Non-traditional Security challenges in East Asia: Prospects for interstate cooperation", Nghien Cuи Quoc Te, No.18 (2006): 65-90.

Rogowski, Ronald. Commerce and Coalition: how trade affect domestic political arrangements. Princeton: Princeton University Press, 1989.

Roper, John. The United States and the legacy of the Vietnam War. New York: Palgrave Macmillan, 2007.

Ross, Robert. "Bipolarity and Balancing in East Asia", in Balance of Power: Theory and Practice in the $21^{\text {st }}$ Century, edited by T.V Paul, James Wirtz and Michel Fortmann, 239267. Stanford: Stanford University Press, 2004.

Oral Message from Chinese Vice Premier Deng Xiaoping to President Carter: Undated, in Foreign Relations of the United States 1977-1980, Volume XIII: China. ed. by David P. Nickles, Washington DC: Department of State, 2013.

Organski and Jacek Kugler. The War Ledger. Chicago: University Of Chicago Press, 1981. 
O'Rourke, Ronald. "China Naval Modernization: Implications for U.S. Navy Capabilities Background and Issues for Congress." Congressional Research Service, www.crs.gov, RL32494, July 22, 2011.

Ott, Marvin. "Looking Ahead: US Foreign Policy Toward Asia and BeyondImplications for Vietnam" in Completing the Vietnam-US Normalization Process, ed. Fredrick Brown. Washington DC: SAIS, 2001.

Pao-min, Chang. "Sino-Vietnamese Relations: Prospects for the $21^{\text {st }}$ century, in Vietnamese Foreign Policy in Transition, edited by Thayer, Carlyle and Ramses Amer, 202-214. Singapore: Institute of Southeast Asia Studies, 1999.

Percival, Bronson. The Dragon Looks South: China and Southeast Asia in the New Century. London: Praeger Security International, 2007.

Percival, Bronson. "China's Influence in Southeast Asia: Implications for the United States", US - China Economic and Security Review no. 7 (2005): 187-224.

Pham, Andrew X. Catfish and Mandala: A Two-Wheeled Voyage through the Landscape and Memory of Vietnam, Picador, New York, 1999.

Pham, Cao Phong. "Vietnam's Economic Security." In Globalization and Economic Security in East Asia, edited by Helen E.S. Nesadurai, 143-158. London: Routledge, 2006.

Pham, Chi Lan. "Business interests in Vietnam foreign affairs", in Dialogue on USVietnam relations: Domestic Dimension, edited by Jonathan R. Stromseth, 51-57. Washington DC: The Asia Foundation, 2003.

Phan, Doan Nam. "Institutions and Processes in Vietnamese Foreign Policy Making: Implications for policy toward the United States", Nghien Cuи Quоc Te, no.3, (2003): 829.

Pham, Huyen. "Adjusting Imports to ease reliance on China" - VietnamNet Bridge, 24 January 2011.

Pham, Peter. "From Normalization to partnership: an overview of relations between the United States and Vietnam", American Foreign Policy Interests, No. 27 (2005): 407-418. 
Pierre, Andrew J. "Vietnam's Contradictions." Foreign Affairs, Vol. 79, No. 6 (Nov.Dec., 2000): 69-86.

Pregelj, Vladimir. The Jackson Vanik Amendment: A Survey. Washington DC: The CRS Report for Congress, 2005.

Ratliff, William. Vietnam Rising: Culture and Change in Asia's Tiger Cub. Oakland: The Independent Institute, 2008.

Richburg, Keith B; Wan, William. "China warns U.S. in islands dispute," The Washington Post, Washington DC: 23 June 2011.

Ron Unz. "China's rise - America's Fall”, The American Conservative, April 2012. (http://www.theamericanconservative.com/articles/chinas-rise-americas-fall/)

Ross, Robert. The Indochina Tangle. New York: Colombia University Press, 1988.

Roy, Stapleton. "Sino - US relations: Implications for Southeast Asia and Vietnam", in Dialogue on US-Vietnam Relations: Global and Regional influences, ed. Jonathan Stromseth. The Asia Foundation, 2003.

Schelling, Thomas C. The Strategy of Conflict. London: Oxford University Press, 1966.

Schoff, James. "Japan - North Korea Relations from an American Perspective”, Japan Forum on International Relations (2005).

Shivakumar, M. S. "A New Era for Vietnam and US?" Economic and Political Weekly, Vol. 40, No. 31 (Jul. 30-Aug. 5, 2005), 3373-3376.

Shivakumar, M. S. "Vietnam: Twenty Years After", Economic and Political Weekly, Vol. 30, No. 29 (Jul. 22, 1995), pp. 1836-1838.

Slabey, Robert. The United States and Vietnam from War to Peace (ed.). North Carolina: McFarland \& Company, Inc., Publisher, 2005.

Slabey, Robert. "The United States and Viet Nam from War to Peace: Papers from an Interdisciplinary Conference on Reconciliation” (1996). 
Stern, Lewis. Defense Relations between US and Vietnam: the Process of Normalization 1977 - 2003. New York: McFarland\& Company Publishers, 2005.

Stern, Lewis M. "U.S.-Vietnam Defense Relations: Deepening Ties, Adding Relevance", Strategic Forum, No. 246, September 2009.

Stern, Lewis M. "Building Strategic Relations with Vietnam.” Joint Forces Quarterly, issue 65, (2d quarter 2012), 53-60.

Stone, Randall W. "The Use Abuse of Game Theory in International Relations: The Theory of Moves." The Journal of Conflict Resolution, Vol. 45, No. 2 (Apr., 2001), 216244.

Storey and Thayer. "Cam Ranh Bay: past imperfect, future conditional", Contemporary Southeast Asia 23. no.3 (2001): 434-467.

Sutter, Robert. China's rise in Asia: Promises and Perils. Maryland: Rowman \& Littlefield Publishers, 2005.

Sutter, Robert. "China's rise, Southeast Asia, and the United States: Is a China-centered order marginalizing the United States", in China, the United States, and Southeast Asia: contending perspectives on politics, security, and economics, edited by Evelyn Goh and Sheldon Simon. New York: Routledge, 2008.

Sutter, Robert. The United States and East Asia: Dynamics and implications. Maryland, USA: Rowman \& Littlefield Publishers, INC, 2003.

Sutter, Robert. U.S Policy toward China: An introduction to the role of interest groups. Maryland, USA: Rowman \& Littlefield Publishers, 1998.

Sutter, Robert. Chinese Foreign Relations: Power and policy since the Cold War. Maryland, USA: Rowman \& Littlefield Publishers, 2007.

Sutter, Robert. "Why does China matter", MIT Press Journal, Winter Vol. 27, No. 1 (2004): 75-89.

Thayer, Carlyle and Ramses Amer. Vietnam Foreign Policy in Transition. Singapore: Institute of Southeast Asia Studies, 1999.

Templer, Robert. Shadows and Wind: A View of Modern Vietnam. New York: Penguin Books, 1998. 
Thayer, Carlyle A. "Vietnam-US Relations: A Scorecard." Asia Pacific Bulletin, No. 67, September 14, 2010.

Thayer, Carlyle A. "Vietnam People's Army: Development and Modernization," Research Monograph, Sultan Haji Bolkiah Institute of Defense and Strategic Studies, August 23, 2009.

Thayer, Carlyle A. "The Structure of Vietnam-China Relations, 1991-2008: Paper for the $3^{\text {rd }}$ International Conference on Vietnamese Studies, Hanoi, Vietnam." Viet-Studies. December 2008.

Thayer, Carlyle A. "Sino-Vietnamese relations: The Interplay of Ideology and National Interest.” Asian Survey 34, no. 6 (June): 513-528.

Tran, Quang Co. "The post-Cold War World and the Asia-Pacific", International Studies of Vietnam, No. 12 (1992).

Tyner, James. America's strategy in Southeast Asia : from the Cold War to the Terror War. USA: Rowman \& Littlefield Publishers, 2007.

U.S. State Department. Background Note: Vietnam. January 12, 2012.

U.S. State Department. "Secretary of State Hillary Rodham Clinton Remarks with Vietnam Deputy Prime Minister and Foreign Minister Pham Gia Khiem," Government Guest House, Hanoi, Vietnam, July 22, 2010.

US- Vietnam WTO Coalition. “Issues Brief: PNTR for Vietnam: Vote Yes!” (2006).

Valencia, Mark J. "Foreign Military Activities in Asian EEZs: Conflict Ahead?" The National Bureau of Asian Research, NBR Special Report \#27 (May 2011.

Vietnam General Department of Statistics. 2006 Report. Hanoi: The Gioi Publisher, 2007.

Vuving, Alexander. "Strategy and evolution of Vietnam's China policy", Asian Survey, Vol. XLVI, No.6 (2006): 256-299.

Waltz, Kenneth. Theory of International Politics. USA: Addison-Wesley, 1979.

Walt, Stephen. The Origins of Alliances. Ithaca: Cornell University Press, 1987. 
Wanadi, Jusuf. "ASEAN's China Strategy: toward deeper engagement", Contemporary Southeast Asia, Vol 38, No.3 (1996): 154-198.

Womack, Brantly. China among unequals: Asymmetric foreign relationships in Asia. Singapore: World Scientific Publishing Co.: 2010.

Womack, Brantly. China's rise in historical perspective (ed.). Maryland: Rowman \& Littlefield Publishers, INC., 2010.

Womack, Brantly. China and Vietnam: the Politics of Asymmetry. Cambridge: Cambridge University Press, 2006.

Womack, Brantly. "China and Southeast Asia: Asymmetry, Leadership and Normalcy" Pacific Affairs, 76, No.4 (Winter 2003-2004): 167-193.

Womack, Brantly. "How size matters: The United States, China and Asymmetry". The journal of Strategic Studies, Vol.24, no.4 (2001): 266-293.

Womack, Brantly. "Asymmetry and Systemic Misperception: the case of China, Vietnam and Cambodia in the 1970s", Journal of Strategic Studies, vol.26, no.3 (2003).

World Bank. “Annual Report on Vietnam” (2003), http://www.worldbank.com.

Wurfel, David. "Between China and ASEAN." In Vietnamese Foreign Policy in Transition, edited by Carlyle A. Thayer and Ramses Amer, 148-169. New York: St. Martin's Press, 1999.

Young, Marilyn. The Vietnam Wars 1945-1990. New York: HarperCollins Publishers, 1991.

Zagare, Frank C. "A Game-Theoretic Analysis of the Vietnam Negotiations: Preferences and Strategies 1968-1973." The Journal of Conflict Resolution, Vol. 21, No. 4, Negotiation (Dec., 1977), 663-684.

Zalmay, Khalilzard et al. The United States and Asia: Towards a new US. Strategy and Force Posture. Santa Monica, CA: RAND, 2001.

Weinstein, Franklin. "US-Vietnam Relations and the Security of Southeast Asia", Foreign Affairs, Vol. 56. No. 4 (1978): 842-856. 